\title{
PREPARING FOR SOCIAL ACTION: \\ A CASE STUDY FROM ZAMBIA ON THE RELATIONSHIP BETWEEN RELIGIOUS KNOWLEDGE AND \\ DEVELOPMENT
}

Laura Skeaff

2011

A thesis submitted to Victoria University of Wellington in partial fulfilment of requirements for the degree of Master in Development Studies

School of Geography, Environment and Earth Sciences Victoria University of Wellington 
"I cannot transform the community when I personally have not transformed myself" - PSA tutor, Kabwe

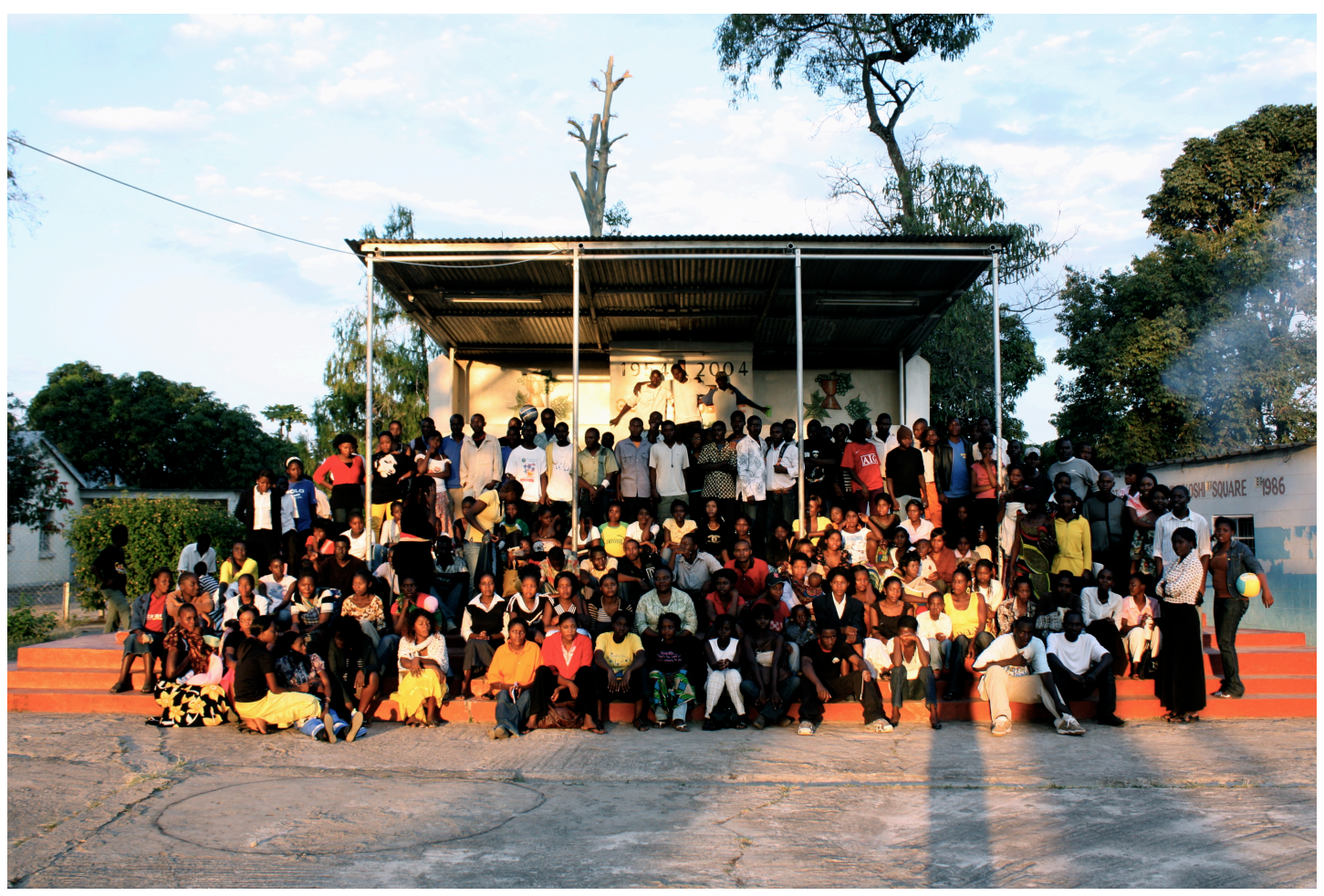

This thesis is dedicated to the students, tutors and coordinators of the PSA programme in Zambia, whose motivation to transform themselves and arise to promote the wellbeing of their communities awakened in me a vision of the inestimable potential that is latent in every human being and the transformative power of knowledge that can manifest this potential for the betterment of the world. 


\section{ACKNOWLEDGEMENTS}

In essence, Masters research is a learning process. I would like to take this opportunity to express my heart-felt gratitude to those who have contributed to my learning throughout the last year. To begin in Zambia: sincere thanks to Mr. Malitonga and Mr. Pollock, for beginning the conversation with me and providing the opportunity where this learning could take place; to Mush, Mwape, and Chisanshi for being by second family in Zambia and teaching me so much; to Chikonde, James, Kawawa, Cllyv, Mohamed, Daniel, and Steven for the overwhelming kindness and knowledge they shared; to the Alavian family, for being another second family in Zambia, and to all the other Bahá'ís who shared so generously of their time, homes, and nshima; to all the tutors and staff who taught me Bemba each day and went out of their way to ensure I had everything I needed for the research; and to the students of the PSA groups for making me feel so at home that I didn't want to leave - natotela sana.

In New Zealand, I would like to thank my parents, Murray and Sheila, for their unfailing love, encouragement, insight, and always amazingly timed perspective, and to my sisters, for the joy they bring to my life and therefore this process; my supervisor, Andrew McGregor, firstly for his interest in the research which in itself was hugely motivating and for truly constructive contributions to my learning and development as a researcher; to Marianne, Renee, Hannah, Laura, Morgan, and AJ for sharing the journey with me; to all my dear friends in Wellington, and particularly Zane, Leah, and Bruce for their love, creativity, faith, and steadfastness that so enhanced my year of learning; and to Taxi Kabb for keeping it real.

Finally, I would like to thank all the Development Studies staff at Victoria University and the School of Geography, Environment, and Earth Sciences. The research could not have been carried out with out financial means, and I am extremely grateful to Victoria University and NZAID for the financial support that enabled me to travel so far. Sincere thanks are also extended to the staff at FUNDAEC, especially Caren Rosenthal, who provided invaluable feedback towards the end of the research. 


\section{ABSTRACT}

This study is based on two premises: the centrality of knowledge to processes of development and the centrality of spirituality and religion to the lives of the majority of the world's population. It is through the generation and application of knowledge that communities and societies progress, and for many this change involves "a dynamic coherence between the spiritual and the material" (Tyndale, 2003, p. 23). Religion can be regarded as a system of knowledge, based upon the sacred texts that lie at the heart of the world's major religions, addressing aspects of spiritual reality. Historically, religious knowledge in development has been marginalised or discredited; secularism has been identified as the normative, rational position. This position has increasingly been challenged over the last decade, which has witnessed a 'global resurgence in religion' (Berger, 1999). A growing number of voices are calling for serious engagement with religion in development.

This research sets out to explore some of the questions raised in an emerging discourse between religion and development by engaging with religion as a system of knowledge that informs development theory and practice. The work focuses on a Bahá'í-inspired organisation in Zambia as a case study. Inshindo Foundation offers an education for development programme, Preparation for Social Action, that emphasizes harmony between the material and spiritual in processes of development. Over a ten-week period in 2010, I used qualitative methods to investigate the conceptions and experiences of PSA students and tutors in relation to their participation in the programme. The findings highlight the potential role of religious knowledge and spiritual values to inform and motivate individual action for change and sustain commitment and effort to achieve collective goals. This makes an important contribution to understandings of how to promote participatory development. At the level of theory, the findings draw attention to a vision of development based on spiritual values and principles that is fundamentally different from mainstream conceptions.

Keywords: religion, knowledge, values, spiritual, development theory, development practice, education, Zambia 


\section{Table of Contents}

$\begin{array}{lr}\text { ACKNOWLEDGEMENTS } & 3 \\ \text { ABSTRACT } & 4 \\ \text { LISTS OF FIGURES AND TABLES } & 8 \\ \text { List of tables } & 8 \\ \text { CHAPTER ONE: INTRODUCTION } & \mathbf{9} \\ \text { BACKGROUND } & 10 \\ \text { OBJECTIVES } & 13 \\ \text { METHODOLOGY } & 14 \\ \text { OUTLINE OF THESIS } & 14 \\ \text { CHAPTER TWO: LITERATURE REVIEW } & \mathbf{1 6} \\ \text { INTRODUCTION: SETTING THE SCENE } & 16 \\ \text { HISTORICAL CONTEXT } & 19 \\ \text { CONTEMPORARY CONTEXT } & 22 \\ \text { FROM 'ESTRANGEMENT TO ENGAGEMENT' } & 25 \\ \text { FAITH-BASED DEVELOPMENT ORGANISATIONS } & 31 \\ \text { INSTRUMENTALITY VS. NON-INSTRUMENTALITY } & 34 \\ \text { SUMMARY } & 36\end{array}$

CHAPTER THREE: FUNDAEC AND PREPARATION FOR SOCIAL ACTION (PSA) 38

INTRODUCTION 38

FUNDAEC 38

i. Origins 38

ii. Foundational Principles $\quad 41$

iii. Foundational Principles and the Bahá'í Faith 44

iv. Evolution of FUNDAEC and the Sistema de Aprendizaje Tutorial (SAT) 45

PREARATION FOR SOCIAL ACTION $\quad 47$

i. Essential Elements 48

PREPARATION FOR SOCIAL ACTION IN ZAMBIA 51

i. Origins and Evolution $\quad 51$

ii. Vision $\quad 53$

CHAPTER FOUR: METHODOLOGY

INTRODUCTION

QUALITATIVE RESEARCH

RESEARCHER AS A CRYSTAL (ANALOGY ONE) 56

PERSONAL WORLDVIEW

$\begin{array}{ll}\text { METHODOLOGY } & 60\end{array}$

i. Constructivist Grounded Theory $\quad 60$

ii. Hermeneutics 61

iii. Case Study Approach $\quad 62$

CRYSTALLISATION (ANALOGY TWO) 63

$\begin{array}{ll}\text { METHODS } & 64\end{array}$

i. Interviews $\quad 64$

ii. Categories of interviews $\quad 65$

iii. Location of interviews $\quad 67$

iv. One-on-one and group interviews 68

v. Participant Observation $\quad 69$

vi. Reflective Learning Journal $\quad 70$

$\begin{array}{ll}\text { DATA ANALYSIS } & 71\end{array}$ 
i. Writing as Analysis $\quad 71$

ii. Short Stories and Creative Writing 72

$\begin{array}{ll}\text { SUMMARY } & 73\end{array}$

CHAPTER FIVE: COUNTRY CONTEXT

\begin{tabular}{lr} 
INTRODUCTION & 75 \\
\hline
\end{tabular}

HOW I CAME TO BE THERE $\quad 75$

$\begin{array}{ll}\text { RELIGIOUS CONTEXT } & 77\end{array}$

$\begin{array}{lr}\text { HEALTH } & 80\end{array}$

AGRICULTURE $\quad 82$

EDUCATION

HISTORICAL, POLITICAL, AND ECONOMIC CONTEXT

KABWE AND MWINILUNGA $\quad 90$

$\begin{array}{lr}\text { SUMMARY } & 93\end{array}$

CHAPTER SIX: INSHINDO FOUNDATION

INTRODUCTION $\quad 95$

HISTORICAL BACKGROUND $\quad 95$

A BAHA'I-INSPIRED ORGANISATION: ORGANISATIONAL FEATURES 100

i. Structural affiliation and governance 101

ii. Values and motivation of staff 102

iii. Mission 103

iv. Strategy and theory of development 104

v. Faith practices and teaching in programmes 105

vi. Choice of beneficiaries and partners 108

vii. Staff and leadership 111

viii. Organizational culture 112

xi. Constituency and sources of funding 113

x. External relationships 114

$\begin{array}{ll}\text { SUMMARY } & 114\end{array}$

CHAPTER SEVEN: EXPERIENCES OF PSA PARTICIPANTS - PERSONAL

TRANSFORMATION

INTRODUCTION 116

SPIRITUAL PRINCIPLES

$\begin{array}{ll}\text { SPIRITUAL QUALITIES } & 117\end{array}$

$\begin{array}{ll}\text { SERVICE } & 118\end{array}$

DIMENSIONS OF TRANSFORMATION 119

i. Self-perception 119

ii. Spiritual transformation $\quad 121$

iii. Social responsibility 124

iv. Self-confidence and language capabilities 130

v. Practical knowledge and skills 132

$\begin{array}{ll}\text { SUMMARY } & 136\end{array}$

CHAPTER EIGHT: CONCEPTIONS OF PSA PARTICIPANTS - KNOWLEDGE AND

$\begin{array}{lr}\text { VALUES } & 138\end{array}$

$\begin{array}{ll}\text { INTRODUCTION } & 138\end{array}$

THE ROLE OF KNOWLEDGE IN DEVELOPMENT 138

CONCEPTIONS OF KNOWLEDGE 141

i. Modern scientific and traditional knowledge 141

ii. Spiritual and material knowledge 142

SPIRITUAL VALUES

ii. Spiritual values and the purpose of human existence 148

iii. Spiritual values and a vision of development 150

$\begin{array}{ll}\text { SUMMARY } & 151\end{array}$ 
CHAPTER NINE: SUMMARY AND CONCLUDING REMARKS

INTRODUCTION

SUMMARY OF MAIN FINDINGS

OBJECTIVE ONE

OBJECTIVE TWO

i. Experiences

ii. Conceptions

PERSONAL REFLECTIONS

REFERENCES:

APPENDIX B: SEMI-STRUCTURED INTERVIEW GUDIE AND FOCUS GROUP GUIDE: PSA STUDENTS

APPENDIX C: SEMI-STRUCTURED INTERVIEW GUIDE: INSHINDO STAFF/PSA COORDINATORS

APPENDIX D. SEMI-STRUCTURED INTERVIEW GUIDE: KABWE DEPARTMENT OF COMMUNITY DEVELOPMENT

APPENDIX E. TABLE OF RESEARCH ACTIVITIES APPENDIX F: ACTIVITIES OF PSA STUDENTS AND THEIR GROUPS IN KABWE AND MWINILUNGA 


\section{LISTS OF FIGURES AND TABLES}

Figure 1. Map of Colombia showing Norte del Cauca (VAL) ....................................................40

Figure 2: Map of Zambia showing Mwinilunga and Kabwe ................................................52

Figure 3. A representation of positionality: My beside table in Mwinilunga ....................... 59

Figure 4. Christianity (and soccer): intrinsic elements of individual and collective life in

Zambia ........................................................................................................................................8 80

Figure 5. Agricultural Cooperative show day in Mwinilunga .................................................8 83

Figure 6. Education profile of Zambia based on 2007 Demographic and Health Survey

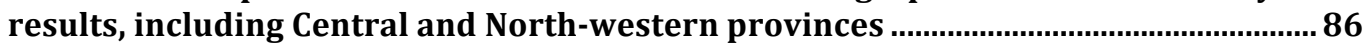

Figure 7. Display board in Mwinilunga for a donor funded food security initiative .............90

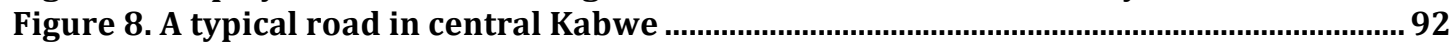

Figure 9. Shops on the main road in Mwinilunga .................................................................... 93

Figure 10. Students from Kabwe preparing a demonstration plot as a component of promoting household food production in the wider community .................................134

Figure 11. A PSA group's completed demonstration plot in Mwinilunga, behind the Inshindo Office

Figure 12. Members of the two environmental clubs that were established at local highschools by one PSA group perform a skit at a student encounter

\section{List of tables}

Table 1. FUNDAEC's Guiding Principles

Table 2. Elements of PSA methodology

Table 3. Interviews and focus groups conducted in Kabwe and Mwinilunga ........................ 67 


\section{CHAPTER ONE: INTRODUCTION}

"The dogmas of the quiet past are inadequate to the stormy present. The occasion is piled high with difficulty, and we must rise to the occasion. As our case is new, so must we think anew and act anew. We must disenthrall ourselves..." - Abraham Lincoln.

It is striking how these words, spoken centuries ago, seem to have taken on a greater relevance today than ever before. With every passing day it seems that fresh afflictions and calamities, both natural and man-made, are attacking at the very fabric of human society with an increasing intensity and frequency. In many areas across the globe, persistent social challenges such as inequality, injustice and intolerance are reaching new heights. The impact of centuries of unrestrained material progress on the physical environment we inhabit is becoming increasingly apparent. Concurrently, the contemporary world is characterized by an unprecedented level of interconnectedness amongst human beings from all walks of life. Through the same global networks facilitating this interconnectedness we are made aware of the most extraordinary displays of human potential and capacity to overcome the challenges that are faced. Integral to this process of rapid change is the questioning and transformation of traditional modes of thought and action at all levels of society.

The global discourse and practice of development, whose fluid bounds encompass a vast range of actors and actions, is explicitly concerned with the processes alluded to above. A salient concern of many in this regard is articulated by Arbab (2000, p. 601), who states: "To deal with development, and in fact with most social issues, at the level of technique is a growing and disturbing tendency of our times." A material worldview that places material means at the centre of social existence and progress has arguably been the dominant force shaping development theory and practice. An alternative approach that is central to the concerns of this thesis seeks to deal with development at a different level, the level of knowledge. One conviction is 
that the generation and application of knowledge, not material means, is the central process of social existence and consequently the driver of collective change and progress. Arbab (2000) goes on to state: "The power that can ultimately raise humanity from its present condition is the power of knowledge." This conception of knowledge is not limited to the material or even social dimensions of human existence but extends to and encompasses a spiritual dimension. Without this spiritual dimension - a dimension that for the majority of the earth's inhabitants is central to their worldview - it becomes increasingly difficult to apply scientific knowledge for the betterment of life on the planet.

A growing discourse in development is exploring how to move a spiritually based worldview from the fringes to occupying a central place in development concerns. Such an exploration necessitates engagement with an area long marginalised in mainstream development discourse, religion. Just as science acts as a system of knowledge and practice informing material progress, religion can be regarded as another system that gives insights into the spiritual dimension of human existence and can guide both spiritual and material progress. This thesis, then, seeks to explore the questions that arise when religion is engaged with as a system of knowledge in development, and how these questions may assist us to 'rise to the occasion' of addressing both the challenges and opportunities facing the contemporary world.

\section{BACKGROUND}

The Preparation for Social Action (PSA) programme is a 'not 18-month' programme of community-based education whose fundamental purpose is to raise up human resources dedicated to the progress of rural and urban communities. In the context of PSA, education is a means to increase the capabilities of young people to understand and transform their material and spiritual reality, on both an individual and collective level, and apply these capabilities to serve humanity through meaningful social action in the community. The PSA programme was developed by FUNDAEC, a rural development institution that originated in Colombia in the 1970s and whose programmes have progressively spread across South America and more 
recently to other continents. The programme has been adapted from the Sistema Aprendizaje Tutorial (SAT) programme, a formal, six-year course at secondary level that has so far involved at least 90,000 students and gained a degree of international recognition (Honeyman, 2010). PSA was first implemented in Zambia in late 2007 by a local non-profit organisation named Inshindo Foundation. A few words about the overarching conceptual framework of these organisations are necessary at the outset of this thesis.

Both FUNDAEC and Inshindo Foundation consider themselves to be 'Bahá'íinspired' development organisations. The literature that I investigated during the early stages of the research explores the role of 'faith-based organisations' in development and led to me certain understandings of what this term means in theory and practice. As the research progressed, I came to understand more fully that FUNDAEC and Inshindo Foundation, while sharing certain characteristics of some faith-based organisations, did not fit neatly within the conceptions and examples I had come across. Neither FUNDAEC or Inshindo Foundation are administered by Bahá'í institutions or dedicated to the propagation of the Bahá'í Faith. In fact, the word 'Bahá'í' is not found in any of their educational materials. What seems to distinguish them from other development organisations are a number of fundamental beliefs that are shaped by the Bahá'í teachings and influence a working approach to development. One is the basic belief shared with most of the world's population that we have a material and spiritual reality. The promotion of wellbeing through development involves a dynamic coherence between these two dimensions. Another is that the two repositories of knowledge that enable humanity to understand and transform this reality are science and religion. Insights drawn from both systems shape the development theory, methodological choices and program activities of the FUNDAEC and Inshindo Foundation. A further belief is that it is the inalienable right of all people, without distinction, to access knowledge and apply it as protagonists in a collective process of transformation - a process in which every individual must be involved. Thus, while not inconsequential in practice, the religious belief of any individual participating in their programmes is immaterial to FUNDAEC and Inshindo Foundation. 
A number of studies have been carried out on aspects of FUNDAEC's programmes, and two in particular contributed to the background of my own research in Zambia. The studies of Catherine Honeyman (2010; 2004) and Michael Leggett (2006) explore the experiences and conceptions of students and tutors who have participated in the SAT programme in Honduras and Colombia, respectively. Both studies, whose findings will be explored in greater depth later in the thesis, put forward questions about the relationship between religion, science, and development. Another study published by the Intentional Development Research Centre, The Lab, the Temple, and the Market: Reflections at the Intersection of Science, Religion and Development, has significantly informed the conceptual framework of this thesis. This study consists of contributions from scientists who explore issues in development in light of views based on four different systems of religious knowledge, Hinduism, Christianity, Islam, and the Bahá'í Faith. As one of the founders of FUNDAEC whose contribution to this discourse is informed by Bahá'í beliefs, the chapter by Farzam Arbab has had particular relevance for my own study.

My own research began with the objective of investigating more specifically the relationship between religion and development and the contribution of a fairly undefined notion of spirituality. The initial aims were essentially to explore some of the central themes and questions that have emerged from the recent discourse engaging with religion and spirituality in development. Two questions of particular interest were: (1) Do "religious and spiritual resources produce a type of knowledge that is, or could be, relevant to development" (Ellis, 2006, p. 353)?; and (2) How can faith-based or inspired organisations who apply religious knowledge act as 'agents of transformation' in development practice (Clarke, 2007)? The objective was to explore such questions as these in light of the experiences and conceptions of those involved with the work of a faith-inspired organisation at the grassroots level. This was based on my own belief that the knowledge of people at the grassroots in development must inform its overarching conceptions and practice if these are to be both relevant to their needs, values, and aspirations, and truly participatory. It is this latter objective that has remained consistent throughout the research, and this same objective that has shifted the focus of the others. 
My experiences and the insights gained throughout the research process advanced questions about the relationship between religion, spirituality and development in ways that I had not anticipated. It became increasingly apparent to me that the central theme emerging was around knowledge - its type, accessibility, and application - and its relationship with participation in development. While this theme is certainly relevant to the emerging discourse around religion and development, the questions it raises, and insights into them it provides, seemed to lie in the nexus between development, as a diverse global discourse and practice, and religion and science, as systems of knowledge and practice that can inform it.

\section{OBJECTIVES}

The overall objective of this study is to explore the relationship between religious knowledge and development. This is to be done through investigating the experiences and conceptions of participants in a programme that, as part of its development theory and practice, draws upon religious knowledge as a source of insight.

Further objectives

1. To identify and describe how religious knowledge informs the development theory and practice of FUNDAEC and Inshindo Foundation.

2. To identify and describe the experiences and conceptions of PSA students and tutors in relation to their participation in the programme.

3. To examine how the experiences and conceptions of PSA participants contribute to understanding the relationship between religious knowledge and development at a conceptual and practical level. 


\section{METHODOLOGY}

This study adopts a case study approach to draw on grassroots experiences and conceptions of development. The comments of students and tutors who were involved in the PSA programme in Zambia at the time of this study, and participated in interviews or focus groups, form the basis of this research. This is supplemented by my personal experiences of the programme and Inshindo Foundation during three months in 2010, and consultation with the staff at Inshindo Foundation and later FUNDAEC. The approach to the themes and insights generated through the process of qualitative research is based on a fundamental conception of knowledge and social reality as coconstructed and co-created. Accordingly, my position in the research as a cocreator of knowledge alongside the research participants requires an acknowledgement of my personal worldviews that shape how I think and act in this process. The ideas expressed throughout this thesis represent my own understanding of the conceptions and experiences of PSA participants, and my own understanding of Bahá'í teachings and their relationship with the development initiatives of FUNDAEC and Inshindo Foundation. While I have tried to present as open and impartial a representation as possible, the thesis should ultimately be read not as an attempt to provide any answers but rather to raise questions and humbly contribute to a conversation about individual and collective progress for the betterment of humanity.

\section{OUTLINE OF THESIS}

The thesis begins by grounding the study in the contemporary religion and development discourse. It then proceeds to describe in detail FUNDAEC and the PSA programme, where it begins to address the first objective of the research by describing how religion, as a system of knowledge and source of insight, is integrated into its overall framework. Providing the reader with an understanding of FUNDAEC and the PSA programme early on will help contextualise the chapters of the thesis that follow. The thesis then moves on to how the conceptual framework behind this study was translated into a practical research design, before describing the local and national context of Zambia where the study was carried out. As the organisation that oversees 
the implementation of PSA, the chapter that follows sets out to describe Inshindo Foundation and explore how religious knowledge informs many of its organizational features. This section has a further purpose of contextualizing the main themes presented in the last three chapters of the thesis. These themes are based on the experiences and conceptions of PSA students and tutors in relation to their participation in the programme. They are examined in the context of wider discourses in development in an endeavour to gain understanding around the relationship between religious knowledge and development at the level of theory and practice. The thesis concludes by summarizing the different sections and proposing some working conclusions, and personal reflections, in relation to the overall objectives of the research.

Ultimately, my hope is that the questions and insights raised throughout this thesis will be engaged with by readers and encourage reflection and individual exploration of questions it may raise. The comments of PSA participants, and my interpretation of the insights they generate around the relationship between religious knowledge and development, are offered from a posture of learning to a process of learning - one contribution to conversations based in practical experience that seek to further learning around the nexus between the material and the spiritual in development. 


\section{CHAPTER TWO: LITERATURE REVIEW}

\section{INTRODUCTION: SETTING THE SCENE}

This literature review started quite simply as an investigation into how religion and spirituality have been addressed in development studies to date. What role have they had, if any, in shaping development discourse, policy and practice? How is this role perceived? As I embarked upon this task and began to read, it became apparent that such an approach was going to result in a report of the literature that was purely descriptive. It would be much like many other accounts that already exist, tracing the historical neglect of religion in early development discourse to the recent move from 'estrangement to engagement', and then addressing the current themes of the contemporary literature around the religion and development interface. While the structure of this review will closely follow this same historical progression, the approach will not be purely descriptive. In the first place, there are already many excellent accounts of this historical progression (see for example Clarke and Jennings, 2008 and Lunn, 2009). More importantly, I didn't feel that this purely descriptive approach would facilitate practical change. While a critical theory approach to the research has not been wholly adopted, this work is nonetheless aligned with the essence of critical theory research in that it is oriented toward critiquing and changing in contrast with approaches that seek only to understand or explain (Lunn, 2009). Also in keeping with critical theory, this review seeks to draw on knowledge from across a range of disciplines, not just 'development studies' (granted that this discipline itself is quite diverse). If the purpose of research is to generate new knowledge, to investigate and draw insights into social realities that lie undiscovered except to those who directly experience them, then drawing from a diversity of sources and critiquing for the purpose of change must be the foremost concern of the entire research. It must shape how the literature is engaged with in this preliminary stage of the research. Thus, the approach to the literature review sets the context for the rest of the research and the findings. 
As an investigation of reality, seeking insights that can guide effective practice, I have chosen to contextualise the literature review through a particular lens that reflects the fundamental research concern - this is the centrality of knowledge to development. Questions that have long been tackled by philosophers, theologians and lay persons alike are central to development, even if the field is more focused on the practical application, transfer and sharing of knowledge and often takes its epistemological foundations for granted. Such questions include: What is knowledge? How do we acquire knowledge? What do we know? How do we know what we know? These considerations are of utmost importance for exploring the role of religion and spirituality in development, because the epistemological foundations of the discipline determine how these subjects are viewed and therefore engaged with (or disengaged with), both historically and in more recent times.

Why is a focus on knowledge important? It is through knowledge that understanding and change occur. However, a focus on knowledge cannot ignore its relationship with power; wielded by power, knowledge can carve out or highlight "a certain reality, casting into oblivion other ways of relating to the world around us" (Sachs, 1992, p. 2). According to Sachs and many others (Crush, 1995b; Escobar, 1995b; Sachs, 1992) this is exactly what happened in development studies and practice, and is one of the main factors accountable for the failures of development. That is, development discourse has "relied exclusively on one knowledge system, namely, the modern Western one" (Escobar, 1995a, p. 13). Even though some of the elements of the discourse have changed over the last fifty years, it is argued that the epistemological foundation is essentially the same.

Therefore, approaching the evolution of development discourse and practice through the critical lens of 'knowledge' opens the way for exploring how other knowledge systems or ways of conceiving of knowledge can shape them, challenging hegemonic uses of knowledge in development. This paves the way for a 'non-instrumental' consideration of religion in development, a fundamental aim of this research that will be explained in detail later in this chapter. Religion, then, is treated as a system of knowledge based upon the 
religious texts that lie at the heart of each of the world's major religions, oral or written, which present the teachings of the prophet-founder and associated historical figures. These texts lay down or 'reveal' "aspects of spirituality reality which, once uttered, can become the subject of exploration, not only by the individual soul, but also by entire populations" (Arbab, 2000, p. 144). This treatment of religion as a system of knowledge draws significantly from the work of Arbab (2000) who explicitly relates his approach to how knowledge is positioned in the Bahá'í Faith. The prophet-founder of the Bahá'í Faith, Bahá'u'lláh, states that a complete and objective grasp on the knowledge of reality is beyond the comprehension of man: "None can grasp the reality of the origin of creation save God, exalted be His glory ... Creation hath neither beginning nor end, and none hath ever unraveled its mystery. Its knowledge hath ever been, and shall remain, hidden and preserved with those Who are the Repositories of divine knowledge" (Bahá'u'lláh, 2006). However, we are able to know and test knowledge through action. Thus, by religious knowledge or truth "is not meant mere assertions about the esoteric, but statements that lead to experimentation, application, and the creation of systems and processes, whose results can be validated through observation and the use of reason" (Arbab, 2000, p. 144).

Although aspects of this literature review will be concerned with epistemology, reflective of how reality and knowledge have been interpreted in development studies, the thesis as a whole adopts a hermeneutical approach and religion is treated accordingly. The exploration of religion as a knowledge system involves seeking "insights into reality that can guide effective practice" and not some fundamental, objective truth that development must be based on (Lample, 2009: 172). This is not to deny the existence of truth. A hermeneutical approach is based on the view that reality exists, but that human beings are fallible and limited in their capacity for understanding. This implies that social reality is to be interpreted in order to be understood (Deneulin, 2009; Lample, 2009). Like the human enterprise, the development enterprise is, then, "a never-ending investigation of reality ... the quest for knowledge ... and the application of knowledge to achieve progress, the betterment of the world, and the prosperity of its peoples" (Lample, 2009: 173). 
The methods of a hermeneutical approach, adopted in this thesis, have as their foundation openness and require a humble posture of learning. Deneulin (2009: 24) identifies three key factors that are required for genuine engagement with religion: genuine openness to other positions, an ability to identify multiple voices within opposing traditions, and an openness to revise one's own worldviews in the light of the encounter with others. The fundamental reason for approaching religion as such is that development has ignored, marginalised and oft-times discredited religion as a potentially viable knowledge system and will continue to do so unless it adopts this humble posture of learning. Religion is a force, or system of knowledge and practice, that has "played a determining role in the advancement of civilization" (Arbab, 2005). And it continues to play a determining role in the individual and collective life of the planet: $87 \%$ of the world's population is religious (Association, 2001). The question that arises, then, is whether religion "produces a type of knowledge that is, or could be, relevant to development" (Ellis, 2006, p. 353). ${ }^{1}$ Why this question has not been addressed in development studies is the focus of the following section of this literature review.

\section{HISTORICAL CONTEXT}

A significant body of authors, especially those who associated themselves with post-development theory in the mid-1990s, point to the post-World War II (WWII) period as the time when the 'discourse of development' was born and pay scant attention to its roots any further back than this (Escobar, 1995a). According to this group, Truman's 1949 speech, introducing the idea that the majority of the world was 'underdeveloped' and it was the responsibility of the 'developed' nations to help these populations, epitomizes the conception that was to form the foundation of the development enterprise. There is a lot

\footnotetext{
${ }^{1}$ Knowledge, according to a non-foundational perspective, is ever-evolving and the wider the diversity of sources and experiences that can be drawn upon, the richer and ultimately more attuned to reality and therefore positive transformation the endeavour of development will become. Without openness to learn and change and be critical of its own cultural milieu, development risks following a path upon which "accumulated knowledge soon becomes obsolete and of little relevance to the changing realities [it] address[es]" (Rahnema, 1997: 8-9).
} 
to be said in support of this assertion, especially when considering the institutional inception of development. However, there is another camp that argues that the roots of development reach back much further than sixty years ago. An understanding of what Escobar (1995) means by 'discourse' actually supports an exploration into the roots of development further back than the post-WWII period. Escobar (1997, p. 40) states that "to understand development as a discourse" one must look at the elements that make up this discourse and, simultaneously, "the system of relations established among them." One of the central elements of a discourse, according to his definition, is the form or system of knowledge that it draws upon. ${ }^{2}$ Knowledge is not created in a vacuum; it is "ever-evolving ... tied to experience and context dependent ... tied to theory and universal norms" (Lample, 2009). Thus, it can be argued that a fuller understanding of the discourse of development (which is an essential prerequisite when seeking to critique and change it) must be informed by an understanding of the knowledge systems and epistemological foundations that shaped it (Rist, 1997; Shenton, 1996). Through this exercise, light can be shed upon why religious knowledge has been discredited and almost discarded.

A brief exploration of the European Enlightenment period and its influence on modern social theory forms the basis of understanding the relationship between development discourse and religion. Beginning in the $18^{\text {th }}$ century the Enlightenment period, also known as the 'Age of Reason', was characterized by an emphasis on human reasoning and scientific investigation as the most reliable means of attaining truth and knowledge. This approach to the investigation of truth, knowledge and reality was particularly important in relation to the role of religion and the Church in society. For over a thousand years, religion (specifically Christianity in the context of Western Europe) had stood as an objective body of knowledge about reality and the Christian Church existed as the primary source of legitimacy and authority. This position was challenged by a growing body of philosophers, in particular, who objected to the Church's position and power, seen in its ability to objectively establish and enforce doctrine in the public sphere, as a

\footnotetext{
2 The other elements outlined by Escobar in this definition include "institutions, socio-economic processes, ... technological factors, and so on."
} 
constraint on the individual's freedom to use their own intellect. The wellknown statement of Nietzsche (1924, p. 169), proclaiming that 'God is dead', is often associated with the ideas of this period and can be interpreted as a reference to the separation of Church and state that occurred parallel to developments in modern science and intellectual reasoning; Christian theology and the Church were no longer held as the objective sources of truth and meaning. However, Nietzsche's declaration cannot be equated with a wholesale 'death of God' in the minds of individuals. A significant number of philosophers and early scientists justified their work in religious terms. Descartes (2008) himself, whose Discourse on the Method is regarded as one of the seminal texts of Enlightenment thought, stated: "By reason there exists a God, and God is the guarantor that reason is not misguided". The statement points to the continuing role of religion as a source of moral principles and individual inspiration, even as its decline in the public sphere continued progressively.

In relation to human society, the increasing emphasis on science and reason fed into the ideology of progress that came to dominate the intellectual landscape from the end of the $17^{\text {th }}$ century (Esteva, 1992; Rist, 1997; Shenton, 1996). Progress, Shenton (1996, p. 14) writes, "connoted a linear unfolding of the universal potential for human improvement ... which was made possible ... through an increasingly scientific understanding of Nature." As scientific knowledge increasingly established a position of uncontestable salience, other knowledge systems were devalued in the development of social theory. This included the knowledge of all societies except those in the West, as the doctrine of social evolutionism had found the latter to be superior over the former (Rist, 1997, p. 40). It also included knowledge from revealed scripture. The work of Auguste Comte exemplifies how science became detached from ideas of God; 'positivism', in contrast to religion, became "the true path of knowledge" (Shenton, 1996, p. 33). Through the use of the objective and universal system of science, it was now possible to investigate reality free from subjective influences (Lample, 2009).

The repute of positivism as an unassailable means by which social reality was interpreted and acted upon cannot be understated. Modernisation theory, 
upon which the early discourse of development was significantly based, as well as its antitheses of Marxist and neo-Marxist theories, were all set within the broader historical and intellectual context of positivist social science (Lunn, 2009). Modernisation theory went hand in hand with secularisation theory. The central tenet of the latter was that "modernisation necessarily leads to a decline of religion in society and the minds of individuals" (Berger, $1999 b)$. Both were heavily influenced by the legal separation of Church and state in Western liberal democracies, underpinned by the aforementioned scientific views on the development of societies (Jennings, 2008a). In contrast to rational 'modern' values, modernisation held that religious worldviews and beliefs were traditional, and therefore backward and irrational, and would gradually disappear as societies advanced economically (Noy, 2009). Religion was perceived as either an irrelevant force in modernizing societies or an obstacle or impediment to economic development (Dugbazah, 2009). According to Clarke and Jennings (2008b, p. 1), "reason and faith were constructed as oppositional, mutually incompatible spheres." Goulet (1980, p. 481) describes how this "reductionist approach to knowledge" led, and arguably continues to lead, most development specialists to "analyse, prescribe and act as if man could live by bread alone, as if human destiny could be stripped to its material dimensions alone." Thus, the soil was prepared in which the seeds of the post-World War II development enterprise were planted and have continued to grow over the last sixty years. Or so the scientific metaphor would have it.

\section{CONTEMPORARY CONTEXT}

In so many ways, the world is an entirely different place than it was sixty years ago when Truman gave his famous speech and the 'development enterprise' was embarked upon. Within development, the number of alternative approaches to modernisation that have arisen as a response to the changing needs of individuals and communities (or springing from a better understanding of these needs), some closely aligned to the former and some radically opposed, is quite staggering. Some have argued that the cumulative result of this range of theories has led the discourse of development to reach 
its maturity (Herath, 2009). Others claim that despite the excitement and controversies that have surrounded various conceptions of development that differ in some features from what has gone before, the most striking feature of the discourse of development is its continuity (Rist, 1997). While the "mainstream emphasis on economic growth [that] permeated that whole field of development thinking in the early days" may have broadened to include a range of 'social' indicators for development, there is still a "pervasive rationalist conception of knowledge as objective, universal and instrumental" (Esteva, 1992, p. 12; McFarlane, 2006, p. 288). The legacy of Western scientific modernity has been so salient and lasting that secularism is still identified as the "normative rational position" in development (Clarke, 2008b, p. 266; Thomas, 2007). Despite trends toward holistic human development and rhetoric of cultural sensitivity and openness, religious knowledge continues to be marginalised (Dugbazah, 2009; Linden, 2008). Religious values and conceptions of development, which emphasise the spiritual dimension of human existence and the importance of religious knowledge for learning about this spiritual dimension, are 'de-linked' from broader development values and conceptions of knowledge (Clarke, 2008b, p. 301).

An exploration of the contemporary discourse of development would be lacking if it ignored what has arguably been the strongest challenge to 'mainstream' development discourse, coming from the diverse range of authors writing under the umbrella of post-development theory. While postdevelopment theory has had a limited effect on development practice and policy, what it has been remarkable for is broadening conceptions of development beyond its early positivist roots. Post-development theory was influenced by the post-modern turn in the social sciences. Post-modernism was notable for what Lample (2009, p. 16) has called a "collapse of reason, or failure of epistemology". Whereas modernism held that there were absolute truths or 'meta-narratives' that human beings were able to understand through the use of reason and scientific methods of investigation, postmodernists drew attention "to the process of construction and promotion of knowledge where certain kinds of knowledge have power and get treated accordingly while other kinds of knowledge, namely, those of the local and indigenous are subordinated and discarded" (Herath, 2009, pp. 1458-1459). 
The idea that knowledge is constructed opened the way for different ways of knowing and alternative experiences or systems of knowledge to be valued (Crush, 1995a). Meta-narratives, in particular that of modern Western science, were rejected (Bernstein, 1983).

Despite its ardent calls for cultural sensitivity and the rejection of modern, Western science as the foundational knowledge system for development, little attention has been directed towards why post-development theory has scarcely addressed the role that religious knowledge has in development. There is some acknowledgement of spirituality as an essential part of culture (Esteva, 1992; Rahnema, 1997), however religion is rarely mentioned. One potential reason for this marginalisation is post-development theory's rejection of meta-narratives. In contrast, a central tenet of all religions is the existence of a God (in monotheistic traditions), or gods, who send down prophets who reveal religious truth. This is contained within the sacred texts associated with all of the world's major religions, which lay out certain principles, laws and values that humanity is to live by, concerning not only the spiritual but also material and social dimensions of human existence. Similar to the knowledge system of science, one can see how religion may be regarded as the ultimate meta-narrative.

A number of other possible reasons can be identified regarding the silence around religion in post-development theory. One relates to the post-modern concern over issues of power and knowledge. The power of many religious institutions, based on exclusive claims over interpretation of religious knowledge as objective truth, seems almost antithetical to a post-modern emphasis on the relativity of knowledge. The historical behaviour of religious institutions based on such claims stands as an evidence of the harmful consequences of such a stance, and is mentioned by several authors in the literature (Holenstein, 2005; Kadt, 2009). The colonial role of Church in marginalizing local spiritual beliefs and traditional systems of knowledge is one prominent example.

The impact of post-development theory on development policy and practice has arguably been limited, particularly in comparison to its impact in 
intellectual circles. This is not to say that mainstream development discourse has not evolved, however. Tracing a history of theories that have made key contributions to development discourse illustrates how there have been clear trends towards more holistic conceptions of development. ${ }^{3}$ Lunn (2009) states that development is now more sensitive to cultural context, including religion, as a result of this trend. Others are not so convinced: Linden (2008) and Dugbazah (2009) both argue that despite these trends cultural marginalisation, particularly in regard to the spiritual and religious dimensions of peoples' lives, continues. However, while secularism may still stand as the 'normative rational position' in development, as aforementioned, James (2009, p. 6) speaks on behalf of a raft of authors when he declares: "The climate for faith in development is changing." The phrase describing this move as one of 'estrangement to engagement' is frequently employed in relation to the increasing interest in the developmental role of religion (Clarke, 2008a). The literature review will now turn to addressing the nature of this engagement.

\section{FROM 'ESTRANGEMENT TO ENGAGEMENT'}

One of the most manifest and emblematic signs of the trend towards engagement with religion in development can be seen in the attitudes and actions of the World Bank. For most of the World Bank's history, religion was "simply absent" (Saanen, 2007, p. 5). Reflective of the Bank's positivist, technical and economically grounded approach to development, this modus operandi has changed markedly over the past decade. In 2001, the World Bank set up a Directorate on Faith, now called the Development Dialogue on Values and Ethics. Then President James Wolfensohn was active in engaging in a dialogue with representatives from faith groups, primarily Christian Churches, and a number of conferences were held between 1998 and 2002 (Jennings, 2008b). The publications proceeding from these conferences, and a

\footnotetext{
${ }^{3}$ Those that stand out are the Basic Needs Approach (BNA) that emerged in the mid-1970s, feminist critiques of development, Amartya Sen's conceptions of development as entitlements, capabilities and freedoms, the participatory, bottom-up approaches promoted by Robert Chambers (1973), the post-development critiques already discussed, and the multi-dimensional approach to poverty advanced by the United Nations Development Programme (UNDP) seen in the Human Development Reports and introduction of the Human Poverty Index in 1997.
} 
number of others published since this time on behalf of the World Bank, indicate that the role of religion in development is now a significant theme in the Bank's discourse and policy (Belshaw, 2001; Keough, 2004; Marsh, 2003; Saanen, 2007). These initiatives are representative of the wider growing interest in the emerging religion and development interface from many other official aid departments in North America and Europe, and a whole range of development practitioners and theorists (James, 2009).

The key issues being addressed around this interface will be explored shortly, but the historical context must first be set (itself one of the major themes addressed in the literature). Why has there been a growing concern for religious issues after five decades of unassailable secularism in official development discourse? To answer this question, one's vision must be widened beyond looking at development to the international climate in which it takes place, and to what several authors have described as a 'global resurgence of religion' (Clarke, 2007, p. 85; Clarke, 2008b, p. 291; Thomas, 2004 , p. 133). This term alludes to how the opposite of what was predicted under modernisation theory is occurring: religion is not declining either in society or in the minds of individuals. Berger (1999a, p. 9) describes how on an international scale, religious movements are on the rise everywhere except in Western Europe and amongst the "international subculture composed of people with Western-type higher education." In particular, it is conservative, orthodox and traditionalist religious movements that are gaining in prominence and popularity. Examples of this can be seen in the revival of the Christian Right in the United States, the surge in popularity of the evangelical churches across East Asia, the South Pacific, Latin America and sub-Saharan Africa, and the increasing prominence of fundamental Islamist groups throughout the Middle East, South East Asia and parts of Africa (Berger, 1999b; Clarke, 2007). Many authors also highlight the Twin Tower attacks of September $11^{\text {th }} 2001$ as a key event contributing to a heightened global consciousness around the role of religion in both international relations and individual lives (Balchin, 2007; Clarke, 2007). Add to this the strength of Hindu nationalism in India and the extent of ecclesiastic power in Iran since the 1979 Revolution, to cite but two more examples, and it is overwhelmingly clear that all these cases contradict the assumption of secularisation theory 
that religion would progressively retreat from the public realm as societies advanced technologically and became more sophisticated (Berger, 1999a; Noy, 2009). ${ }^{4}$

The growing interest in religion and spirituality can also be attributed to the failure of 'Western, modern science' to bring peace and prosperity to the world. Despite the firm convictions of development specialists that poverty consists purely of material deprivation and that its eradication is therefore a material undertaking (Clarke, 2008a), the outlay of immense resources and technical know-how under the umbrella of development has failed to curb growing inequality, conflict and poverty in absolute terms. What is more, people the world around continue to seek meaning and purpose to their existence as well as "experience the moral life...within the context of the virtues, social practices, and traditions of their communities, including their religious traditions" (Thomas, 2004, p. 135). A sense of existential security does not suffice for many (Thomas, 2007, p. 22) and Western, modern science does not provide answers to life's deeper questions: What does it mean to be human? What is the purpose of life? Do we have a soul? Is there life after death? Where did we come from? How do we find true happiness or contentment in life? The knowledge system of religion provides working answers to all of these questions, as seen in teachings of all the major world religions.

\section{WHAT IS BEING ENGAGED WITH?}

The emphasis on faith as a fundamental guiding and motivational force in people's lives is the most salient theme that emerges from literature at the religion and development interface. This realization has been painfully slow in development studies. Even the term 'resurgence' of religion is only apt from a Western secular perspective; the historical reality has been that the centrality of religion and spirituality to most people's lives has never ceased (Association, 2001). This is why De Cordier (2009, p. 680) states that engaging with religion in development is "a matter of realism." The World Bank study, 
Voices of the Poor, concluded that "spirituality, faith in God and connecting to the sacred in nature are an integral part of poor people's lives in many parts of the world" (Narayan, 2000, p. 222).

The role that religion and spirituality have in peoples' lives extends into every area; the Western division between the sacred and secular as respectively private and public does not reflect this reality (Bornstein, 2005; Haynes, 2007; Jennings, 2008b). Religion provides laws, ethics, values and a framework for moral decisions at both an individual and community level, and spirituality is integral to people's understanding of the world, their purpose and place in it (Linden, 2008; Thomas, 2004). This naturally means that religious belief and spirituality are also central to decisions that individuals and communities make about their development (Beerk, 2000). At a more fundamental level, they also shape conceptions of what development is. Tyndale (2003, p. 23) states: "Many people from all over the world share the view that development means a change which involves a dynamic coherence between the spiritual and the material." This is a fundamental challenge to the conceptions of development drawn from a positivist epistemology that have been explored already in this chapter. So how much do those working in development really understand about how religious knowledge informs and motivates beliefs and actions in people's lives, let alone how this relates to development. The overwhelming response from those engaged in the religion and development interface is that the time has come to "stop pretending development is exclusively secular" and strive to "understand the important role religion plays in most people's lives" (Harcourt, 2003, p. 5).

\section{THE HISTORICAL REALITY OF RELIGION IN DEVELOPMENT}

The spiritual reality of people's lives is not the only reason why the omission of religious and spiritual concerns from mainstream development discourse has been so "monumental" (Goulet, 1980, p. 481). The oversight also disregards the immensely significant role that religion has had in development practice, considered here to encompass the vast range of activities and efforts carried out by organisations or institutions for the 
betterment of individuals and communities. This role can be seen in the work of faith-based organisations working under the umbrella of 'development' and inspired by religious teachings. It is also visible in the activities of religious institutions that would not consider themselves to be working for externally dictated development goals, because the very nature of their religion is to promote the material and spiritual wellbeing of their believers as well as that of the wider community. Essentially, all religious traditions have been "deeply involved in social justice work" (Saanen, 2007, p. 3). Some religions have framed their activities in more explicit development terms than others. For instance, Barnett and Weiss (2008: 19-20) argue: “... it is Christianity and Christian faith-based organizations that so far have had the most significant influence on contemporary humanitarian action." Indeed, Christianity's influence on humanitarian and developmental activities stretches back to the work of Christian missions in colonial times, and continued following WWII with a strong emphasis by the World Council of Churches on the Catholic social teachings on development (Saanen, 2007; Thaut, 2009). This influence stands unabated in contemporary development. To cite one example, around half of all health and education services in subSaharan African are provided by faith-based organisations, predominantly from Christian backgrounds (Deneulin, 2009; Thaut, 2009). Speaking on this influence from the Diocesan Direction of Development in one African country, an individual interviewed by Thaut (2009, p. 323) remarked: “...the church is always there."

The strong focus on Christianity by many authors of the religion and development interface is somewhat reflective of a continued Eurocentric focus in development discourse. The influence of faith-based humanitarian activities inspired by different religious traditions and often originating in 'developing' countries instead of 'developed' should not be ignored. Kumar (2003) and Bradley (2009b) draw attention to the influence of Gandhian movements in India as having a significant impact on development activities and conceptions in that country. Clarke (2008a, p. 21) discusses how there has been a dramatic growth in the number of Islamic faith-based organisations in the Arab world since the 1980s, and Deneulin (2009, p. 88) explores the development-related activities of many Islamic states and organisations based 
on the centrality of ensuring social justice to "being a good Muslim." The works of all these authors, and many more, draw attention to a connection between religion and development that has been predominantly overlooked as a result of the secularisation of Western society and largely unquestioned assumptions of secularisation theory in development (Ellis, 2006, p. 355).

\section{THE SACRED AND THE SECULAR: COMMON GROUND IN DEVELOPMENT?}

The Jubilee 2000 Debt Campaign is further evidence and a standout instance of religious communities offering an alternative to dominant development discourse and practice on behalf of the world's poor and marginalised. The vision of founders Bill Peters and Martin Dent, who both "cite their Christian faith as a foundation for their activism", was "a year of biblical jubilee, when creditors would forgive all debts and developing countries could begin again" (Keough, 2004, p. 36). Then Chancellor of the Exchequer in the United Kingdom Gordon Brown described it "as the most important church-led social movement in Britain since ...the campaign to outlaw slavery in the $18^{\text {th }}$ century" (Wallis, 2005, pp. 271-272). While the religious message of the Jubilee 2000 Campaign has not necessarily influenced conceptions of development held by the international financial institutions that its criticisms were aimed against, many authors contend that religious beliefs and values have significantly influenced notions of development that are today considered secular. Barrow and Jennings (2001), Lunn (2009), Ter Haar and Ellis (2006) and Thaut (2009) propose that the very origins of the vision of development have clear religious roots and have been fundamentally influenced by the same nineteenth century Christian thought that inspired evangelical movements and missionary organisations. Barrow and Jennings (2001, p. 9) deem the Christian Good Samaritan principle to be "the foundation of twentieth century philanthropy and aid," while Ter Haar and Ellis (2006, p. 354) make the particularly strong conviction that the modern idea of development may be seen as a 'coercive utopia' that is "the secular translation of a millenarian belief." 
Some confusion may arise at this point, as I asserted earlier that the foundations of development rested upon the knowledge system of science and not of religion. Evidently, there are arguments in support of both positions. However, what is clear from reflection on the historical and contemporary influence of religion in development and the nature of religion itself, is that "there is an important nexus between the sacred and the secular in the context of international development" (Jennings, 2008b, p. 2). Speaking of a 'nexus' between the sacred and the secular simply refers to the idea that "the sacred texts and teachings of the major religions contain values and principles relating to global challenges" that development aims to overcome (Lunn, 2009, p. 944). There is common ground. According to Deneulin (2009, p. 73), "development is inherent in what members of religious traditions have been doing for a long time, and continue to do." While the views put forward by several authors suggest that religious knowledge is relevant to development, the engagement with this issue on a practical level has tended towards what Goulet (1980) has called 'instrumental'.

\section{FAITH-BASED DEVELOPMENT ORGANISATIONS}

To better understand this idea of 'instrumental' engagement with religion in development, the discussion will now turn to addressing the rise in attention being given to faith-based development organisations on behalf of academics, practitioners and policy-makers of development alike. The role of faith-based organisations has arguably received the greatest coverage in the religion and development interface to date. Many of these studies explore particular case studies and relate these experiences to wider debates about the role of religion and spirituality in development (Bradley, 2009b; Martinez, 2003; Timmel, 2003; Tyndale, 2006), while several authors have taken a broader view and attempted to differentiate faith-based organisations into typologies (Bradley, 2009a; Clarke, 2008a; James, 2009; Thaut, 2009).

Three broad themes emerge from these considerations. The first is that faithbased organisations are extraordinarily heterogeneous (James, 2009; Thaut, 2009; Bradley, 2009b: 101; Marshall and Van Saanen, 2007: 2-3). Lunn (2009, p. 
942) accurately states that the term 'faith-based organisation' "masks enormous complexity." At the simplest level, a faith-based organisation is a development organisation that is influenced in some way by religion (and it could be added here that it is explicit about this influence). Religion can effect everything from the values and motivations of the organisation's staff, to the conception and subsequent strategy of development adopted, to an organisation's choice of partners and beneficiaries (James, 2009, p. 12). These variations in how religion influences a development organisation have profound "implications for the success of humanitarian efforts in the field", whether positive or negative (Thaut, 2009, p. 347). Clarke (2008) distinguishes five main types of faith-based organisations, while Thaut (2009) proposes a taxonomy of how religious principles are translated into humanitarian action. She defines three categories, accommodative-humanitarianism, synthesishumanitarianism, and evangelistic humanitarianism, to demonstrate the importance of distinguishing among faith-based agencies themselves. What is essential to recognise in relation to all types of faith-based organisations is that the faith element is not an 'add-on' (Jennings, 2008b, p. 16). It is an integral part of the nature and activities of the organisation.

A second substantial theme that emerges from the religion and development interface is the distinct nature of faith-based organisations in comparison to secular non-governmental organisations. Academics and donors alike increasingly recognise that there can be a 'value-added' element to development activities carried out by faith-based organisations. This valueadded element is identified in the nature of relationships between faith-based organisations and the people they work with. Research suggests that faithbased organisations are closer to the grassroots level and therefore more effectively reach and are valued by the poorest (James, 2009; Jennings, 2008b; O. Odumosum, 2009). In ratings of effectiveness in Voices of the Poor, "religious organisations feature more prominently than any single type of institution" (Narayan, 2000, p. 222). Clarke and Jennings (2008b, p. 2) suggest that one reason for this closeness is the "great historical resonance" of the idioms of faith compared to contemporary development discourse, the former reflecting older discourses and long-held communitarian values. The contemporary relevance can be found in the spiritual element of religion 
whose application in development is unique to faith-based organisations. This spiritual element alters both the means and ends of development (James, 2009). Spiritual resources are a means for development alongside material, intellectual, and social resources, while spiritual growth on an individual level and the realization of goals relating to religious or spiritually based visions of society are an end. One faith-inspired organisation in India describes how: "Spiritual principles not only point the way to practical solutions, but they also induce the attitudes, the will and the dynamics that facilitate the implementation of those solutions" (Tyndale, 2006, p. 109). The collection of experiences found in Tyndale's volume on faith-inspired organisations plainly demonstrates how spiritual motivations are often "the main driving force of many of the materially poorest people in the world" (2006, p. 170). To ignore the spiritual dimension of faith-based organisations and their activities is to ignore the life-shaping force of much of humankind.

However, it is precisely the spiritual and religious elements of faith-based organisations that donors and development specialists are most hesitant to engage with. Hovland (cited in Kadt, 2009) and De Kadt (2009) in particular voice the widely held concern that because it is difficult to separate religious beliefs from the 'development' work of faith-based organisations, the line between providing development and proselytizing or conversion can be all too easily crossed. There is also a fear that a move "from observations on the social role of faith or spirituality to intellectual endorsements of faith-like perspectives on social life" could lead to an oversight of the "substantial hindrance" that religion can be to development (Kadt, 2009, p. 785; McLennan, 2007, p. 859). In relation to the "undeniable darkside" of faithbased organisations (Clarke, 2008b, p. 299), Lunn (2009) and Holenstein (2005) present a range of issues associated with religion that are not beneficial for development, such as the legitimization of power abuses and rights violations based on certain interpretations of religious teachings, or lack of transparency and accountability within religious structures. These concerns reflect upon a certain manner of exercise of and engagement with religion that does not occur consistently across the spectrum. Religious values become a hindrance to development when they are promoted with rigidity and take on totalitarian characteristics, leading to intolerance, exclusivity and fundamentalism (Kadt, 
2009). Such concerns are not unfounded; indeed they are important to address if religion and spirituality are to be taken seriously in development. However, the evidence from the literature predominantly demonstrates a judicial and critical approach to the issues at hand and the majority of advocates in favour of an enhanced space for exploring the role of religion and spirituality in development do not overlook the potential dangers. It is not an unreserved inclusion of all aspects of religious thought and practice into development that is being sought but enhanced and open analysis and discourse. And then a course of action.

\section{INSTRUMENTALITY VS. NON-INSTRUMENTALITY}

In part the concern about the hindrance of religion to develop stems from this notion of instrumental engagement of religion in development. Arguably, one of the main reasons why there has been such great attention devoted to institutional forms of religion, and not so much to the fundamental spiritual nature of religion that inspires them, is because faith-based organisations can be engaged with instrumentally (Goulet, 1980). They provide services and resources that can be employed for the realization of pre-existing development goals. Religious and spiritual values under this perspective are viewed as "mere means - aids or obstacles - to the achievement of goals derived from sources outside the value systems in question" (Goulet, 1980, p. 484). For example, in relation to the Millennium Development Goals the role of religious communities and organisations is seen to be through (1) the provision of services (such as health and education) and (2) their ability to galvanize moral commitment for the goals at a community level (Jennings, $2008 \mathrm{~b})$. This instrumental view of religion leads development specialists to 'cherry-pick' from certain aspects or social constructions of religion that are seen as either a hindrance or help to development based on development outcomes conceived of by secular donors. According to Deneulin (2009, p. 25) this limits the credibility and effectiveness of "development interventions in contexts where religious and secular worldviews are in greater opposition and tension." This theme illustrates how, for the most part, religion is still being engaged with from the perspective that modern, scientific knowledge 
determines a particular objective worldview and standards by which everything else is compared with and judged by.

This position is being challenged by a small but pioneering group of authors calling for 'non-instrumental' engagement of religion in development (Deneulin, 2009; Goulet, 1980; Lunn, 2009). Having identified that the religion and development interface has only skimmed the surface of the religious knowledge that underlies the behaviour of believers, communities and institutions, there is a sense of unity in thinking around how this can and should be overcome so that 'cherry-picking' is avoided. This unity centres upon the assertion that the world's major religions must be studied in their entirety, and that this study should be focused upon the moral and spiritual teachings contained in the sacred religious texts of each (Arbab, 2000; Deneulin, 2009). Deneulin's (2009) entire book is devoted to the objective of studying the scripts of religions in order to understand the role of religion and spirituality in development. A number of other studies focus on one or two religions and explore first and foremost the spiritual teachings found in their authentic scriptures, and then how these are being applied in development contexts (Dugbazah, 2009; Kliksberg, 2003; Kumar, 2003; Loy, 2003; Timmel, 2003). Adoption of this approach sheds light upon the overwhelmingly unity that exists amongst the spiritual teachings of all the world's religions (Arbab, 2000; Deneulin, 2009). It is in spiritual values and principles that religious knowledge offers something qualitatively different to development that cannot be engaged with instrumentally. These broaden our understanding of what development is - a process that is inherently spiritual and therefore by its nature requires the practical application of spiritual principles and values (Haynes, 2007; James, 2009; Tsele, 2001). At this point we return to the question, now more refined, of whether these spiritual principles and values drawn from religious knowledge are relevant to development? Their purpose is to build peace, justice and unity in the world, and foster love and justice, respect and compassion, honesty and generosity in individuals. Are these principles and qualities that are relevant to development? 
And if thine eyes be turned towards justice, choose thou for thy neighbour that which thou choosest for thyself. -Bahá'u'lláh (The Bahá'í Faith)

One who, while himself seeking happiness, oppresses with violence other beings who also desire happiness, will not attain happiness hereafter. - Dhammapada

(Buddhism)

In everything, do to others what you would want them to do to you. This is what is written in the Law and in the Prophets. - Matthew 7:12 (Christianity)

One should never do that to another which one regards as injurious to one's own self.

This, in brief, is the rule of dharma. - Brihaspati, Mahabharata (Hinduism)

Woe to those ... who, when they have to receive by measure from men, exact full measure, but when they have to give by measure or weight to men, give less than due. -Qur'an (Islam)

You shall not take vengeance or bear a grudge against your kinsfolk. Love your neighbor as yourself. - Leviticus 19:18 (Judaism)

\section{SUMMARY}

Muzaffar (2003, p. 31) states: "The great task of the $21^{\text {st }}$ century is to provide a moral foundation and a moral framework to the monumental challenge of eradicating poverty." There is resounding agreement that exclusively material conceptions of and solutions to the issues facing humanity are insufficient. The knowledge and solutions provided by science do not address the holistic nature of these issues. As discussed, this has led to movement towards taking religion seriously in development and acknowledging that religious knowledge contains insights that may be relevant. Yet so much remains unexplored. Just like scientific knowledge, religious knowledge must be critically tested (Goulet, 1980), and this knowledge cannot be separated from experience and action. Thus the area that requires significantly more 
investigation in the religion and development interface is around the practical application of religious knowledge in development contexts.

Research into the work of organisations whose theory and practice of development is informed by religious knowledge is a crucial way to learn about this. Taking into account the truly enormous diversity of religious and spiritual beliefs and development activities that exist across the world today, it can be firmly established that there can be "no alternative to a nuanced case-by-case approach" (Berger, 1999, quoted in Holenstein, 2005: 382). Such an exploration must be made cognizant of the differing facets of religious knowledge, both theoretical and practical, and the range of actors who facilitate its generation and application in society. This requires an understanding of the religious scriptures from which faith-based organisations draw their inspiration and how these influence its work. Following this, an integral part of such research should also aim to learn from the conceptions and experiences of those whom this work directly impacts at a grassroots level. The bottom line is that religious knowledge and spiritual values are only relevant to development if they are held to be such by those whose lives are to be transformed by them. Through an exploration of the conceptions and descriptions of participants involved in one development initiative informed by religious knowledge, this thesis seeks to raise questions, gain insight and contribute to the growing discourse around these important areas of inquiry at the interface between religion and development. 


\section{CHAPTER THREE: FUNDAEC AND PREPARATION FOR SOCIAL ACTION (PSA)}

\section{INTRODUCTION}

The Preparation for Social Action (PSA) programme was initiated in Zambia in early 2008 when Inshindo Foundation was established to oversee its implementation. While Inshindo Foundation is a locally inspired and staffed non-profit organisation, it was a Colombian-based rural development foundation by the name of FUNDAEC that developed PSA, a programme being implemented by a range of organisations in countries across South America, Africa, Southeast Asia and the Pacific. This chapter will outline the origins, evolution and foundational principles of FUNDAEC in order to provide a context for the discussion of PSA in Zambia. Addressing the first objective of this research, particular attention will be given to exploring how religious knowledge, drawn primarily from the Bahá'i teachings, can be identified as one source of insight that shapes the conceptual framework, methodology and programme activities of FUNDAEC. The main sources of information for this chapter are publications produced by FUNDAEC, a number of brief articles by Inshindo Foundation, and the contribution to The Lab, the Temple, and the Market by Farzam Arbab (2000) in which he reflects upon his involvement during the early stages of FUNDAEC.

\section{FUNDAEC}

\section{i. Origins}

Fundación para la Aplicación y Enseñanzas de las Ciencias ${ }^{5}$ (FUNDAEC) was created in 1974 by a group of six professors from the Universidad del Valle in Colombia at a time when the deficiencies of development based on modernisation theory were becoming increasingly blatant. The pattern of ever-widening disparity between the two sectors that contemporary

\footnotetext{
${ }^{5}$ English translation: Foundation for the Application and Teaching of the Sciences
} 
approaches of development were producing in 'developing' countries - a small modern sector whose activities and behaviours corresponded with those of industrialized nations and a large traditional sector still occupied with daily subsistence in rural and urban slum areas - was clearly evident in Colombia. Within this context, the group was particularly concerned with the role of education in development and how to engender truly participatory rural development (Farzam Arbab, 1988).

Many of the concerns held by this group were not unique to the time. A range of development actors, practitioners and theorists alike, were increasingly exploring how to achieve participation and involve communities more directly in development work to promote their wellbeing. The 1970s was also a period of interdisciplinary and multisectoral approaches, a rise in emphasis on the role of both formal and non-formal education to achieve development ends, and a particularly strong focus on rural development. "New social visions" were emerging from different countries and a number of theories that remain influential in development discourse today were first developed during this time (Farzam Arbab, 1988). To cite one example, we can see in the work of Paulo Freire many parallels with FUNDAEC's approach to education for development; in his seminal work Pedagogy of the Oppressed Freire asserts that learners must be co-creators of knowledge and that 'freedom' will be the result of action informed by praxis, "reflection and action upon the world in order to transform it" (Freire, 1970).

FUNDAEC grew out of the efforts of the founding group not to apply a preexisting theory of development, but to engage local populations in Colombia in a process that would ultimately lead them to be protagonists on their own path of development. Three basic elements were held to be central to this process: (1) the need for the existence of institutions and structures that truly belong to the population concerned; (2) the centrality of knowledge to participatory development and corresponding requirement for the building of individual and community capacities to generate and apply knowledge drawn from "the universe of knowledge: their own, the modern knowledge system, as well as the experiences of other people and groups in the world" (Farzam Arbab, 1988); and (3) that development is participatory only when a 
people are involved in systematically learning about the changes occurring in their society and consciously incorporating knowledge into the process to effect further change (Farzam Arbab, 1988).

The group of professors began their efforts with the people of the region of Norte del Cauca (an area of 90,000 hectares and 100,000 inhabitants, shown in Figure 1), involving them in the establishment of a 'learning institution' for the region that was called a Rural University, although it differed in many ways from traditional university models. "The tasks of the Rural University were defined in terms of setting in motion a series of learning processes among the population of the region, hoping that the knowledge they generated would create and increase the forces that are necessary to resist the opposing forces of social disintegration and gradually lead to positive change" (Farzam Arbab, 1988).

Figure 1. Map of Colombia showing Norte del Cauca (VAL)

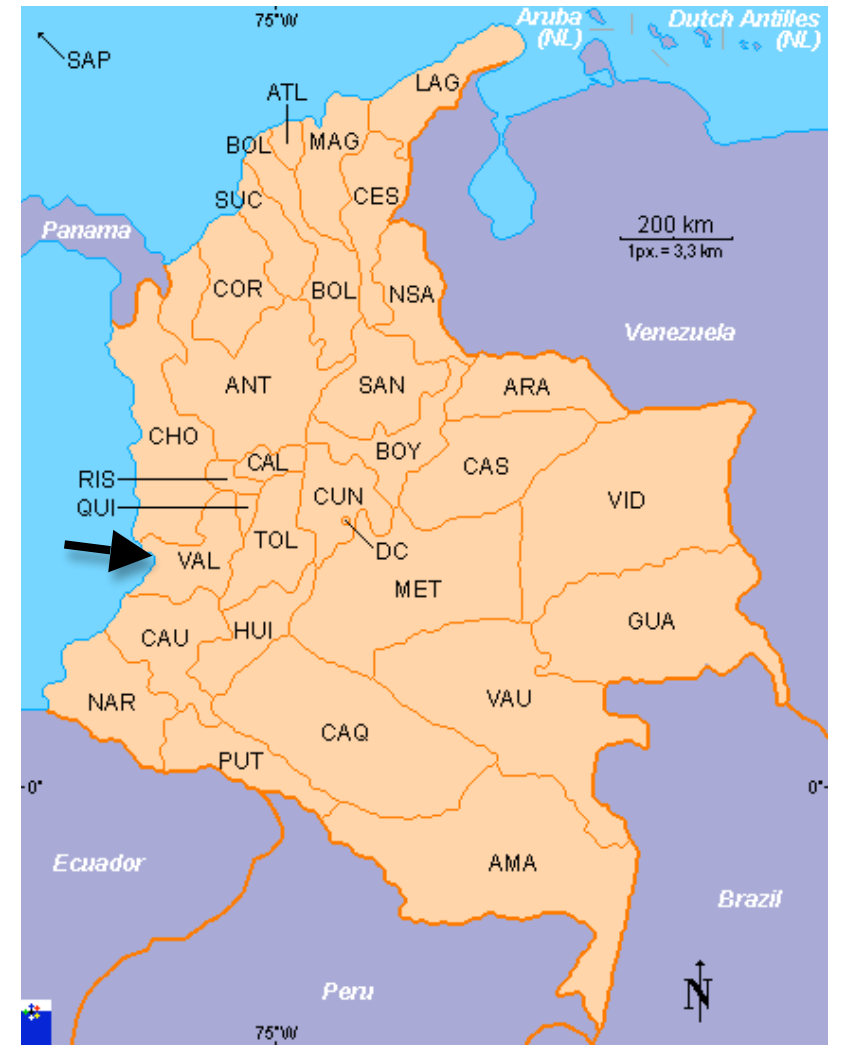

(Source: http: / / flagspot.net/flags/ co\%28.html) 


\section{ii. Foundational Principles}

From the outset, the conception of development held by the founding members of FUNDAEC was significantly different from mainstream conceptions in the 1970s and even today. Development was conceived of as a material, social and spiritual process of transformation leading to the wellbeing of humanity and informed by the knowledge systems of science and religion. Addressing what he terms the "collective evolution of the human race", one member of the founding FUNDAEC group, Farzam Arbab, explains:

"The primary force propelling this new, now conscious, evolutionary process is knowledge, a knowledge that is created and constantly recreated on the basis of a sound understanding of one's self, of those promptings that lead to abasement and of those that lead to dignity and honour. The two repositories of this knowledge are religion and science. With their aid we discover in ourselves the powers of nobility, freedom, and oneness and learn to apply these powers in building an everadvancing civilization" (Arbab, 2000, p. 123).

Thus, the knowledge systems informing the conceptual framework of development that guided the founders of FUNDAEC (Table 1) were both scientific and religious. As a number of the original founders were from the Bahá'í Faith, the Bahá'í teachings were one of the primary sources of religious knowledge that were drawn upon. However, other members were Catholic or from other religious orientations and FUNDAEC clearly defined itself as nonsectarian: it looked to religion in general as a source of knowledge, but did not associate itself exclusively with one religion. 
Table 1. FUNDAEC's Guiding Principles

\begin{tabular}{|c|c|}
\hline Development of human resources: & $\begin{array}{l}\text { Participants of FUNDAEC, regardless } \\
\text { of social status, are irreplaceable } \\
\text { resources in a self-sustaining process } \\
\text { of change; }\end{array}$ \\
\hline $\begin{array}{l}\text { Education as a means of releasing } \\
\text { potential: }\end{array}$ & $\begin{array}{l}\text { Every human being possesses great } \\
\text { potentialities that an appropriate } \\
\text { education process can develop and } \\
\text { channel towards service to the } \\
\text { community and to society at large; }\end{array}$ \\
\hline $\begin{array}{l}\text { Commitment to understanding problems } \\
\text { of poverty and social disintegration: }\end{array}$ & $\begin{array}{l}\text { FUNDAEC would always be } \\
\text { committed to analyzing the problems } \\
\text { of poverty and social disintegration, } \\
\text { and would develop its programs as } \\
\text { contributions to a far more exalted } \\
\text { vision of the human being; }\end{array}$ \\
\hline $\begin{array}{l}\text { Education as a means of fostering } \\
\text { spiritual development: }\end{array}$ & $\begin{array}{l}\text { In spite of all the manifestations of } \\
\text { cruelty and injustice in the world, } \\
\text { through a proper educational } \\
\text { process, the spiritual nature of every } \\
\text { human being can flower and a } \\
\text { prosperous and advanced civilization } \\
\text { can come into existence; }\end{array}$ \\
\hline $\begin{array}{l}\text { Modernization within the context of } \\
\text { addressing the needs of the integral } \\
\text { nature of man: }\end{array}$ & $\begin{array}{l}\text { The development programs of } \\
\text { FUNDAEC would have to evolve in } \\
\text { the context of a search for a } \\
\text { scientifically and technologically } \\
\text { modern society, which, however, } \\
\text { would base its educational, economic, } \\
\text { administrative, political, and cultural } \\
\text { structures on the concept of the } \\
\text { integral nature of man rather than his } \\
\text { mere material needs. Under such } \\
\text { conditions, the relations between }\end{array}$ \\
\hline
\end{tabular}




\begin{tabular}{|c|c|}
\hline & $\begin{array}{l}\text { urban and rural life would also } \\
\text { develop in a far more balanced way } \\
\text { than the patterns that have evolved } \\
\text { within the present world system; }\end{array}$ \\
\hline $\begin{array}{l}\text { Enabling rural people to contend with } \\
\text { their own challenges using the tools of } \\
\text { research and education: }\end{array}$ & $\begin{array}{l}\text { Research and education, the two } \\
\text { main components of the activities of } \\
\text { the rural university, would be carried } \\
\text { out precisely in the context of a } \\
\text { delicately balanced interaction of } \\
\text { science and the development of the } \\
\text { capacity of rural people to participate } \\
\text { in the generation and application of } \\
\text { knowledge that responds to their } \\
\text { exigencies; }\end{array}$ \\
\hline Search and learning: & $\begin{array}{l}\text { The element of search and learning } \\
\text { would always have to be present to } \\
\text { some degree within the plan of action } \\
\text { for FUNDAEC; }\end{array}$ \\
\hline $\begin{array}{l}\text { Development of structures that will truly } \\
\text { serve the needs of rural populations: }\end{array}$ & $\begin{array}{l}\text { Rural needs are much more than } \\
\text { usual interventions, since old } \\
\text { structures and organizations or rural } \\
\text { people have been destroyed by the } \\
\text { forces of modernization, with no new } \\
\text { structures taking their place. Hence, } \\
\text { the processes of rural life, production, } \\
\text { simple construction and repair, } \\
\text { marketing, the development of } \\
\text { human resources, socialization, the } \\
\text { flow of information, adaptation and } \\
\text { the improvement of technologies, } \\
\text { health care and sanitation, and } \\
\text { decision making are in need of } \\
\text { structures that will truly serve the } \\
\text { needs of rural populations. }\end{array}$ \\
\hline
\end{tabular}

Source: (Leggett, 2006, p. 46, sourced from Arbab et al, 1988)) 
iii. Foundational Principles and the Bahá'í Faith

As stated, FUNDAEC considers itself to be a non-sectarian organisation and does not identify the Bahá'í Faith as the sole source of religious knowledge that informs its approach to development. While two beliefs central to the conceptual framework of FUNDAEC are drawn from Bahá'í teachings, these appear to be in harmony with the teachings and spiritual values of many other religions. The reflections of Farzam Arbab, one of the original members of FUNDAEC and a member of the Bahá'í community, provide some insight into the role of these beliefs in FUNDAEC's theory of development. These are prefaced by quotations from the Bahá'í Writings that I have selected based on my own understanding of their relevance to the teachings discussed.

"The tabernacle of unity hath been raised; regard ye not one another as strangers. Ye are the fruits of one tree, and the leaves of one branch" (Bahá'u'lláh, 2006).

A central teaching of Bahá'u'lláh is the oneness of humanity - that as creations of one God all people are part of one human family. This teaching shapes an approach to development that is based on unity and oneness and rejects traditional 'insider-outsider' and 'developed-underdeveloped' dichotomies so often extolled in development. Arbab describes his experiences of becoming acquainted with the local population of Norte del Cauca where FUNDAEC began and his position not as "an agent of a development organization or bearer of charity" but as a friend working among friends "for a common purpose" (Arbab, 2000, p. 121). Such an approach to development strives to work against attitudes of superiority often held either consciously or sub-consciously by those who consider themselves 'developed' within a dichotomized framework. The following statement captures Arbab's vision of development based on the spiritual principle of the oneness of humanity, a conception that its methodology and publications demonstrate is shared by FUNDAEC:

"Belief in the unity of humankind, with its implications of equity and selfless love, is after all, ultimately a religious 
conception of reality. Viewed from the angle of oneness, development ceases to be something one does for others. A vision begins to emerge according to which the rich and poor, the illiterate and educated, are all to participate in building a new civilization, one that ensures the material and spiritual prosperity of the entire human race" (Arbab, 2000, p. 121).

"O Son of Spirit! Noble have I created thee, yet thou hast abased thyself. Rise then unto that for which thou wast created" (Bahá'u'lláh).

One question that the original FUNDAEC members asked in the early days was related to the way development programmes view the essential nature of human beings. The group felt that even as people-centred development approaches were becoming mainstream at the time there was a prevailing misconception of human nature based on a notion of humans as Homo economicus. The members agreed that human beings possess a dual nature - a physical nature shaped by millions of years of animal evolution and a higher, spiritual nature. It is the spiritual nature, based on religious notions of human dignity that are central not only to the Bahá'í Faith but to all major world religions, which allows individuals and communities to transcend their physical, animal nature that is capable of inflicting acts of unspeakable cruelty and injustice. Thus, FUNDAEC saw a central challenge of development as enabling populations to develop the capacity to "overcome the limitations urged on us by the demands of survival, to learn to control the appetites of the animal, and to develop the qualities of the higher nature that struggles for expression" (Arbab, 2000, p. 123). Thus the conception of development that embraces FUNDAEC's endeavours is that "only belief in its inherent nobility can equip humanity to respond to the demands of this crucial historical moment" (Arbab, 2000, p. 124).

iv. Evolution of FUNDAEC and the Sistema de Aprendizaje Tutorial (SAT)

The rural university developed by FUNDAEC and the local population of Norte del Cauca was given the name University for Integral Development (UDI). Two main programmes have been developed by the UDI: the Centro 
Universitario de Bienestar Rural (CUBR) which is the university's training centre, and the Sistema de Aprendizaje Tutorial (SAT), an 'education for development' programme. Since their formation, the CUBR and SAT have together trained over 50,000 graduates and there are currently around 40,000 students enrolled in the programmes in Colombia (Honeyman, 2010, p. 601). Both programmes have expanded in reach beyond Colombia, with various modifications to suit different contexts.

In the early stages of the FUNDAEC group's deliberations the question arose of whether approaches to education in development that focused primarily on the expansion of primary education were actually changing rural areas for the better. The SAT, whose education is for rural youth and adults, is based on the conviction that "educational investment at higher levels within a rural population is more efficient than at lower levels if it sets in motion a dynamic process for the development of human resources at different levels according to regional requirements" (Arbab, unknown, p. 13). The programme began modestly in 1974 with a small number of rural youth in Colombia who were trained to become Promoters of Rural Well-being. A Promoter of Rural Wellbeing is regarded as a human resource who has developed the necessary practical, intellectual and spiritual capacities and attitudes to contribute to processes of social change in their community (Farzam Arbab, 1988, p. 12). For seven years FUNDAEC was engaged in a process of extensive training and assisting the groups. The research generated from this early learning process formed the basis for the SAT curriculum today. Over the next two decades, the programme continued to expand into other rural regions of Colombia and in the 1990s gained the support of Colombia's Ministry of Education who accredited the programme and made it equivalent to completing formal secondary school. An important feature is that although SAT is spread across Colombia, the administration, structure, and culture in each area is distinct and in some occasions modified to better suit local needs and culture.

The SAT programme is a three-year course in which students study 28 textbooks developed by FUNDAEC. It is structured into three levels, each designed to develop particular practical and intellectual abilities and qualities 
and attitudes. At the end of the completion of each level, a student is recognized respectively as a Promoter of Rural Well-being, a Technician of Rural Well-being, and finally receives of Baccalaureate for Rural Well-being. The texts integrate subject areas and concepts from a diverse range of fields, including agriculture, health, education, mathematics, science, and philosophy. These concepts are then organized into sets of capabilities that are developed for the two-fold purpose of contributing to individual and community wellbeing. SAT is accredited in Colombia as a formal education programme, but its delivery method is informal in nature. Groups of students meet for around ten hours a week at times agreed upon by the group and are guided in their study by a tutor trained by the rural university. The role of the tutor is to act as a 'facilitator' of the students' learning and not lecture or dictate. The groups are also engaged in 'action-learning' projects around their community in which they put into practice the knowledge and skills learned in the texts in a way that simultaneously contributes to processes of community development.

As the SAT programme has spread throughout Colombia and into other countries of Latin America, particularly to Honduras where it is also an accredited alternative to secondary high school, it has gained international recognition for its approach to education. In 2002, SAT was awarded a Club of Budapest Change the World Best Practice Award, and was rated as the best educatory project of the time by the Euro Expo 2000 international jury (Richards; The Club of Budapest International Foundation). Some important foundational studies have also been carried out focusing on the experiences of SAT graduates that were introduced in Chapter One of this thesis.

\section{PREARATION FOR SOCIAL ACTION}

The Preparation for Social Action programme evolved out of the experiences of SAT and is part of a systematic process of expanding FUNDAEC's activities outside of South America. The texts of PSA were adapted for different contexts and into English from the first level of SAT (the Promoter of Rural Well-being) and the programme shares its predecessor's purpose and 
many of the essential characteristics outlined thus far. At the end of the 18month PSA course a student will graduate as a Promoter of Community Wellbeing. The main objective of PSA is to empower young people with the capabilities needed to become "agents of social and economic development of society", strengthening their capacities to assume responsibility for social transformation and acquire relevant knowledge, skills, attitudes and qualities (Inshindo Foundation, 2008, p. 3).

\section{i. Essential Elements}

One of the essential elements of PSA is the harmony sought between spiritual and material development. The texts integrate scientific knowledge and spiritual principles and qualities in a way that emphasises the simultaneous development of the two, both in the life of the individual and through participation in service to the community. Lessons often begin by exploring a certain concept in the physical world, and this is followed by a section that reflects on a related spiritual concept or the spiritual qualities required to apply this practical knowledge in a way that contributes to community wellbeing. One Inshindo staff member described an example of the integration of the material and spiritual in PSA in these words:

"I'll give you an example of the very first book that the students go through, it's called Properties. They start with properties like shape, size, matter, boiling points, hardness, things like that, but then the last three chapters or units they talk ... about the qualities of a human being. They go on to say things like truthfulness, honesty, patience, they are qualities of a human being, so we will not call them 'properties' of a human being, because they're human beings, but the same concept. So they're trying to show that even human beings have properties, we just call them attitudes or qualities. Then they go in to explain for example the quality of truthfulness, the quality of honesty, the quality of ... so right there the students when they are coming out of the training they know 
that there is a parallel between the material and the spiritual" (Inshindo Staff 1).

A second essential element of PSA is the integration sought between theory and practice and the pattern of action and reflection that is followed. Individual development comes from applying theoretical knowledge in practice, often through acts of community service, and reflecting on this action in order to reinforce existing knowledge, generate insights and develop experiential knowledge that is relevant to the local community. Closely related to the second element is PSA's focus on the purpose of students' education as the development of capabilities, not the assimilation of information. PSA seeks to develop five capabilities in students in the areas of mathematics, science, language, technology, and service to the community. Capacities are built in these areas by applying knowledge in practice in one's own life and in the community. This process guided by an overarching purpose that holds individual and community transformation as inseparable for the advancement of society.

\section{ii. Elements of Methodology}

PSA "is delivered at the community level though groups composed of peers who learn and serve together" (Inshindo Foundation, 2008, p. 3). Delivery at the community level allows students to understand the society they are seeking to transform and apply the knowledge gained from studying the texts through practice and service activities that reinforce the learning process of the individual as well as contribute to processes of community transformation. Table 2 below describes in more detail five the five main elements of the PSA methodology. 
Table 2. Elements of PSA methodology

\begin{tabular}{|c|c|}
\hline The text: & $\begin{array}{l}\text { Students study } 24 \text { texts structured } \\
\text { around five capabilities. Taken at the } \\
\text { level of application, these texts seek } \\
\text { to develop mental and practical skills } \\
\text { and abilities and the knowledge, } \\
\text { attitudes and qualities needed for an } \\
\text { individual to become an effective } \\
\text { agent of change. Integration of } \\
\text { knowledge from diverse subject areas } \\
\text { is a distinguishing feature; }\end{array}$ \\
\hline The tutor: & $\begin{array}{l}\text { The tutor guides the students as they } \\
\text { study the text and carry out service } \\
\text { and production projects in the } \\
\text { community. Tutors are friends or co- } \\
\text { workers who accompany students, } \\
\text { evaluate their progress, make } \\
\text { necessary clarifications and provide } \\
\text { additional information, but do not } \\
\text { instruct or lecture as a teacher would; }\end{array}$ \\
\hline The group: & $\begin{array}{l}\text { The groups are ideally comprised of } \\
15 \text { to } 20 \text { students who study the text, } \\
\text { carry out projects, and consult and } \\
\text { make collective decisions together. } \\
\text { Students are encouraged to think of } \\
\text { their groups as (1) the first area of } \\
\text { service and community where } \\
\text { knowledge and qualities are applied } \\
\text { and (2) a body distinguished for its } \\
\text { unity, moral and intellectual } \\
\text { excellence, and humble service; }\end{array}$ \\
\hline Service and production projects: & $\begin{array}{l}\text { Through these projects students learn } \\
\text { to apply the knowledge, skills, } \\
\text { qualities and attitudes studied in the } \\
\text { texts. The groups choose together }\end{array}$ \\
\hline
\end{tabular}




\begin{tabular}{|c|c|}
\hline & $\begin{array}{l}\text { what community activities they will } \\
\text { initiate and areas of service include } \\
\text { promotion of small-scale food } \\
\text { production, environmental health, } \\
\text { family and community health, and } \\
\text { the education of children and } \\
\text { younger youth; }\end{array}$ \\
\hline The community: & $\begin{array}{l}\text { The community is the arena where } \\
\text { knowledge is applied in PSA and it is } \\
\text { viewed as a partner in the learning } \\
\text { process of students. Humble service } \\
\text { to the community is conducive to the } \\
\text { highest form of individual } \\
\text { development and contributes to its } \\
\text { advancement. }\end{array}$ \\
\hline
\end{tabular}

Source: (Adapted from Inshindo Foundation, 2008).

\section{PREPARATION FOR SOCIAL ACTION IN ZAMBIA}

\section{i. Origins and Evolution}

In 2007, the three founding directors of Inshindo Foundation approached FUNDAEC with an expression of interest to implement the PSA programme in Zambia. Mwinilunga was selected as a rural area where PSA would be offered. One director of Inshindo explained how this decision was significantly influenced by the presence of Zambia's large Bahá'í population in this region, many of whom had been supporting social and economic development activity for some time already. Involvement in PSA would build upon these efforts. Although the SAT and PSA programmes were designed with rural areas in mind, the directors of Inshindo were interested in how the programme would work in a more urbanized area. They selected Kabwe, a peri-urban area, as the second site for PSA and the base for the national office because of the advantages afforded by the town's close proximity to the capital, Lusaka. It was also perceived that working in Lusaka 
would be too difficult because of the 'clutter' of non-governmental organisations already active there. The locations of Kabwe and Mwinilunga are shown with arrows in Figure 2.

Figure 2: Map of Zambia showing Mwinilunga and Kabwe

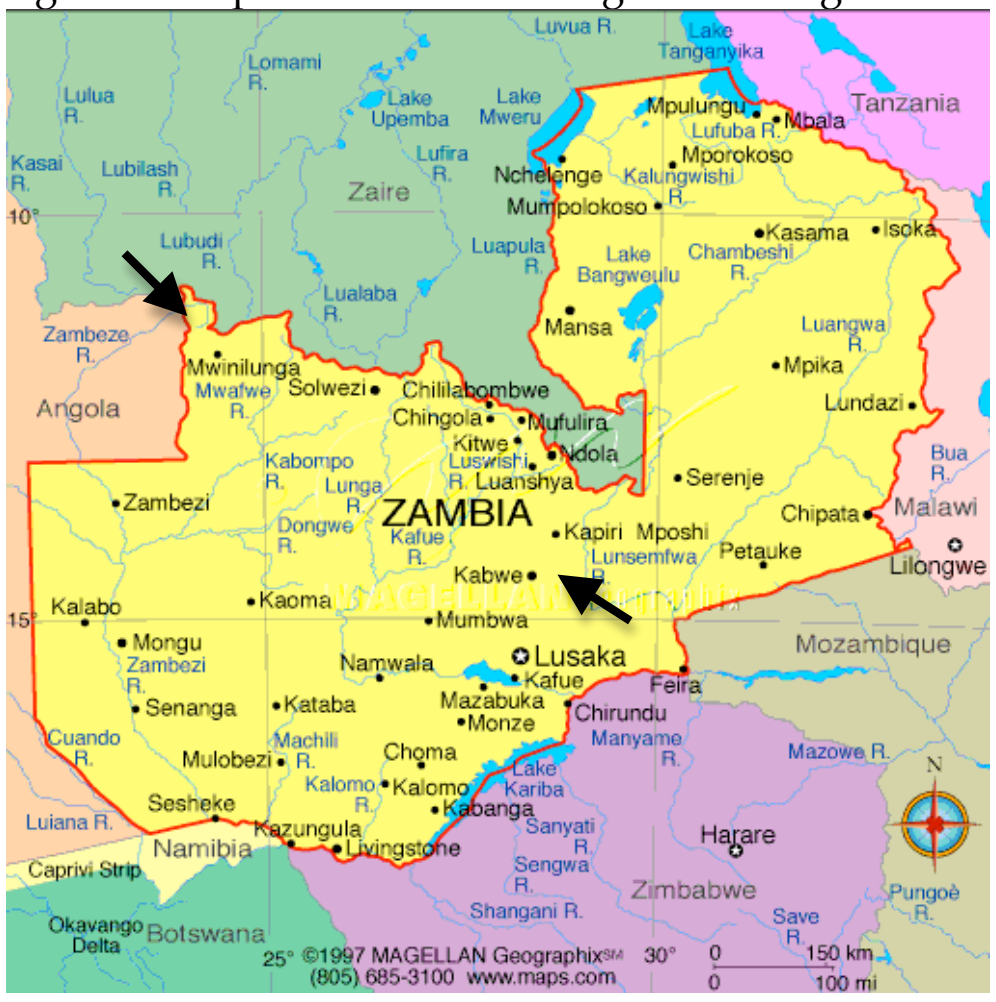

(Source: Honey, 2011)

The initial stages of implementing PSA involved a number of meetings between the directors of Inshindo Foundation and local community leaders in Mwinilunga and Kabwe to discuss the programme and gain support. These leaders were asked to recommend youth in the community who may be interested in and had the required qualifications (completion of high school) to become PSA tutors. After a process of interviews, selection and training, tutors were chosen in each area and formed eight groups in Kabwe and six in Mwinilunga. A number of the early groups collapsed in the following months, and after reflection on these experiences new groups were established with the help of Inshindo staff. Of the original groups formed in 2008, four are remaining in Kabwe and four in Mwinilunga that have an average of ten students in each. These students graduated at the beginning of 2011 as I was finishing this thesis. 
Early in 2010, Inshindo Foundation decided to build upon what it had learned with the early groups and expand the programme in order to reach more youth and generate further learnings. Twenty tutors from Kabwe and fifteen from Mwinilunga were recruited and took part in a two-week training near Kabwe in April. In May, a period of group formation began that resulted in around ten new groups in Mwinilunga and ten in Kabwe. The group formation of 2010 was facilitated by the staff of Inshindo and informed by reflections on the experiences of the initial groups, an example of the systematic approach to development as a learning process that Inshindo Foundation and FUNDAEC have adopted.

ii. Vision

The description of the implementation of PSA in Zambia since 2008 serves to illustrate the organic and systematic nature of its evolution. PSA is in its formative years and there are no students who have fully completed the programme and becoming recognised Promoters of Community Wellbeing. At the time when this study was carried out, there were approximately 250 students in Kabwe and 250 students in Mwinilunga. In the future, Inshindo Foundation envisions the continuing expansion of PSA to a much larger scale involving thousands of students in a range of locations. As PSA expands, Inshindo's objective is that the impact on communities in Zambia will concurrently increase, giving rise to a growing number of young people who build their capacities through study and service and act as human resources in ever-advancing processes of community development.

\section{SUMMARY}

This chapter has provided a description of the Preparation for Social Action programme, beginning with the history of FUNDAEC and the SAT programme that preceded the development of PSA and whose foundational principles and methodological approaches inform it. The PSA programme itself was then explored in more detail, and a range of its activities in Zambia since its inception outlined. The detailed description of the programme is 
important here because it provides a context for the conceptions and experiences of PSA participants that are explored in the last three chapters of this thesis.

Given the infancy of PSA in Zambia evident from this description, it is important to emphasise once again that this study is exploratory in nature. It does not attempt to evaluate the impact of PSA on communities in Zambia, or the role of religious knowledge in relation to this impact. Nonetheless, the description of FUNDAEC and PSA in this chapter has given rise to a number of insights around how religion acts as a source of knowledge in development at an institutional level, shaping the conceptions of development that determine actions taken at the grassroots level. The chapter illustrated how beliefs based on teachings drawn from a system of religious knowledge, the Bahá'í Faith, have shaped FUNDAEC's conceptual framework and methodological approach. At the level of programme activity, it was described how religious knowledge is integrated into the PSA textbooks as spiritual principles and spiritual qualities that participants study together and are encouraged to act upon. Each one of the three levels is characterized by the harmony between the spiritual and the material, between religious and scientific knowledge, that FUNDAEC seeks to achieve and PSA embodies. 


\section{CHAPTER FOUR: METHODOLOGY}

\section{INTRODUCTION}

This chapter will describe the conceptual and practical framework that guided the investigation into the PSA programme described in the previous chapter. At the outset, the chapter will discuss my role as the researcher and how I have chosen to situate rather than detach myself from the process. I assert that this approach is appropriate for engaging with religion and spirituality at a grassroots level. Following this, the second section will explore the elements of the conceptual and methodological approach chosen. It will focus on the characteristics of qualitative research that the study aligns with more broadly before discussing the particular theoretical lenses of constructivism and hermeneutics that have shaped the research process. This section will also describe the features of a case study approach to research and a 'crystallization' of methods. The third section will describe in some detail the range of methods employed during the research in Zambia and the justifications, both theoretical and practical, for those selected. The chapter will finish by briefly describing the process of analysis that was carried out and the role of 'writing as analysis' within this.

\section{QUALITATIVE RESEARCH}

According to Denzin and Lincoln (2003, p. 4): "Qualitative research is a situated activity that locates the observer in the world." This observer, the researcher, uses a set of practices to understand and interpret the world, making visible particular realities and by doing so transforming it. Although the word 'observer' is used, describing one aspect of a researcher's role, I believe the qualitative researcher is more like a conscious instrument that seeks to interpret and understand the meanings people bring to their lives and then communicate these to a wider audience. While qualitative research is often called 'naturalistic' in the sense that the researcher "studies a social setting to understanding the meaning of participants' lives in the participants' own terms" (Janesick, 2003, p. 51), the interactions between the researcher and 
those who live in that social setting give rise to a process through which social reality is co-created or co-constructed in different ways. The latter contribute their meanings based on grounded experiences and the former is guided by principles through which these meanings are interpreted, examined and conveyed (Lincoln, 2003). Thus qualitative research is 'situated' because the interpretations of both parties cannot be separated from their particular backgrounds, history, contexts and prior understandings (Creswell, 2009).

\section{RESEARCHER AS A CRYSTAL (ANALOGY ONE)}

I have found it useful to use an analogy from the physical world when talking about qualitative research and the researcher as an instrument. We can think of qualitative research in terms of a crystal. Light shines on the crystal and is reflected and refracted in a myriad ways. This light represents lived experiences and phenomena in the world and the meanings that people bring to them. While the light ultimately comes from one source, we can never get close enough to fully understand its true nature (i.e. an objective understanding); we know about it through the qualities of its different rays, where it rises from, it's intensity, and so on (human capacities and qualities, backgrounds, contexts). The different panes and sides of the crystal represent the complexity of the researcher, who is not a uni-functional, objective data collector but a human being. This complexity includes axes of identity such as gender, ethnicity, age, and religion, cultural background, the epistemological and ontological frameworks they adopt, and everything that is influenced by these, such as the choice of methodological approach, interpretive practices and behaviour throughout the research process. The crystal does not produce an exact reflection of the rays; rather it refracts the light and provides a representation or an insight into the light. No one crystal, as it naturally exists, is the same - qualitative research is ultimately subjective. However, the researcher can strive to 'polish their surface' and make known their various angles in order to refract the rays of the light as truthfully and clearly as possible. The light that is refracted represents the knowledge that the research produces, knowledge that arises from the interactions between the rays and the crystal and has the potential to affect change in the social world. In the 
natural world, the effects of light depend upon the properties and characteristics of objects. Similarly, how the knowledge produced through qualitative research is received, interpreted and acted upon in the social world is influenced by the capacities, attitudes, background and context of the observer. Ultimately, all three participants in qualitative research play a role in determining how knowledge shapes the social reality of the world we live in.

The following section addresses the diverse sides of the crystal that shape my own ontological, epistemological, and methodological approach to the research, as well as outlining the ultimate research design that was carried out. Because qualitative research "privileges no single methodological practice" it is up to the researcher to judge what is most appropriate to the study (Lincoln, 2003, p. 9). As this research is concerned primarily with religious knowledge, and cognizant of the spiritually based ontology of the majority of those who were involved (including myself as researcher), the choice of methodology has been greatly influenced by these factors. Linda Tuhiwai Smith (1999, p. 65) writes how "the concept of science as an allembracing method for gaining an understanding of the world" is still the pervasive norm at universities. Even though a range of qualitative methodologies "espouse an openness to consider and include the perspectives and orientations of marginalized voices ... some of the core assumptions of these same methodologies remain unchallenged and at odds with a spiritually-based ontology" (Leggett, 2006, p. 20). Opening a space for the critical and serious consideration of the role of religious knowledge and spirituality in development thus necessitates departing from some of the traditionally accepted methodologies in academia. “The master's tools will never dismantle the master's house" (Audre Lorde quoted in Smith, 1999, p. 42).

\section{PERSONAL WORLDVIEW}

The first step towards 'dismantling the master's house' (the unquestioned salience of modern, scientific knowledge and secularism in development) is to openly acknowledge my own personal worldview and how this has led to the 
selection of a particular set of 'tools' for this endeavour. My view of the world is deeply spiritually embedded and shaped by my faith in religious knowledge, in particular, that of the Bahá'í Faith. Slater (2004) writes about how few geographers speak as 'insiders' when writing about religious geography, and the same is certainly true for writers at the religion and development interface. This is despite the fact that qualitative methodological approaches for have, for some time now, emphasized the subjective nature of research and the consciousness of one's own positionality that is required (Creswell, 2009; Lincoln, 2003; Sullivan, 2003). Considerations of positionality have (importantly) focused on axes of identity such as gender, ethnicity or race, sexuality, socio-economic status and age; yet the consistent absence of religious or spiritual beliefs from this list is an unfortunate oversight. To be fair, I have been continually exploring how explicit I should be about my own personal religious beliefs throughout this research.

However impossible the 'view from nowhere' may be, making effort to minimize bias and maximize fairness and impartiality is of utmost concern in qualitative research. At the same time, it is clear that "the researcher's values and dispositions influence the knowledge that is constructed through the interaction with the phenomenon and participants of the inquiry" (Costantino, 2008, p. 118). Ultimately then, the decision to openly acknowledge the influence of the Bahá'í Faith on all aspects of the research is a matter of truthfulness and honesty with the researcher participants, the reader and myself. It is through uncovering underlying beliefs and attitudes, making them explicit and then consciously reflecting upon them throughout the research that a researcher contributes knowledge that escapes being 'the [subconscious] container into which data must be poured' (Lather (1991) quoted in J. Mills, 2006, p. 11). Furthermore, I reject the fragmentary notion of researchers having several 'selves' that separates an academic self from, for example, a spiritual self (J. Mills, 2006; Slater, 2004). To refer back to the earlier metaphor, academic and religious influences represent different sides of the crystal's cohesive whole. I have included Figure 3 here, a photograph taken of my bedside table in Mwinilunga, as a visual representation of the themes discussed in this section. The photograph shows my research 
reflection journal, Bahá'í prayer book and prayer beads on the left across from a Christian gospel book that came in the motel room where I stayed.

Figure 3. A representation of positionality: My beside table in Mwinilunga ${ }^{6}$

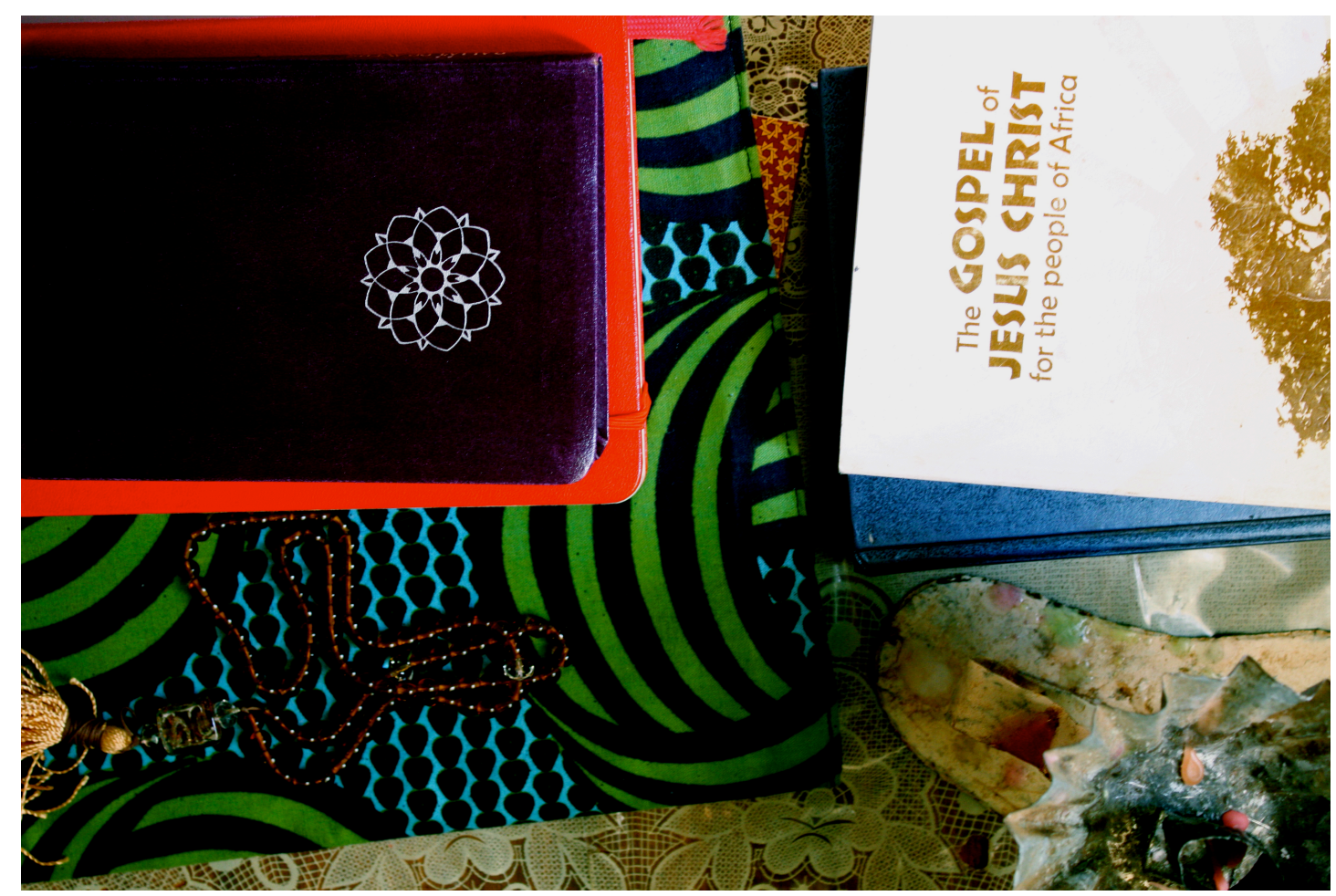

To be a Bahá'í means to acknowledge that the prophet-founder of the Bahá'í Faith, Bahá' 'u'lláh, is the manifestation of God for this day, and to follow the laws and guidance He has revealed. It means to have faith, described by Bahá'u'lláh's son, 'Abdu'l-Bahá, as 'conscious knowledge embodied in action', that the guidance revealed by Bahá'u'lláh constitutes the "supreme animating power for the advancement of the world and the exaltation of its' peoples" (Bahá'u'lláh, p. 93). Thus Bahá'u'lláh's Revelation, enshrined in the body of sacred Writings He revealed, is a system of knowledge that I explore and apply in my daily life both as an individual and a member of a wider Bahá'i community. There are two aspects of the Bahá'i Faith that are fundamental to the methodological approach I have taken to this research. These are the principle of the oneness of humanity, and an understanding of the spiritual nature of reality shared by all human beings. Unlike the

\footnotetext{
6 This image, and all the images that are included throughout the rest of the thesis, were taken by me in 2010 during my time in Zambia.
} 
traditional insider-outsider dichotomy assumed in social science research, this approach views the differences between people not as barriers impossible to overcome, but as part of humanity's richness and beauty that find unity in working towards the betterment of society and are harmonized when we recognize that we are all part of one spiritual family. In order for this unity in diversity to be achieved, the exercise of spiritual qualities is essential. In terms of my research, this meant that I was as much a participant in the process of social transformation as those who would traditionally be termed 'participants'. They were collaborators who contributed their knowledge and experiences as co-creators of social reality. Some of the spiritual qualities that were necessary to consciously embody during the research were an attitude of humility, love, respect, truthfulness, trustworthiness, and fellowship. I was not a researcher going to ask questions of the researched, but an individual working among friends for the shared purpose of generating knowledge that works towards, in some small way, the transformation of social reality. This meant listening with a humble posture of learning, sharing about my own experiences and beliefs and developing friendships, and being of service to those around me. While there were innumerable differences between myself and the other participants in the research, the exercise of these spiritual qualities based on a belief in the oneness of humanity meant that I was not an 'outsider' and they were not 'others'.

\section{METHODOLOGY}

\section{i. Constructivist Grounded Theory}

The approach to the generation of knowledge taken throughout this research is guided by constructivism. Constructivism "assumes a relativist ontology (there are multiple realities), a subjectivist epistemology (knower and respondent co-create understandings), and a naturalistic (in the natural world) set of methodological procedures" (Lincoln, 2003, p. 35). The implication of regarding reality as multiple, relative and socially constructed is that the researcher gives equal attention and value to the meanings that research participants bring to their experiences, or a "balanced presentation of 
all perspectives, values, and beliefs related to the inquiry" (Costantino, 2008, p. 118). Similarly, working from a subjectivist epistemology posits knowledge as actively co-created and co-constructed by the inquirer and participants and "brings to the fore the notion of researcher as author" (Costantino, 2008; Jane Mills, 2006, p. 6; Keating, 2008). Because the research involves interactions with other human beings, constructivism is bound by moral considerations and a concern for fairness (Costantino, 2008; Lincoln, 2005). Further, the knowledge that arises from the research process is regarded not as a "window on reality" but as insights into the socially constructed reality of the research context (Charmaz, 2003, p. 273). These insights are not an end in themselves, as "constructivism is grounded in the emancipatory narratives of critical theorists" (Lincoln, 2005, p. 204). Through including elements of critical theory and grounded theory, which seeks to "move a theoretically sensitive analysis of participants' stories onto a higher plane while still retaining a clear connection to the data from which it was derived" (J. Mills, 2006, p. 12), this research is oriented towards the emancipatory power of knowledge to change social reality, not just to understand and explain it (Charmaz, 2003; J. Mills, 2006; Lunn, 2009).

\section{ii. Hermeneutics}

A hermeneutical methodological approach is intimately aligned with the constructivist paradigm. Hermeneutics is concerned with interpretation and understanding, interpretation being "a ubiquitous and inescapable feature of all human efforts to understanding" (Schwandt, 2007, p. 134). A hermeneutical approach to inquiry explores "the processes through which understanding and interpretation occur, the truthfulness of interpretative statements, and the conditions for new understandings" (Freeman, 2008, p. 386). In these processes, the inquirer is bound to both their own history and tradition on the one hand, and the object of interpretation on the other, and it is the space between the two in which meanings are open to interpretation (Freeman, 2008; Schwandt, 2007). It is through this intersubjectivity that insights into reality are manifest through language and dialogue (Gadamer in Linge, 1977). A further feature of a hermeneutical methodology is the idea that the meaning of the whole is found through making sense of its parts, and 
conversely finding the meaning of the parts is dependent upon a sense of the whole. This is important for a case study strategy of inquiry that rests in constructivist grounded theory, where meaning is sought in the space that exists between the specific details of the case itself and more abstract concepts and meaning about the relationship between religious knowledge and development.

\section{iii. Case Study Approach}

The single case study strategy of inquiry was chosen because of the 'opportunity to learn' that it provides (Stake, 2003, p. 152, emphasis original). One of the main features of a single case study that is often regarded as a limitation is the lack of representativeness (Bennett, 2004). However, Stake (2003, p. 152) argues that "potential for learning is a different and sometimes superior criterion to representativeness." This is the case when the case study is chosen to be 'revelatory' in nature, "bringing invisible experiences into the map of social life and discussion" (Reinharz (1999) quoted in Leggett, 2006, p. 19), and portraying what is uncommon about the case in order to learn from it (Stake, 2003; Yin, 2003). Such cases, then, are deliberately selected based on dependent variables and act as exploratory endeavours where preliminary knowledge generated can form the basis for later, more comprehensive and exhaustive studies. The 'invisible experiences' referred to are "complex social phenomena", such as the role of religious knowledge in development, that researchers desire to understand (Yin, 2003, p. 2). This understanding necessitates an approach that is holistic, reflective and pays close attention to context. Knowledge is sought about both the particular and the general, and the reader is provided with material that facilitates 'discovery learning' (Stake, 2005). The researcher must also pay close attention to how their experience of the case and the meanings of participants are communicated. A hermeneutical approach is appropriate for a case study because it pays close attention to the importance of language and dialogue in the interpretation of meaning from the case, with the researcher 'teaching' dialectically through the written communication of this meaning (Gadamer in Linge, 1977; Stake, 2003). 


\section{CRYSTALLISATION (ANALOGY TWO)}

The simultaneous holism and complexity that a case study approach seeks to generate knowledge around calls for employment of a diverse range of methods of inquiry (Bennett, 2004; Stake, 2005; Yin, 2003). Many authors advocate for a triangulation of methods (Creswell, 2009; Frey, 2005; Schwandt, 2007; Stake, 2005). Triangulation arises from recognition of the diversity of human perception and experience and therefore the more sources and methods used to study them, the more valid and reliable the data gathered, especially when multiple perceptions converge around recurring themes (Schwandt, 2007, pp. 297-298). This study acknowledges the advantages of triangulation, but moves beyond the plane of geometry to 'light theory' or 'new physics' with the concept of crystallisation (Pierre, 2005, p. 963). The crystal "combines symmetry and substance with an infinite variety of shapes, substances, transmutations, multidimensionalities, and angles of approach. Crystals grow, change, and are altered, but they are not amorphous" (Pierre, 2005, p. 963). Crystallisation incorporates not only a range of methods as part of multifaceted research, but also knowledge and practices from other disciplines, providing us "with a deepened, complex, thoroughly partial understanding of the topic" (Pierre, 2005, p. 963). Crystallisation also recognizes that what we see depends on how we hold the crystal up to the light, suggesting that there are diverse ways of understanding beyond the intellectual mode that is traditionally sought in modern research, such as emotional and spiritual. The following section outlines the range of methods adopted and disciplines drawn upon in the research design with the desire of encouraging intellectual, emotional and even spiritual understanding around peoples' conceptions and experiences of the role of religious knowledge in development.

\footnotetext{
${ }^{7}$ While using the same subject, the crystal, this analogy is different from the earlier analogy used in this chapter where the crystal was a metaphor for the researcher.
} 


\section{METHODS}

\section{i. Interviews}

In line with a constructivist paradigm, interviews play a pivotal role in the cocreation of knowledge for the research process (Hand, 2003; J. Mills, 2006; Lincoln, 2005). The researcher and the participant "give and take" from one another by asking questions and listening (J. Mills, 2006, p. 9), and the exploration of meaning through this process gives rise to a "collaborative effort that leads to a contextually bound and mutually created story" (Frey, 2005, p. 696). While the aim of the interview is not to be representative, it is an important method for allowing people to 'speak for themselves' in the research process (Sullivan, 2003). To enhance this ability, quotations will be used throughout this report and conscious effort has been made not to decontextualise the respondents. As the interview is a social interaction between people, great care must be taken to show respect, make the respondent comfortable, and facilitate reciprocity. This was done throughout the research by developing what academia may call 'rapport', or what I call friendship, with those being interviewed; spending time getting to know them both in the days and weeks both before and after the interviews. I was able to do this because of the three-month duration of my time in Zambia. I also made a conscious effort to promote a more equal sharing of power by encouraging respondents to choose a time and place for the interviews that was most suitable and comfortable for them. I began our interviews by explaining that I was there to learn from them and so anything that they could contribute was valuable to the study.

The interviews were semi-structured in that an interview guide was used in a flexible manner that encouraged respondents to "open up and express themselves in their own terms, and at their own pace" (Bernard, 1994, p. 209). There was a set of core questions that I asked in each interview, depending on whether the respondent was a tutor, student, or coordinator. The order in which questions were asked was not fixed and many more questions were 
asked based upon the unique and individual responses given (see Appendices $\mathrm{A}$ to $\mathrm{D}$ for interview guides). A conscious decision was made, in consultation with key informants who were involved with PSA, to begin with asking broader questions about peoples' conceptions of and experiences with PSA, letting what was most important to each respondent arise naturally. The interviews later turned to discussion of spirituality within the programme, using the language that this concept is described with in PSA so as not to lead respondents by prejudging that this was important to them. While another option would have been to ask more explicit questions about the role of religion and spirituality in PSA, upon reflection I believe the approach taken was most suitable. Discussion of the role of religion in PSA arose naturally in interviews with some respondents and not with others, arguably reflective of the different meanings and relevance respondents had around this area.

An important aspect of the approach taken to the interviews was the continual evolvement of their content and character, always conscious of maintaining coherency and consistency across all interviews. In terms of content, I reflected upon the wording, order and content of the interview guide after each interview and consulted with others, making changes where necessary. This process of reflection, consultation and action is an important aspect of exploratory research and constructivist grounded theory, as one's understanding of the context in which the research is taking place grows and previously unimagined experiences and conceptions of relevance to the research are progressively revealed (Hennink, 2007).

\section{ii. Categories of interviews}

Forty-four interviews, some one on one and some with pairs or groups of three, were conducted over a three-month period while in Zambia. As this study seeks to understand the range of conceptions and experiences around the role of religious knowledge in development, purposive sampling of individuals from different groups involved with the Preparation for Social Action programme was used. Purposive sampling means that the 'subjects', or people, are chosen based on certain dependent variables that determine "their relevance to the research question, analytical framework, and 
explanation or account being developed" (Schwandt, 2007, p. 269). How the sample is purposefully chosen emerges from the experiences of the researcher within the research context (Bernard, 1994). The dependent variable that I based the selection of research participants upon was the nature of their involvement with PSA: the main actors in PSA are the students, the tutors, and the coordinators. While the views of local community members not participating in the programme would have made a valuable contribution to this study, three months was not enough time to broaden the scope of the study to include these. It is hoped that future studies can explore the relationship between the community and PSA programme from this perspective. The three categories of participants selected each provide meanings based on different kinds of experience within PSA that provide both particular understandings and broader overall insights into the programme and the role of religious knowledge and spirituality within it. These include, respectively, the ground level activities and implementation of PSA (students), the agents through which the programme is provided (tutors), and the administrative and higher-level coordination activities (coordinators).

The PSA student and tutor groups were further categorized into different samples based on the length of their involvement in the programme. Preparation for Social Action is a fledgling initiative that is progressively evolving and involving a larger number of people as it does. During the three months I was there, the number of tutors and students involved more than doubled and two new staff members became involved in administration and coordination at Inshindo Foundation. While my research involved interacting with both new and old participants of PSA on a daily basis, it was decided that interviewing those students and tutors who had been involved in the programme for a longer period of time would give a greater depth to the research, as their reflections would be based on a larger and more diverse range of experiences. 


\section{iii. Location of interviews}

A significantly longer period of time was spent in Kabwe, where the national office of Inshindo Foundation is located, than Mwinilunga (ten weeks vs. one week). This longer period of time gave me the opportunity to experience a full range of activities that the PSA groups are involved in, make strong bonds of friendship with those involved in the programme, and have a clearer understanding of its administrative and organizational aspects. Kabwe is therefore considered to be the main area of focus in the case study, and the methods used here differ from those in Mwinilunga. However, the methods used in Mwinilunga were based on the accumulation of research experience in Kabwe and the data collected during this more intense week of research is a valuable component of the study. Table 3 illustrates the research methods and number of participants involved in the two research locations.

Table 3. Interviews and focus groups conducted in Kabwe and Mwinilunga

\begin{tabular}{|c|c|c|c|c|}
\hline & Students & $\begin{array}{l}\text { Tutors } \\
(2008)\end{array}$ & $\begin{array}{l}\text { Tutors } \\
(2010)\end{array}$ & Coordinators \\
\hline Kabwe & $\begin{array}{l}\text { Pair or } \\
\text { three-person } \\
\text { semi- } \\
\text { structured } \\
\text { interviews } \\
\text { (12) }\end{array}$ & $\begin{array}{l}\text { One-on-one } \\
\text { in-depth, } \\
\text { semi- } \\
\text { structured } \\
\text { interviews } \\
\text { (8) }\end{array}$ & $\begin{array}{l}\text { One-on-one } \\
\text { semi- } \\
\text { structured } \\
\text { interviews } \\
\text { (6) }\end{array}$ & $\begin{array}{l}\text { One-on-one in- } \\
\text { depth, semi- } \\
\text { structured } \\
\text { interviews (3) }\end{array}$ \\
\hline Mwinilunga & $\begin{array}{l}\text { Informal } \\
\text { focus groups } \\
\text { (3) }\end{array}$ & $\begin{array}{l}\text { One-on-one } \\
\text { in-depth, } \\
\text { semi- } \\
\text { structured } \\
\text { interviews } \\
\text { (6) }\end{array}$ & $\begin{array}{l}\text { One-on-one } \\
\text { semi- } \\
\text { structured } \\
\text { interviews } \\
\text { (4) }\end{array}$ & $\mathrm{N} / \mathrm{A}$ \\
\hline
\end{tabular}


In Kabwe, semi-structured interviews were conducted with all the 2008 tutors, a portion of the 2010 tutors, and the majority of students from the four PSA groups. While random or stratified sampling procedures are often necessary in very large sample sizes, it was possible to aim for one hundred percent participation in the interviews. The extent to which this was achieved was affected by unanticipated factors that arose during the research, mainly in difficulties in communication and organisation across geographic distance. Nonetheless, an effort was made to speak with as many as possible during my time and I was able to speak with the majority of those involved for the past two years.

In Mwinilunga, interviews were carried out with most of 2008 tutors and a small number of 2010 tutors. However, informal focus groups were done involving the students. This choice was made in consultation with the PSA coordinators and tutors from Mwinilunga about how the students would be most comfortable given that I had not spent a long time building a relationship with them. These focus groups were carried out in the preexisting PSA groups that the students participate in. One of the advantages of focus groups is that a large amount of quality data can be gathered in a shorter period of time (Shamdasani, 1990, p. 16). While the group dynamics undoubtedly affected the nature of the information shared, and some individuals shared their experiences and views more freely and regularly than others, there was a definite feeling that the students were comfortable during these conversations and that it was an enjoyable and empowering experience. The difference in methods and nature of responses between the data gathered in Mwinilunga and Kabwe mean that caution has been taken in drawing any overarching comparisons or conclusions between the two contexts. Nonetheless, the knowledge shared during the briefer research period in Mwinilunga provides crucial insights into the diversity of experiences and conceptions held by PSA participants.

iv. One-on-one and group interviews

An important consideration when doing interviews is that their usefulness and validity "are affected by the extent to which participants feel comfortable 
about openly communicating their ideas, views or opinions" (Shamdasani, 1990, p. 33). The tutors were comfortable sharing their experiences in one-onone interviews, and this was appropriate for the depth of meaning and intimacy of subject matter sought from these conversations. However, it was agreed upon through consultation with some of the coordinators and tutors that the students may be more comfortable to share if they were in pairs or threes with fellow students they were close with. The advantage of this approach was that the students were comfortable to offer personal information and talk in more depth about personal views and experiences. A further feature of group interviews relates to the nature of social interactions involving more than one person. These can be synergistic and lead to the "unearthing of information seldom easy to reach in individual memory" and democratize the research process through "de-centering the role of the researcher" (Dimitriadis, 2005, p. 902 and 904).

\section{v. Participant Observation}

Observation is the fundamental base of all research methods (Angrosino, 2005). Bernard (1994, p. 311) states: "When you want to know what people actually $d o$, there is no substitute for watching them or studying the traces their behaviour leaves behind." Participant observation is much more than something that just happens as a result of physically conducting research, it is a conscious and reflexive process that emphasises the "legitimacy of the researcher's interpretation of observed cultural phenomena from their participation and immersion in them" (Sullivan, 2003, p. 65). It also draws attention the different ways of knowing that exist beyond the language of words and dialogue. In this method of inquiry, the researcher is much more than a passive observer, hence the term 'participant'. During my research, I participated in a full range of activities that those involved in PSA experience, asking questions, offering service based on my own capacities, and learning alongside those taking part (see Appendix E for a detailed list of the research activities). Fontana and Frey (2005) add that participant observation enhances interviewing because of the important knowledge shared through informal interviewing or questions asked during daily activities. This was certainly the case during the research in Zambia. Indeed, many of the insights into PSA 
were gained when students, tutors and coordinators shared their personal experiences and views during the time we spent together as friends involved in the activities of PSA.

\section{vi. Reflective Learning Journal}

As discussed, consistent conscious effort to be reflexive about one's own position and experiences while researching are a crucial component of constructivist grounded theory research and hermeneutical methodology. During the research period in Zambia, I recorded my experiences, conversations, and interpretations of these in a reflection journal that I wrote in each day, often several times a day. Use of a reflection journal is recommended in qualitative research to "uncover underlying assumptions and make them explicit to both the research and, in time, to the readers" (J. Mills, 2006, p. 11). Recording my reflections was also crucial to my experience as it facilitated learning and striving to improve the research in a more systematic way. I would regularly read over the notes I had taken previously and these reflections would form the basis for modifying my approach in ways that were more cognizant of the cultural context that I was continually learning more about and the PSA programme itself. The journal was also used to document important un-recorded conversations that I had with people that were directly relevant to the research. As part of constructivist grounded theory research, these reflections were simultaneously grounded in the lived realities that I experienced and were communicated to me while maintaining a relationship to abstract, conceptual and theoretical concerns.

An important aspect of reflection during the research in Zambia is that it was both an intellectual and spiritual process. Being aware of the spiritual qualities that I needed to manifest in my social interactions with those giving so generously of their time and energy to help me was of utmost concern to me. This realization itself came through reflection on the daily entries into my journal early in the research. Reflection shed light upon the importance of exercising spiritual qualities, particularly on my behalf but also by the participants, in facilitating the entire research endeavour. Without qualities such as love, cooperation, respect, sincerity, patience and an attitude of 
selfless service, qualities that the participants radiated and I also strove to develop, this research would not have been possible.

\section{DATA ANALYSIS}

Constructivist grounded theory research advocates a layered process of data analysis that takes place throughout the research and progressively builds upon itself. 'Open coding' was the first step of analysis and took place during my time in Zambia. This first stage focused upon my experiences in the field and the details of the interviews. I personally transcribed all of the interviews, mostly in Zambia within a few days of each interview taking place, although some were transcribed once I arrived back in New Zealand due to time constraints. After transcription, the interviews were continually re-read in order to build a strong "familiarity and intimacy" with the data (Leggett, 2006, p. 28). The second layer of analysis was carried out after I returned home and was directed towards investigating the broader themes and overall insights that emerged from the body of interviews and journal reflections as a whole. From this analysis, a number of codes or categories emerged. This stage paid greater attention to generating knowledge in the space between the data collected in Zambia and other concepts and ideas explored not only in the religion and development interface, but also a wide range of relevant literature from various disciplinary backgrounds.

\section{i. Writing as Analysis}

Qualitative research acknowledges that (1) "interpretations are constructed, and they are endlessly creative and interpretive" (Lincoln, 2003, p. 37), and (2) these interpretations are communicated in a body of writing that emerges as the product of such research. Less emphasis is placed upon the stage that lies between (but also transcends and embraces) interpretation and the written product, which is the process of writing itself. From the standpoint of a hermeneutical methodology and a constructivist theoretical paradigm, language and dialogue are of utmost concern: "Language does not 'reflect' social reality but rather produces meaning and creates social reality" (Pierre, 
2005, p. 961). Through the process of making sense of one's findings and translating these interpretations that exist within ones mind into language, the researcher is "actively reacting to and working with data" (Cobin, 1998, p. 58). This condition creates the possibility of "producing different knowledge and producing knowledge differently" (Richardson, 1997: 175). Milan Kundera states: "To write, means ... to crush the wall behind which something that 'was always there' hides".

Language is also central to hermeneutics because of the knowledge created in the space between the author and the reader. Language facilitates dialectic and discovery learning on behalf of the reader (Stake, 2003). How this learning and understanding is facilitated depends largely on the nature of the language used. Constructivist grounded theory requires that researchers clarify their position as the author and make meaning that is both abstract and "transparently grounded in the lives of those who co-constructed the data" (J. Mills, 2006, p. 11). This supports a writing style that is both analytical and evocative of participants' experiences, which are often personal and intimate and cannot be adequately communicated through the use of technical, disembodied, academic language. In order to facilitate understandings of the meanings participants bring to their own experiences that go beyond pure intellectualization, as well as avoid decontextualising these meanings, this study draws upon 'creative analytical processes' (Richardson, 1994). This will involve the use of creative writing as a method of analysis and communication through which we "learn about the topics and [our]selves that which was unknowable and unimaginable using conventional analytical procedures, metaphors and writing formats ... Science is one lens and creative arts is another" (Pierre, 2005, pp. 962-962, 964).

\section{ii. Short Stories and Creative Writing}

The medium of short stories has been chosen as a creative analytical process for this study and is included in the following chapter about Zambia. This was inspired by personal experiences, undoubtedly shared by countless others, of the power of short stories to engage, move and connect the reader 
to social realities that, when conveyed through academic language, seem distant and sterile. The collection of short stories in Diversi (1998) provided an excellent example that inspired me to experiment with this method of analysis. Diversi $(1998$, pp. 132, 133) explains:

\begin{abstract}
"The short story genre has the potential to render lived experiences with more verisimilitude than does the traditional realist text. Short stories ... have a unique potential to bring lived experience unknown to the reader closer to his or her own struggles for humanization, to touch the feelings and emotions of people ... [and] connect, at least initially, in an emotional realm, human beings living in extremely different social contexts."
\end{abstract}

More fundamentally, 'telling stories' is a fundamental part of humanity's cultural and particularly religious history that connects us across distances of culture, time and place and draws attention to the concept that I outlined as so personally important at the beginning of this section and that is a central concern of this research, the oneness of humanity.

\title{
SUMMARY
}

This chapter has provided a detailed description of the conceptual and practical framework for this study's methodology. I began by situating myself as the researcher within the research process, highlighting how my methodological approach to the research strives to be personal yet fair, ethical, and practical. The chapter then described the choice of a constructivist and hermeneutical approach to the research, the crystallization of a range of practical methods including interviews, participant observation and use of a reflective learning journal, and finally the process of analysis that followed. As with the construction of any physical structure, the methodological framework that has guided this study was progressively developed over time as I learned more from previous research examples and colleagues, gained deeper understanding of the realities of Kabwe and Mwinilunga and the lives of participants, and developed as a researcher. While there are many 
limitations acknowledged herein, it is hoped that the detailed description provided will help inform future studies about the PSA programme in Zambia and other countries, and research engaging with religion and spirituality in development more broadly. 


\section{CHAPTER FIVE: COUNTRY CONTEXT}

\section{INTRODUCTION}

This chapter aims to contextualise this study and the Preparation for Social Action (PSA) programme in Zambia. The national level cultural, social, economic, political and historical context of Zambia will be explored across five sections that relate most directly to the lives of those involved in the PSA programme: religion, health, agriculture, education, and historical, political and economic context. The final section of the chapter provides a brief overview of Kabwe (Central province) and Mwinilunga (North-Western province), the two locations where the PSA programme is operating, based primarily on the availability of statistical information and details about these locations and my own observations. An aim of the chapter is to ground the study in the lives of those who participate in PSA by providing insights into how they themselves experience their social reality. This will be done by incorporating short stories based upon my personal experiences in Zambia as well as interactions with PSA participants. The selection of stories included in this chapter has been chosen to represent commonly held attitudes and experiences.

The chapter will begin by discussing how I came to be in Zambia carrying out this research. This story draws attention to the role of social capital and global networks in this research, a small example of the significant role that they have in peoples' lives throughout the world and especially in processes of development.

\section{HOW I CAME TO BE THERE}

Ver Beerk opens his contribution to development literature, 'Spirituality: a development taboo', by clearly situating spirituality within one (broad) context in which processes of development occur. He writes: "For most people of the 'South' spirituality is integral to their understanding of the world and their place in it, and so is central to the decisions they make about 
their own and their communities' development" (Beerk, 2000, p. 31). He goes on to state that silence around the relationship between development and religion or spirituality "is a failure to explore and understand an integral aspect of how Southern people understand the world, make decisions, and take action" (ibid). Recognising the centrality of spirituality and/or religion to the lives of the majority of people in the 'South' has been a crucial advancement in development, as discussed in Chapter Two. To date however, there has been little acknowledgement of the role that these forces play in the lives of those on the other side of the metaphorical divide - those in the 'global North' who are also involved in processes of development in different ways. That religion and spirituality are predominantly absent from public life does not predetermine the religious or spiritual beliefs that people in the North hold, even if it may shape the level and openness of dialogue that occurs around them. I argue that these beliefs, be they in a religion, a sense of personal spirituality or the non-existence of either, influence peoples' decisions and actions in the North just as they do in the South, and therefore should not be silenced. Furthermore, the social capital of networks that extend across the world, based on shared beliefs and values and often unobstructed by socio-economic, cultural and ethnic differences, influence development in both the South and North.

My experience of investigating the role of religious knowledge in development through a case study in Zambia, having never set foot in the country before 2010, is illustrative of the role of global networks in development based on shared beliefs and values. My own religious beliefs influenced the decision made to explore this area of inquiry. I sought to challenge the core assumptions of development discourses that claim to be people-centred and open to alternative perspectives whilst the spiritual and religious dimensions of peoples' lives remain largely silent and invisible. Over email, I communicated my concern with this situation to a Bahá'í friend of my fathers who works for the Canadian Bahá'í International Development Agency. He recommended exploring the work of FUNDAEC, a Bahá'íinspired institution founded in Colombia whose work could be described as systematically learning about how spiritual principles can be applied in development for human betterment. It was difficult to get in touch with many 
of the associated organisations offering FUNDAEC's programmes through contact details I found on the web, and I ended up emailing another Bahá'í friend whom our family had met in 2008 while on pilgrimage to Haifa, the spiritual and administrative centre of the Bahá'í Faith. He and his wife moved from Canada to Zambia thirty years ago to serve the Bahá'í Faith there. He put me in touch with the Bahá'i directors of a young Bahá'í-inspired organisation in Zambia that, coincidentally, offered one of the programmes developed by FUNDAEC (Preparation for Social Action). In the first email I sent them, I introduced myself as Bahá'í student from New Zealand interested in the role of religion and spirituality in development, and we started communication from there. I have shared this story because I believe it illustrates how a shared conviction in the spiritual reality of human existence inspired by religious belief can connect individuals in networks that spread across the world. These connections can then form the basis for sharing experiences and learnings and opening up opportunities for action based on a motivation to participate in the promotion of human wellbeing.

Having established the background behind how Zambia was chosen as the location for this study, this chapter will now go on to discuss the cultural, social, economic, political, and historical context of the country.

\section{RELIGIOUS CONTEXT}

I have been in Zambia for all of three days when I am dropped at the Lusaka central station to catch a bus to Kabwe. The sun is only just rising behind a haze of city dust and morning cloud, yet already there are more people here than on the main street of New Zealand's capital at midday. For each towering bus in the yard there are at least three conductors hustling people aboard, and for each conductor at least three more men scouting the yard for more ticket sales. Town names from around Zambia echo through the air, scarcely distinguishable to my foreign ears from exchanges in what I assume to be Bemba or Nyanja. All are punctuated with frequent outbursts of 
mwizungu $u^{8}$, the only Zambian word I learnt before arriving. Mingling amongst the travelers and conductors are men and women who balance laden cardboard boxes and plastic bags, enquiring of each and every potential passenger, 'Biscuits? Drink? Sunglasses? Watch? Gloves? Eggs?' I am ushered by a group of men onto the Kabwe bus, climbing aboard the two steps, clambering over bags full of luggage and cheap Chinese merchandise to be sold further north. I am conscious that the eyes of each person on the bus are curiously enquiring as to my presence and quickly choose a seat near the front.

Squeezed up against the window sits an older gentleman wearing a worn bowler hat and navy suit reading The Post. To my left is young mother whose child stares at my white face without tiring at its novelty. We sit like this for two hours before the bus leaves the station. As we patiently wait, a steady procession of vendors come aboard, walking the length of the bus and seldom stepping off with their trays any lighter than minutes earlier. As they do outside, these vendors sell mostly food and accessories, except for one man. He has a tidy black suit and a sharp hat that he removes to reveal a shiny black head. When he opens his mouth, his voice booms. The man begins reciting passages from the Bible and in a mixture of English and Bemba directs his sermon to us, the passengers on the bus, his congregation for the next twenty minutes. There are a few murmurs of appreciation throughout and a more audible 'amen' once he passes his hat around for collection. Aside from this, nobody blinks.

I try to imagine the response if this happened on a bus in New Zealand.

My discomfort and trepidation following what, on reflection, may be described as 'culture shock' at the bus station completely vanishes upon arrival at the school where the Preparation for Social Action training course is taking place. Warm smiles and firm handshakes greet me at the gate. I forget that I am white, don't speak a word of Bemba and have only been here three days. The tutors are dispersed in small groups around the lawn waiting for dinner. One young man immediately introduces himself, curious to know

\footnotetext{
${ }^{8}$ White person.
} 
why I am here and where I have come from. It is the first conversation I have with someone from PSA, and he eagerly tells me how he feels having almost completed the training to become a tutor.

"It's like, having a purpose, it ignites you. Like you are a candle and you can give light and having a purpose is the match to light you. It ignites new feelings and attitudes inside you, inside all people. And you also feel noble because you are learning and you are going to transform your community through learning."

I tell him I am here to learn about PSA, and that I am especially interested in the relationship between the spiritual and the material in the programme.

“What religion are most people in New Zealand?" He asks.

"Well, most people who are religious are Christian, but there are people from all religions, like Islam and Buddhism and Bahá'í and more. There are also a lot of people who don't believe in religion though, and some who don't believe in God at all."

He doesn't believe me.

Like the majority of Africa (Association, 2001), religion is an intrinsic part of individual and collective life in Zambia (Figure 4). Christianity was first introduced in the 1880s with the arrival of Christian missionaries, and since this time "the indigenization of the Christian faith in Zambia remains ongoing and dialectical" (Carmody, 2007, p. 121). Former President Frederick Chiluba, a born-again Christian, declared Zambia a Christian nation in 1991. Over 70\% of the population is Christian, less than one percent Muslim, Hindu and Buddhist, and the remaining population classified as holding 'traditional' religious beliefs. Of the Christian population, about 30\% are Roman Catholic, $30 \%$ mainline Protestant, and the rest from various Christian sects such as Seventh Day Adventist and Jehovah Witnesses (Carmody, 2006). Many people hold both Christian and traditional religious beliefs that shape each 
other. Aside from the churches, religion also influences Zambian society through the activities of faith-based organisations that are prominent in the area of service provision, especially of education and health care. In Mwinilunga, a number of the PSA tutors had also worked for World Vision providing care to people with HIV / AIDS.

Figure 4. Christianity (and soccer): intrinsic elements of individual and collective life in Zambia

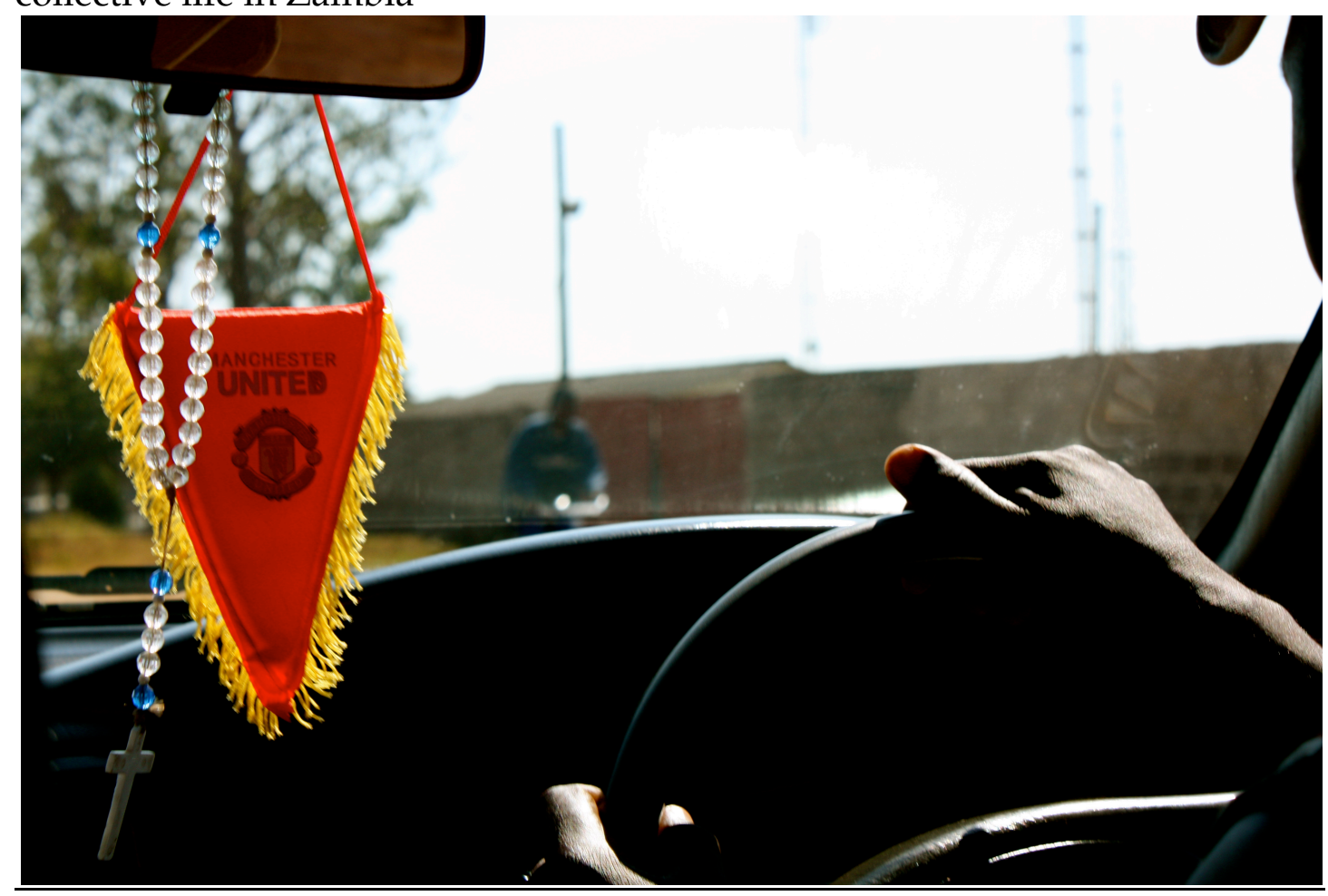

\section{HEALTH}

It is Sunday afternoon in Kabwe and five of us are sitting around the kitchen table. Our empty plates are stacked in the centre and the last heavy clump of nshima that no one had space for lies in the dish. Sipiwe ${ }^{9}$ sits closest to the kitchen, ready to switch off the stovetop kettle when the water for tea boils. Across from her is Adam, who has recently started working for Inshindo Foundation, and on either side of me are his wife Hope, a doctor here in Kabwe, and her sister Judith who is in her first year of placement as a nurse. Hope leads the conversation. She speaks through a beaming smile with such

\footnotetext{
${ }^{9}$ Names have been changed to maintain confidentiality.
} 
love and joy that if some one didn't understand the language they might infer that she was speaking about the happiest things in life.

This afternoon, she is talking to us about cholera.

“Have you been to visit the group in Makululu yet?" she asks me. I haven't.

"Makululu is one of the areas where the cholera clinic was set up this year. They set it up every year, because there are always cholera outbreaks there. You know, cholera is seasonal here in Zambia?" she laughs, seemingly at how ridiculous this is. "It's seasonal! It's so easy to prevent but every year they have an outbreak and they set up the clinic, not just Makululu but all over the place. It's crazy!"

"But this year there was only one case reported in Makululu right, and quite late?" Adam turns his attention to me. "The PSA group in that area had a service project, a sensitization about cholera and what causes it and how it can be prevented through simple changes in behaviour. I mean, we can't say for certain how much of it is PSA, maybe there are other things too, but it's really tangible - the results of PSA are tangible."

Hope's mind is elsewhere.

"HIV, that's another big issue here." She goes on for a few minutes as we listen, talking about the patients she meets who don't believe they will die from the disease. There is laughter about some of the men who go to the bank days before they die to withdraw cash for some kind of remedy.

"And then there's all the people lined up in the hospital corridors, waiting for a 'cure'. Ha. Some people know though. I hate going to that section, the men's ward especially... it's just silent. People all around, in beds or sitting against the wall, just waiting to die. Total silence."

The smile has vanished. "God help this country." 
HIV / AIDS is one of the biggest health issues in Zambia. Zambia's adult (1549 years) HIV prevalence rate is $14.3 \%$, the seventh highest prevalence rate in the world (Morgan, 2009). The World Bank (2004) estimates that HIV / AIDS reduces economic growth by about $1 \%$ a year and increases poverty substantially. To give a clearer picture of the enormity of the issue: the entire budget of the Zambian Health Ministry in 2008 was $\$ 317.5$ million; in the same year \$269.2 million from U.S. President's Emergency Plan for AIDS Relief (PEPFAR) went towards providing anti-retroviral treatment, introduced in 2004 and received by 120,000 people (Morgan, 2009). The country also has high rates of tuberculosis, cholera, syphilis and malaria. Malnutrition is high in Zambia, as evidenced by data on the health status of under five year olds. Nineteen percent of the population under five years old are categorized as 'moderately to severely underweight' and $45 \%$ of the same group suffer from moderate to severe stunting of growth (WHO/UNICEF). In 2005 the Ministry of Health introduced a National Strategic Health Plan, aimed at "reducing the disease burden and accelerating the attainment of the Millennium Development Goals and other national priorities" (Central Statistical Office (CSO), 2009).

\section{AGRICULTURE}

Michael is laughing as he comes out from the kitchen. Mutale and I are his guests and he serves us bowls of brown rice and scrambled egg instead of the nshima and relish that he and his family ate earlier. He has been telling us about his crop this year.

"I was on the bike home the other night, and I had seven bags of ground nuts on the back. Seven bags! It's been such a good year. I got pulled over by the police officer because I guess they say it's unsteady so it's dangerous or something. I just said to him, 'come on man, I've got seven bags of groundnuts. Seven bags! And so he let me go on.' 
A large proportion of Zambians are involved in agriculture in some form, be it at the household level through subsistence farming or formally employed. Seventy-two percent of all workers in 2000 were employed in the agricultural industry, and small-holders work about two-thirds of the agricultural land (Carmody, 2009; Central Statistical Office (CSO), 2009). The major crops grown in Zambia provide the staples of the average Zambian diet; maize, sweet potatoes and groundnuts have the highest yields of all crops grown in the 2007/2008 agricultural season (Central Statistical Office (CSO), 2009). Many of the students and tutors who participate in PSA, especially in Mwinilunga, were engaged in small-scale farming and sold some of their produce at local markets, while those who weren't often had backyard gardens that produced vegetables for their families. Figure 5 shows a stall displaying produce at Mwinilunga's Agricultural Cooperative show day that I attended with a number of the PSA tutors who were involved in small-scale food production.

Figure 5. Agricultural Cooperative show day in Mwinilunga

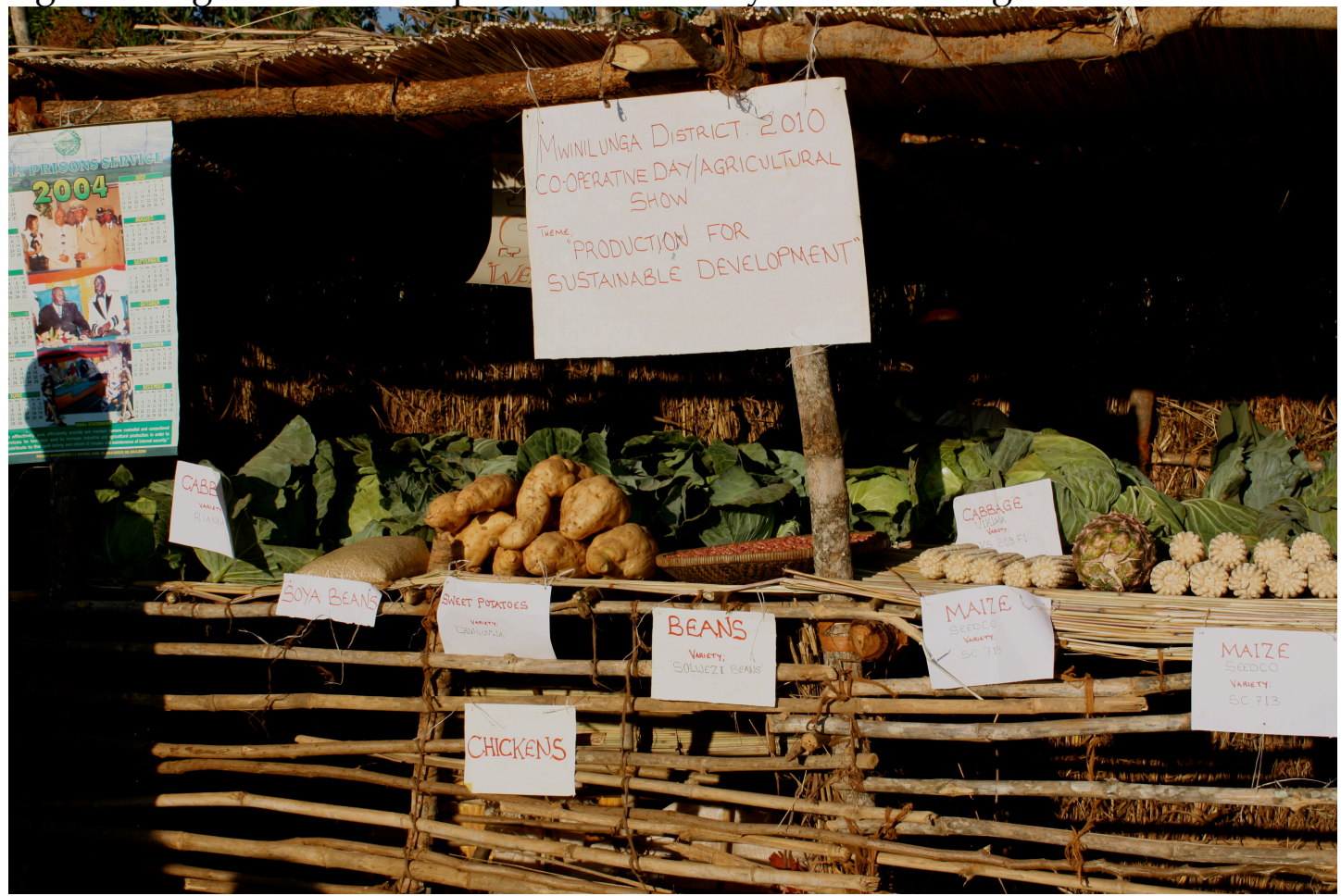




\section{EDUCATION}

The sun sets in a glorious pink sky. Under its light Kabwe's dusty roads glow like flattened, discarded orange peels that have lost their luster. Men and women make their way home from town, a few on gearless, brakeless bicycles weaving their way between the gaping potholes, and many more on foot. The three of us wander against the flow, towards town, venturing out after a day of work for fresh bread from Shoprite, the one supermarket in town. Kaunda decides it's time I learn a bit more about Zambia.

"You look around now, you wouldn't know it, but Zambia made real progress when Mwanawasa was president. That's what I would do if I was president, clean up the finances."

"But finances, that's just one part of it all. There's so much more needed for real change to happen right?" Years learning about modernisation theory and the devastating impacts of solely economic solutions to development issues puts up instant warning flags in my mind.

"Listen, Mwanawasa made a big difference. He was only in power for a few years but in that short, short time he started to restructure finances and tackle all the corruption from Chiluba's time so that it got to a more acceptable level."

I'm not quite sure what 'a more acceptable level' means. “Why was his term so short if he did such a good job?"

"He died," chips in Chawa.

"And the government now, mwandi. They receive so much money in foreign aid and so little of it is seen at all," Kaunda continues.

"Yeah or we see it because we see the ridiculous things that it's spent on." 
"Like what?"

Chawa explains: “Ah, huge escorts for presidents and ministers, like all these jeeps and people following them around, and nice houses for their family members. Or they'll only pave the roads that go to their houses, or to their mothers' houses. And when they go places, like to the villages to campaign, they'll hand out t-shirts to everyone. Or say they go to inspect a worksite, all the workers will get new overalls. They're just going to get muddy anyway!"

"And NGOs just make things worse you know. They come in with a lot of money too, for a short period of time, so much money that they don't know what to do with it. So a lot of the time they just buy stuff and give it to people. It means that people just come to expect money or expect things and nothing actually changes."

We speculate for a while about what Zambia might look like in 15 or 30 years if Kaunda became president.

“The first thing I would do is implement PSA for all young people. I'll restructure finances and tackle corruption of course, but education is how this country will move forward. Education that's practical for peoples' lives and builds them to contribute to their communities. There needs to be morals too, so education can teach these. In fifteen years, maybe more, Zambia would be a different place!"

The Zambian government, based on census findings, recognized "the important role education plays in grooming morally and intellectually upright individuals with the intentions of using the acquired skills and knowledge for the overall development of the country" (Central Statistical Office, Zambia, 2006: 51). However, this commitment is threatened by a range of factors from corruption in government, the national emergency in HIV/AIDS and the continuing adverse effects of the strict measures of economic liberalization attached to the SAPs of the 1980s and 1990s. There remains significant progress to be made in the education sector in Zambia, as 
illustrated by school attendance ratios in Figure 6 below. This is particularly pertinent with regards to overcoming the inequalities between rural and urban areas, and inequalities between males and females at secondary level.

Figure 6. Education profile of Zambia based on 2007 Demographic and Health Survey results, including Central and North-western provinces

\begin{tabular}{|l|l|l|}
\hline & $\begin{array}{l}\text { Net attendance ratio at } \\
\text { primary level (\%) }\end{array}$ & $\begin{array}{l}\text { Net attendance ratio at } \\
\text { secondary level (\%) }\end{array}$ \\
\hline Urban female (national) & 86.5 & 52.6 \\
\hline Urban male (national) & 87.7 & 57.8 \\
\hline Rural female & 76.7 & 20.5 \\
\hline Rural male (Central & 83 & 24.2 \\
\hline $\begin{array}{l}\text { Female } \\
\text { province) }\end{array}$ & 76.1 & 32.8 \\
\hline $\begin{array}{l}\text { Male (Central province) } \\
\text { Female (North-western } \\
\text { province) }\end{array}$ & 83 & 36.2 \\
\hline $\begin{array}{l}\text { Male (North-Western } \\
\text { province) }\end{array}$ & 77.3 & 31.1 \\
\hline
\end{tabular}

(Source: (Central Statistical Office (CSO), 2009).

Education in Zambia is a three-tiered system of primary level (grades 1 to 7), secondary level (grades 8 to 12), and tertiary level. In addition to primary and secondary education, there has been a significant increase over the past three decades in institutions offering early childhood education and in community schools, which cater for less privileged and vulnerable children and school dropouts and orphans. Non-formal education programmes are another form of learning that takes place in Zambia, of which Preparation for Social Action is one example. Although the Zambian government recognizes that education is a human rights issue and directly impacts on poverty and the development of the nation, immense challenges remain in all areas. As of 2002, education 
up to Grade 7 is paid for by the government in an effort to achieve primary universal education.

\section{HISTORICAL, POLITICAL, AND ECONOMIC CONTEXT}

Mulenga is reading something on the one computer available to tutors in the Inshindo Office. The office is a simple brick house with five rooms and a small kitchen stocked with tea, coffee, and millie-meal for the guard dog, Kaya. Two hand-made bookcases in the tutors' room, which is also the resource room, are filled with a range of texts about agriculture, education, health, development and a few Bahá'i publications. The tutors come here most mornings before their afternoon classes to plan their lessons together, reflect and consult, seek guidance from the coordinators, and check their recently created Facebook accounts.

All the tutors enthusiastically teach me phrases in Bemba each day, and I greet Mulenga with one of them. "Mwatchi buken mokoai?"

He grins and shakes my hand. "E mokoai. Mulishani?"

"Bwino, bwino sana! Mulealenda nshi?" I think this roughly translates to 'I'm good, very good. What are you reading', although Mulenga's kind-hearted laughter suggests otherwise.

“You're learning, you're learning, it's good. I'm reading some articles about Zambia on the BBC website. It's really good, BBC. Listen, this one says that $85 \%$ of land in Zambia is arable but only $15 \%$ of it is being used for agriculture because there is a lack of training and resources and knowledge." He shakes his head and continues. "It also says, did you know that Zambia provides $65 \%$ of Southern Africa's water? This other article is talking about how we are so rich in copper but none of the profits are seen here, all that's left here is lead pollution and damage to people's health... $68 \%$ of the country is in poverty, and there is widespread malnutrition." 
I think I say something that seems completely inadequate, like 'that's really sad' or 'that's crazy'.

"It's catastrophic," Mulenga states. "We know there's enough money there, but there's a lack of morals and spiritual qualities. Did you read that one in the paper the other day, about the corruption in the health ministry? Over two million dollars went missing, so now countries have cut the funding and all the services the government runs, like for HIV and malaria and all that, now they can only run with half the money."

I sit quietly as Mulenga keeps reading, trying to think about how it all came to be like this. My thoughts drift back to the Structural Adjustment Programmes of the 1980s and 1990s and their strict neoliberal conditionalities, and then further back to colonialism and its legacies not only in Zambia but also on the global economic and political system that countries must compete in. Faced with the human reality of all this stuff I learned about at university, I find myself for a moment feeling saddened and utterly helpless. Mulenga's voice interrupts my thoughts.

"It's up to us to change it now though."

The development of Zambia since independence is arguably most remarkable for the potential that remains unrealised. Zambia is one of the most impoverished countries in the world. The Human Poverty Index (HPI) measures the proportion of people living below certain thresholds in three dimensions of human development - living a long and healthy life, having access to education, and a decent standard of living (reference). The HPI value of Zambia is $35.5 \%, 110^{\text {th }}$ out of 135 countries for which the index has been calculated. Perhaps more telling than indicators of Zambia's development in comparison with other countries are the figures that relate to its own development over time. In 1997, Zambia was the only country for which information was available that had a lower Human Development Index ranking than it did in 1975, and the average life expectancy of 45 years 
is five years less than it stood at independence (Carmody, 2009, p. 1198; JanBart Gewald, 2008, p. 3).

At independence in 1964, Zambia was one of the most prosperous countries in sub-Saharan Africa and rich in copper deposits and agricultural potential (Jan-Bart Gewald, 2008, p. 2). There were great expectations that President Kenneth Kaunda's United National Independence Party (UNIP) would reverse inequalities in income distribution and lead the newly independent country to prosperity. However, this was not the legacy of the Kaunda and UNIP's 27 year reign; instead it was marked by mismanagement, patronage, corruption and growing political authoritarianism (Jan-Bart Gewald, 2008). In the 1970s, the nationalized Zambian economy was severely affected by the formation of OPEC and the ensuing oil crisis, and the worldwide recession and large-scale cutbacks in production that accompanied it (Hawkins, 1991, p. 843). Copper was the base of the economy and when world copper prices dropped from 1975 onwards and remained low for the next decade, the Zambian economy essentially collapsed (Hawkins, 1991, p. 844). The economic situation was so bleak that Zambia had to enter into a number of agreements with the International Monetary Fund for substantial aid, to which were attached strict reform packages that included devaluations, cuts in government food subsidies, wage freezes and price decontrol. Economic liberalization weakened support for Kaunda and UNIP and in 1991 one-party rule was ended when the Movement for Multi-Party Democracy (MMD), led by trade unionist Frederick Chiluba, won the first multi-party elections of the country. In 1991 Zambia adopted a Structural Adjustment Programme from the IMF and the economy was liberalized. However, Chiluba's rule was also marked by corruption and failure to arrest the social and economic decline of Zambia's people (Jan-Bart Gewald, 2008). “By the time Chiluba was evicted from power in 2001, unemployment, malnutrition and infant mortality were all at higher levels than they had been at any other stage in Zambia's postcolonial history" (Jan-Bart Gewald, 2008, p. 3).

There have been some significant advances since the turn of the century, and Zambia's liberalized economy experienced a period of sustained growth from 2002 to 2005. In 2005, following the satisfactory progress with its Poverty 
Reduction Strategy Paper, Zambia qualified for the enhanced Heavily Indebted Poor Countries (HIPC) initiative and received US\$4 billion of debt relief that is now being invested into health and education (Association, 2005). Despite this progress, "tremendous income inequalities are still the norm, and the costs of education, housing, healthcare, nutrition and so on, are far beyond the reach of the majority of ordinary Zambians" (Jan-Bart Gewald, 2008, p. 3). Figure 7 shows a board signposting a food security initiative supported by the European Union in Mwinilunga, one of many evidences of donor financing that I saw in both Kabwe and Mwinilunga.

Figure 7. Display board in Mwinilunga for a donor funded food security initiative

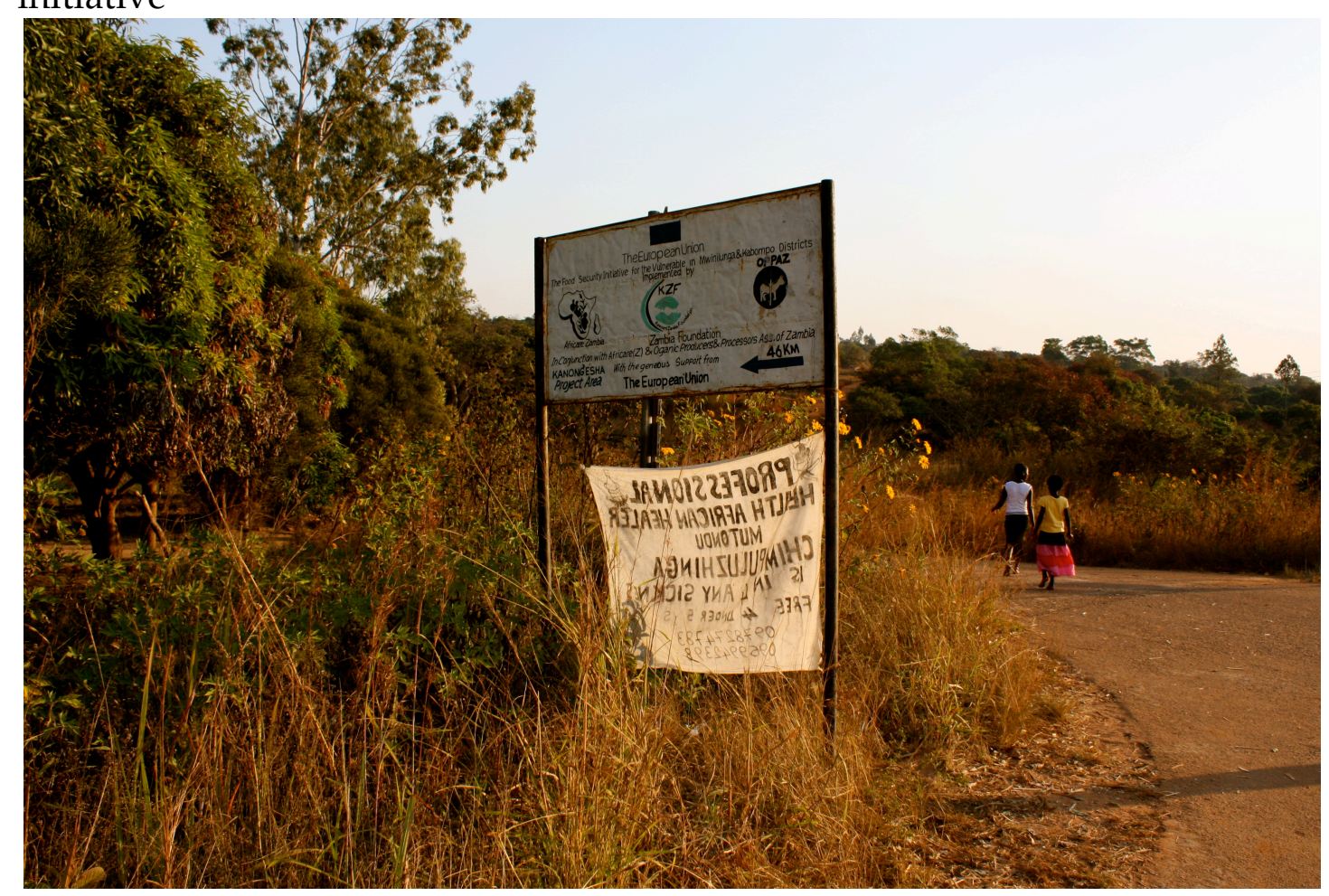

\section{KABWE AND MWINILUNGA}

According to a newspaper article published to mark the centenary of Kabwe, what was "once [a] vibrant commercial and industrial town, now with a population of 180,000 , is economically depressed to an extent that [it] is now referred to as a 'ghost town'" (Zambia Daily Mail, 2007). The socio-economic development of Kabwe over the twentieth century is typical of many towns in Zambia, with steady investment in the early and mid parts of the century, a peak of economic activity during the 1960s and 1970s, followed by significant 
economic problems from the 1980s onwards. The basis of Kabwe's economic activity was the mining industry and the town largely depended on Zambia Consolidated Copper Mines, Kabwe Lead and Zinc Mine and activities of the Zambian Railway headquarters for its social and economic development. The closure of the mines by the government in 1994 had "devastating effects" on the town, causing the closure or relocation of many companies and industries upon which people depended for their survival. Efforts have been made during the last decade to diversify Kabwe's economy and today a number of companies 'struggle to survive' in the town. One of these is Mulungushi Textiles, a company that has received heavy investment from China and is one of the major employers in the town. Looking to the future, the Kabwe Chamber of Commerce and Industry chairperson, Albert Chifita, noted that "no investor would invest in a town with inadequate infrastructure, impassable roads ... poor water and sanitation, rigid loan policies by financial institutions and lack of incentives" (Zambia Daily Mail, 2007).

Aside from a few figures included throughout this chapter, information about Kabwe's social context is scarce. Based on my time spent traveling around the town and conversations with local residents, an overall picture of Kabwe is notable for: a range of public, private and community schools at primary and secondary level, a number of growing 'middle class' areas, a number of compounds with poor sanitation, infrastructure, educational and employment opportunities, many Churches, one mosque, one public and one private hospital, modest community health centres, a large number of unemployed young people, and high levels of lead in soil remaining from mining activity. Figure 8 shows a typical road in Kabwe near the town centre, lined with beautiful flowering trees and filled with potholes. 
Figure 8. A typical road in central Kabwe

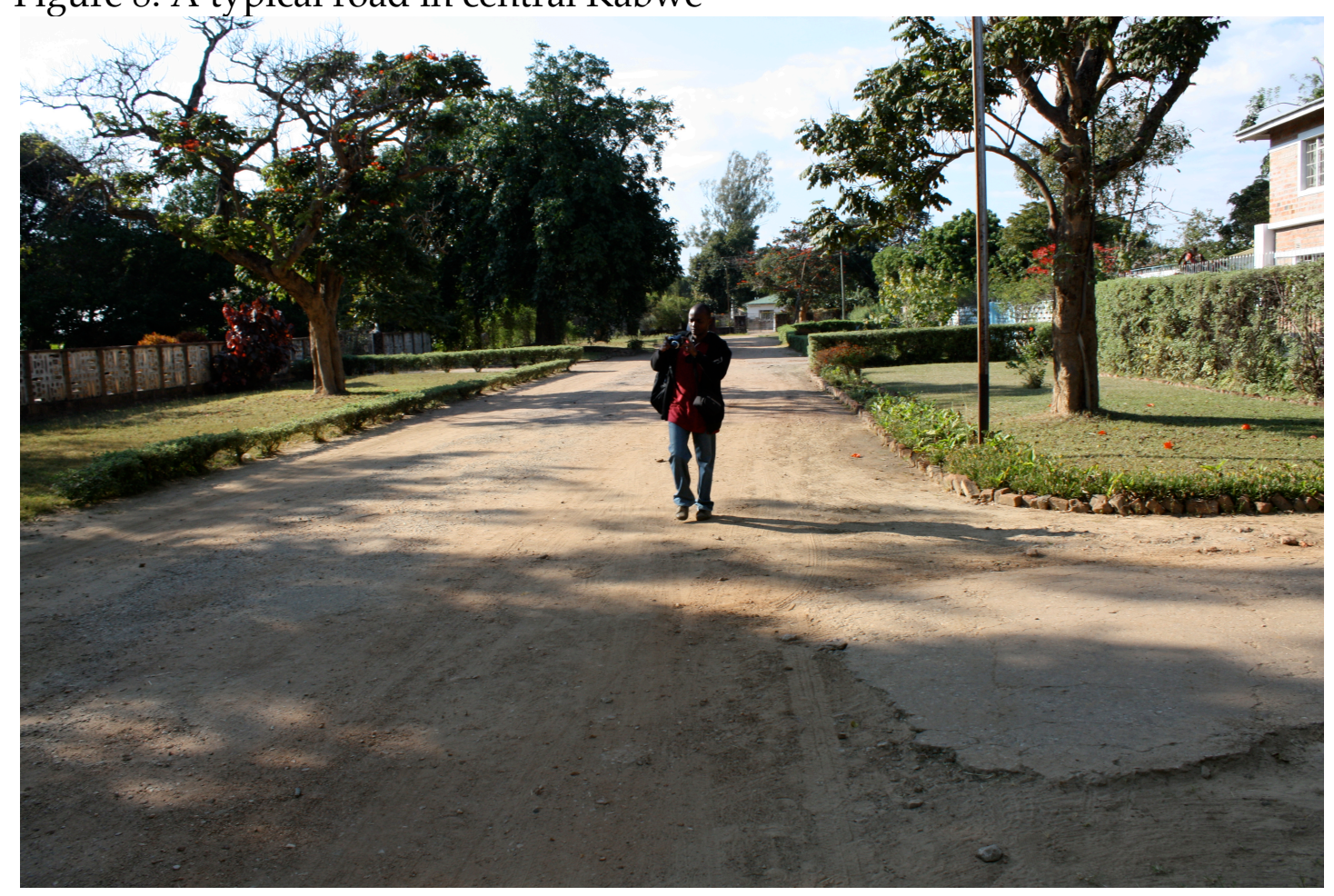

(Source: Laura Skeaff)

A report based on research commissioned by the Civil Society for Poverty Reduction group provides more information about the socio-economic situation of Mwinilunga in North-Western province. Mwinilunga itself is a small township of around 14,500 people, out of a total provincial population estimated at 583,350 (Central Statistical Office (CSO), 2006). Figure 9 shows the main road running through the township. The Inshindo office is located on this road, but the PSA groups are spread throughout the surrounding areas. The report describes how subsistence farming is the 'uniform' source of livelihood for the inhabitants of Mwinilunga. People primarily grow maize, cassava, beans, pineapple, millet and sweet potatoes and also engage in fish farming. While households generally have enough food to eat year round, there are a number of constraints on the growth of the agricultural sector, such as an inadequate market and poor infrastructure and transportation to and from villages. The provision of health services in Mwinilunga is very poor. Malaria is the most common disease, followed by a high prevalence of sexually transmitted diseases amongst young people aged 15 to 25 , and no 
definite information exists regarding the prevalence of HIV/AIDS due to a non-existence of screening facilities. In regards to education, the provision of services is also very poor; there is an inadequate number of schools, inadequate physical and human resources at those that exist, and pupils must travel long distances to attend. The report states that there is a high level of youth dependency on parents and relatives for livelihoods (Emmanuel Kamwi, 2003). It is interesting that while the picture painted of Mwinilunga by such reports on material conditions seems dire, what struck me most upon spending time there was the overwhelming warmth of heart, purity of motive, ethic of hard work, and generosity and joy of the people of this region.

Figure 9. Shops on the main road in Mwinilunga

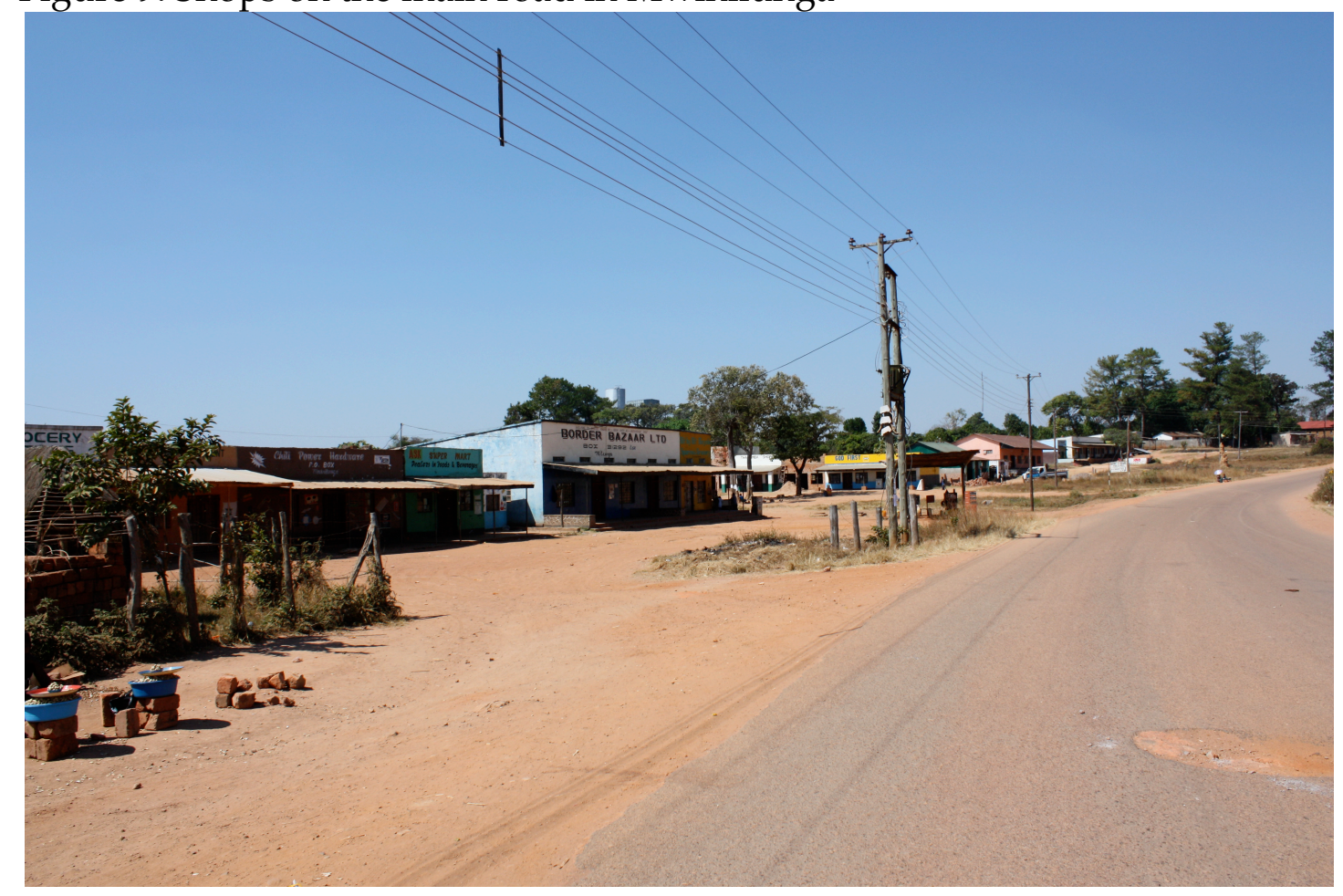

\section{SUMMARY}

This chapter has provided an overview of Zambia's recent history and its major religious, cultural, health, education, political and socio-economic characteristics. In an effort to ground and personalize the data presented and demonstrate its relevance to the broader social reality that affects the 
participants of the PSA programme, short stories based on my experiences in Zambia have been included throughout (an approach based on the work of Diversi (1998) discussed in Chapter Four). Although much of this chapter has focused on the economic and social materialistic aspects of Zambia's development across a range of sectors, the impact of failure to develop in these areas affects people at a much more fundamental level. It contributes to the perpetuation of an injustice by which Zambians are unable not only to live to basic standards, but to reach their immense and full potential as human beings with unique talents and capacities that can contribute towards the advancement of society. It is within this context that Inshindo Foundation, described in the following chapter, operates and this injustice they seek to address. 


\section{CHAPTER SIX: INSHINDO FOUNDATION}

\section{INTRODUCTION}

The twofold purpose of this chapter is to address the first objective of this study by identifying how religious knowledge informs the theory and practice of Inshindo Foundation, and to assist the reader to contextualise the researcher findings discussed in later chapters. The chapter will begin by outlining the historical background of Inshindo Foundation as part of socioeconomic development efforts made by members of the Zambian Bahá'í community since the 1980s. The second half will focus on ten organizational features to explore how religious knowledge contributes to particular characteristics of Inshindo Foundation. While Inshindo identifies as a Bahá'íinspired organisation, the characteristics described here are not necessarily a representation of Bahá'í-inspired organisations in general. My aim is to explore one working example of the diverse ways that religious knowledge can inform development organisations.

Inshindo, in many Zambia languages, is a word described 'footsteps that one hears when people are moving from one place to another' and implies movement with a purpose. Established in the Zambian towns of Kabwe (Central province) and Mwinilunga (North-Western province), the purpose of Inshindo Foundation is to empower young people through education in the PSA programme to actively promote the wellbeing of their communities, contributing to a process of collective transformation; these youth develop the skills, knowledge, qualities and attitudes necessary to be the protagonists of their own individual and community development. The processes of community transformation that Inshindo is concerned with are material, social, and spiritual in nature.

\section{HISTORICAL BACKGROUND}

Early in 2008, three Bahá'ís in Zambia who had been involved for several years in the socio-economic development efforts of members of the Bahá'í 
Faith in Zambia established Inshindo Foundation. From the outset, the purpose of the organisation was to oversee the implementation and operation of the Preparation for Social Action programme in the country. PSA is the 'education for development' programme originally developed in Columbia and was explained in-depth in Chapter Three. While the PSA programme is new to Zambia, the roots of Inshindo Foundation can be traced back several decades. Its existence can be situated within the wider historical context of socio-economic development efforts that have been systematically pursued by members of the Bahá'í community in Zambia and around the world since the 1980s. Bahá'í engagement in development is, in essence, a process of learning to apply Bahá'í teachings to achieve progress. The history of the development initiatives started by members of the Zambian Bahá'í community will be briefly outlined in Table 4 in this section in order to provide an understanding of the background of Inshindo Foundation. The history also demonstrates some of the central features of many development initiatives that are guided by Bahá'í teachings. These include: (1) the promotion of a dynamic coherence between the spiritual and practical elements of life; (2) an approach to development as an organic yet systematic 'learning process'; and (3) a particular emphasis upon developing human resources and peoples' capacities at the grassroots level to enable them to be the protagonists of their own development. 
Table 4: History of Bahá'í-inspired socio-economic development activity in Zambia since the 1980s

\begin{tabular}{|c|c|c|}
\hline Year & Activity/Initiative & Description \\
\hline 1983 & $\begin{array}{l}\text { Establishment of } \\
\text { the William } \\
\text { Mmutle Masetlha } \\
\text { Institute }\end{array}$ & $\begin{array}{l}\text { Established to develop human resources } \\
\text { through combining spiritual education with } \\
\text { practical training for volunteers in a wide } \\
\text { variety of skill areas, including agriculture, } \\
\text { health education, children's education, } \\
\text { literacy and numeracy. Spiritual education, } \\
\text { for example developing qualities such as } \\
\text { dedication and service, was approached as } \\
\text { leading to self-sufficiency when taught } \\
\text { alongside practical skills. } \\
\text { The early focus was on the rural population } \\
\text { of } 50,000 \text { in the Kabwe district. This } \\
\text { expanded in following years. }\end{array}$ \\
\hline 1987 & $\begin{array}{l}\text { Promotion of the } \\
\text { advancement of } \\
\text { women }\end{array}$ & $\begin{array}{l}\text { The William Masetlha Foundation created a } \\
\text { programme to promote the Bahá'i } \\
\text { commitment to the spiritual principle of } \\
\text { equality between men and women. This } \\
\text { included components on spiritual } \\
\text { enrichment, literacy and numeracy, } \\
\text { mothering skills, and agricultural training. }\end{array}$ \\
\hline $\begin{array}{l}\text { Early } \\
1990 s\end{array}$ & $\begin{array}{l}\text { The Bahá'í Literacy } \\
\text { Campaign (I) }\end{array}$ & $\begin{array}{l}\text { The campaign initially trained } 200 \text { tutors to } \\
\text { each hold literacy classes for approx. twenty } \\
\text { students. This was part of promoting the } \\
\text { Bahá'í commitment to the principle of } \\
\text { universal education. }\end{array}$ \\
\hline 1993 & $\begin{array}{l}\text { The Bahá'í Primary } \\
\text { Health Care Project }\end{array}$ & $\begin{array}{l}\text { This project was initiated to assist the } \\
\text { Zambian government's efforts to achieve } \\
\text { 'Health for All' by the year } 2000 \text { through } \\
\text { primary health care education. It trained } \\
\text { volunteer Community Health Educators }\end{array}$ \\
\hline
\end{tabular}




\begin{tabular}{|c|c|c|}
\hline & & $\begin{array}{l}\text { (CHEs) and Care Workers (CHWs) to actively } \\
\text { promote preventative health education } \\
\text { methods in their own communities. The } \\
\text { program focused on immunization coverage, } \\
\text { increasing knowledge of primary health care, } \\
\text { and AIDS and malaria prevention. }\end{array}$ \\
\hline 1993 & $\begin{array}{l}\text { Establishment of } \\
\text { the Banani } \\
\text { International } \\
\text { Secondary School }\end{array}$ & $\begin{array}{l}\text { A secondary school established for girls. In } \\
\text { addition to traditional subjects, courses also } \\
\text { teach about world religions and character } \\
\text { development, and a community service } \\
\text { program focusing on the surrounding } \\
\text { community is a key element in the moral } \\
\text { training received by students. }\end{array}$ \\
\hline 1995 & $\begin{array}{l}\text { Establishment of } \\
\text { the William } \\
\text { Mmutle Masetlha } \\
\text { Foundation }\end{array}$ & $\begin{array}{l}\text { Created by the national Bahá'í administrative } \\
\text { body of Zambia to support a spiritual } \\
\text { approach to social and economic } \\
\text { development that develops self-sufficiency in } \\
\text { individuals and communities. The } \\
\text { Foundation oversees the William Mmutle } \\
\text { Masetlha Institute and the Banani Secondary } \\
\text { School for girls, and is funded by both } \\
\text { government agencies and a range of civil- } \\
\text { society organisations. }\end{array}$ \\
\hline 1996 & $\begin{array}{l}\text { The Bahá'í Literacy } \\
\text { Campaign (II) }\end{array}$ & $\begin{array}{l}\text { The Zambian Bahá'í Community became part } \\
\text { of a wider literacy campaign coordinated by } \\
\text { the Office of Social and Economic } \\
\text { Development at the Bahá'í World Centre. The } \\
\text { twin objectives of the campaign were to } \\
\text { improve literacy standards within the } \\
\text { Zambian Bahá'i community and to endow } \\
\text { participants with the power to communicate } \\
\text { in such a way that they could shape their own } \\
\text { destiny. This program was focused } \\
\text { particularly on women and youth, but also } \\
\text { sought to educate entire villages in concert }\end{array}$ \\
\hline
\end{tabular}




\begin{tabular}{|c|c|c|}
\hline & & $\begin{array}{l}\text { with efforts to improve their social } \\
\text { conditions. The first, year-long phase } \\
\text { included the development or a core } \\
\text { curriculum, the training of facilitators and } \\
\text { trainers of facilitators, and the establishment } \\
\text { of literacy classes. }\end{array}$ \\
\hline $\begin{array}{l}\text { 2000s - } \\
\text { present }\end{array}$ & $\begin{array}{l}\text { Junior Youth } \\
\text { Empowerment } \\
\text { Programme is } \\
\text { initiated in Zambia }\end{array}$ & $\begin{array}{l}\text { This programme is a part of the Ruhi Institute } \\
\text { process that focuses specifically on the } \\
\text { empowerment of youth aged } 12 \text { to } 15 \text {. The } \\
\text { programme is offered to junior youth in small } \\
\text { groups usually formed at neighbourhood or } \\
\text { village level by an older youth. Its purpose is } \\
\text { to develop in young people spiritual } \\
\text { perception, powers of expression and } \\
\text { language skills, and build a sound moral } \\
\text { structure. These capacities are developed to } \\
\text { empower young people to contribute to the } \\
\text { transformation of society through acts of } \\
\text { service in their communities. The moral } \\
\text { concepts in the materials are drawn from the } \\
\text { Bahá'í teachings, but are not specifically } \\
\text { religious in nature and participants in junior } \\
\text { youth groups come from diverse } \\
\text { backgrounds. }\end{array}$ \\
\hline $\begin{array}{l}\text { 2000s - } \\
\text { present }\end{array}$ & $\begin{array}{l}\text { Ruhi Institute } \\
\text { process is initiated } \\
\text { in Zambia }\end{array}$ & $\begin{array}{l}\text { The Ruhi Institute process is a global process } \\
\text { that seeks to build capacities of individuals to } \\
\text { study, act, reflect and consult upon the Bahá'i } \\
\text { teachings. In this process of spiritual } \\
\text { education participants are described as } \\
\text { "walking a path of service" in the } \\
\text { transformation of society. A course of seven }\end{array}$ \\
\hline
\end{tabular}




\begin{tabular}{|l|l|l|}
\hline & & $\begin{array}{l}\text { texts developed by the Ruhi Institute in } \\
\text { Columbia are studied in groups facilitated by } \\
\text { trained tutors at the grassroots level, and } \\
\text { these courses are open to everyone regardless } \\
\text { of religious background. }\end{array}$ \\
\hline 2008 & $\begin{array}{l}\text { Establishment of } \\
\text { Inshindo } \\
\text { Foundation }\end{array}$ & \begin{tabular}{l} 
Refer to other sections in this chapter. \\
\hline
\end{tabular}
\end{tabular}

(Sources of information: Bahá'í International Community, 1996, 2010c; DL Publications, 2007; The Ruhi Foundation, 2008).

\section{A BAHA'I-INSPIRED ORGANISATION: ORGANISATIONAL FEATURES}

The literature around the religion and development interface emphasizes the enormous diversity that exists amongst faith-based or faith-inspired organisations (Bradley, 2009a; J. Paul Martin, 2007; Jennings, 2008a). On one hand, this diversity presents challenges for how the secular development industry engages with faith-inspired organisations. However, the description of Inshindo Foundation presented in this chapter suggests that religious knowledge is inherent to its theory and practice of development. On this basis, the perceived complexity of engaging with the religious framework that informs development organisations would not be a sufficient reason to overlook it. Clarke and Jennings (2008b, p. 15) draw attention to this point at the outset of their book, stating: "The faith element of the FBO is not an addon to its development activity. It is an essential part of that activity, informing it completely. This makes the FBO both distinct (to the extent that faith values imbue its very identity) and yet also reflecting a broader non-governmental response to poverty and development, sharing many of the same values."

The remainder of this section will explore what I understood to be the relationship Bahá'í teachings and the organizational features of Inshindo Foundation, based on my own experiences and interviews with Inshindo staff. The purpose of this exercise is not to categorize Inshindo Foundation 
into a typology of faith-inspired organisations, as some writers have sought to do (Clarke, 2008a; Thaut, 2009; Unruh, 2004). The chapter makes clear that Inshindo Foundation does not fit neatly within many conceptions of 'faithbased organisations' found in the literature. Moreover, I suggest that religiously-inspired organisations should be engaged with on a case-by-case basis, particularly due to the unexplored and complex nature of this area of research. In support of this, James (2009, p. 12) states: “Any typology will oversimplify complex, dynamic entities". The exercise will instead be guided by the framework proposed by James (2009) whose research with Christian faith-based organisations revealed ten organizational features that distinguish these organisations from their secular counterparts in development. This framework is taken as a point of departure and a useful tool for enabling the reader to gain a deeper understanding of Inshindo Foundation as the case study for this research. The features of this case study will be examined in relation to themes in the religion and development literature.

\section{i. Structural affiliation and governance}

Inshindo Foundation identifies itself as a Bahá'í-inspired organisation and a distinction has intentionally been made in this study not to define Inshindo as a faith-based organisation. One of the primary reasons for this distinction is that Inshindo Foundation is not formally affiliated with Bahá'í institutions that administer and are primarily concerned with the affairs of the Bahá'i community. Inshindo is affiliated with the Bahá'í global Office of Social and Economic Development (OSED) ${ }^{10}$, which currently oversees the development of the Preparation for Social Action (PSA) programme on a global scale and facilitates the sharing of learning and experiences between the different countries where the programme is being offered. However Inshindo has its own internal governance structure independent of the structures and institutions governing Bahá'í community life.

\footnotetext{
10 The Office of Social and Economic Development (OSED) was created in 1993 in an effort to systematize the initiatives of Bahá'ís in the area of social and economic development. Paul Lample traces a history of Bahá'í involvement in development. In his book, he describes how the purpose of OSED is to "facilitate learning about development by fostering and supporting action, reflection on action, study, consultation, the gathering and systematization of experience, conceptualization, and training - all carried out in the light of the Teachings of the Faith" (Lample, 2009: 131).
} 
ii. Values and motivation of staff

Religious belief has made a significant contribution in development practice as a source of personal motivation for many individuals working for both faith-based and secular development organisations (Bradley, 2009a; James, 2009). All of the fulltime staff of Inshindo Foundation hold strong religious beliefs and regularly participate in communal religious activities outside of their work (one is Christian and six are Bahá'í). The interview responses of a number of the fulltime staff at Inshindo suggest that they see their religious beliefs as being aligned with the values that are promoted by the PSA programme. Furthermore, their personal belief in religious values influences how they approach their work with Inshindo Foundation. In terms of religious beliefs as a direct source of motivation, only one staff member mentioned these when I asked what motivated him in his work for Inshindo Foundation:

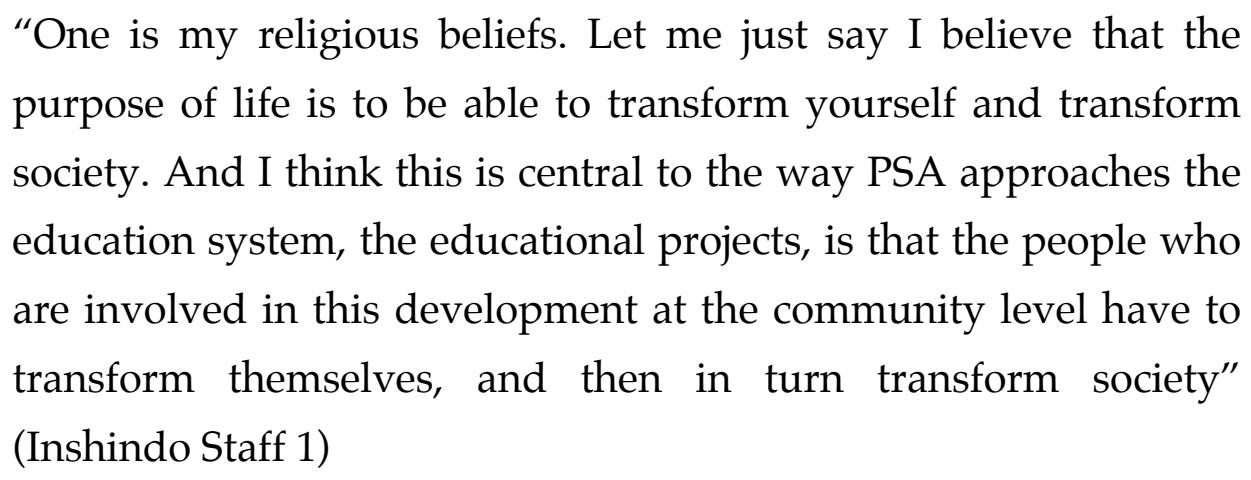

For the other staff members, their primary motivations all come under a broad theme of possessing a desire to see and contribute to transformation in their community or society. This was not explicitly associated with religious belief. Asked the same question, other staff members responded:

"The picture that we envision as an organisation, one, inspires. You know I can foresee a situation where if our activities were a success, you know, I can see a lot of smiles on peoples' faces. That inspires me. And I'm one person who likes working with people 
and helping people out there, so then I find the motivation in meeting people, sharing the challenges ..." (Inshindo Staff 2).

"So when I came here [to Inshindo] then it was explained to me, you know, it's about the issue of trying to promote the sharing of knowledge within the community where each member of the community can be able to share what they know in terms of different kinds of sectors. ... So that also encouraged me, I wanted to take part in creating these people, because I used to see a lot of problems in our community" (Inshindo Staff 3).

\section{iii. Mission}

Inshindo Foundation's objective in offering the PSA programme is to empower young people in Zambia to develop the capabilities they need to become effective agents of social transformation and act as human resources within their communities to address the challenges being faced. James (2009, p. 14) explains how the mission of faith-based organisations often differs from secular NGOs because they have "a different 'end' goal they exist to achieve." Using the language of 'end' goals does not align with Inshindo's approach to development as a continually evolving process. It is more appropriate to speak of the vision of Inshindo Foundation: that communities will become the protagonists of their own development or the promoters of their own wellbeing. This vision clearly shares common ground with secular visions of 'sustainable development' and is not a strictly religious vision in terms of association with the Bahá'í Faith. The difference lies in the spiritual dimension of this vision of development that Inshindo Foundation is striving towards; wellbeing is viewed as a state of spiritual and material prosperity and accordingly the means employed to achieve this are spiritual and material, a view shared with populations throughout the world that maintain a spiritually based world view. 
iv. Strategy and theory of development

In his study of European faith-based organisations, James (2009) briefly explores the practical implications of theology on an organisation's strategy and theory of development. Indeed a central distinguishing feature of faithbased organisations is that religion exists as "not just an emotional drive that motivates them to act but also represents a source of inspiration and knowledge" (Bradley, 2009a, p. 105, emphasis added). The influence of religious knowledge can range from "missionary driven FBDOs, whose concept and practice of development is more concerned with achieving religious salvation for all" to "grassroots organizations whose spirituality shapes their identity" (Bradley, 2009a, p. 103). Speaking about what it means for Inshindo to be a Bahá'í-inspired organisation, the words of one of Inshindo's staff illustrate how the contribution of religious knowledge as one source of insight in the organisation's work would position it towards the latter end of such a continuum:

"I think it means that the principles behind Inshindo are based on the Bahá'i teachings, that's my understanding of it. The first one of the principles is the nobility of man, that's one. The second is the importance of knowledge that is attached to the Bahá'í teachings.

But also just the method, in itself the method matters. Because you see the Bahá'i method about development, the same one that is being [adopted in] the social and economic development patterns that the Bahá'i world is developing, is that method of action and reflection...

Basically you don't have your own assumptions and then assume that that's the solution and you take it to people and force it on them. But you start an activity, as a response to certain development needs that you see in a place, and slowly, slowly you start to reflect on the effects of your activities ... you record that learning, that learning builds up and your experience also builds up, and that sharpens the way you approach development. 
So I think those approaches you could say that ... it's a Bahá'í method that's being used basically to develop social and economic projects all around the world" (Inshindo Staff 1).

This statement illustrates how, as a Bahá'í-inspired organisation, Inshindo Foundation approaches development as a process of learning, through action and reflection, about how to apply spiritual principles drawn from the Bahá'í teachings in efforts to promote community wellbeing. Religious knowledge is a source of insight that shapes both the strategy and theory of the organisation.

These two features of Inshindo Foundation are consistent with a broader Bahá'í approach to development outlined in a number of publications on the subject (Bahá'í International Community, 2008, 2010b). Five central features of this approach are: (1) The process is organic in nature, beginning with grassroots initiatives that grow in scale and complexity as experience is gained and local capacities are developed; as such, (2) Development is approached as a systemic and ongoing process of learning about how to promote material and spiritual wellbeing; (3) In line with the principle of the nobility of man and viewing each individual as "a mine rich in gems of inestimable value" (Bahá'u'lláh), initiatives seek to build the capacities of all men and women to take part in the development of their communities; (4) Development is not imposed from above, instead institutions respond to the particular needs and aspirations of local communities; (5) Knowledge is central to processes of development, and this knowledge is drawn from various fields and systems. These core features all reflect an overarching attempt to take Bahá'u'lláh's teachings as a point of departure and "translate what is written into reality" (Lample, 2009, p. to find).

v. Faith practices and teaching in programmes

\section{Teaching}

One of the most well known (and ill-reputed) features of faith-based organisations is the practice of evangelism and proselytizing alongside 
activities that address social and economic development (Kadt, 2009). While it is clear that spiritual principles drawn from the Bahá'í Faith are an inherent part of Inshindo, it is important to note that in the Bahá'í Faith proselytizing is prohibited. As such, the Bahá'í International Community states that development initiatives "are not conducted for the purpose of public relations or as a means of converting people" $(2008$, p. 6). Inshindo Foundation is very clear about making a distinction between its activities and teaching the Bahá'í Faith.

The perception in some communities that Inshindo Foundation had come 'to make people Bahá'ís' was a significant challenge for the establishment of groups and recruitment of students in the early stages when the programme was being offered. All the tutors interviewed from Mwinilunga explained how this was particularly the case in this area, where the closer community bonds characteristic of the small, rural area meant that communities were well-aware that Inshindo was being offered by Bahá'ís (unlike in Kabwe where many more students and communities are unaware that it is a Bahá'íinspired initiative). In Mwinilunga, this awareness that Inshindo is a Bahá'íinspired initiative often went hand-in-hand with misconceptions about the role of the Bahá'í Faith within the organisation and about the Bahá'i Faith itself. The comments of one tutor describe this challenge:

"To some extent some [the community] would think that we
were trying to actually make them Bahá'ís, because most of the
people ... are Christians, and then the Bahá'í Faith they don't
even know what it is; sometimes they wouldn't even welcome
you to come up with the issue of talking about the Bahá'í Faith.
Some people actually even bring confusion that has remained
and then that has been leading to the loss of participants"
(Mwinilunga 1).

After describing these initial challenges, all of the Mwinilunga tutors spoke about how there is a growing understanding in the communities where PSA is being offered about its true purpose of disinterested service to the community. In large part, the tutors attribute this to the increasing 
interactions and service projects that the PSA groups have carried out in their communities. As one tutor explained:

“That problem, I feel, it came to an end. People are appreciating the programme because of the service activities that we engage in. [In] those activities we are engaging people that are around the community. Whenever we have a service we have to involve some people around the community so that they get to see what we are doing. We have to share together with them so that we can come up with one common goal" (Mwinilunga 2).

It is important to acknowledge that teaching the Bahá'i Faith, while not an objective of Inshindo Foundation, has often been an unintended consequence. A number of Bahá'í staff and PSA tutors described how it is natural for some of the other students and tutors to have questions about where PSA came from and by whom it was developed. Furthermore, the Bahá'í identity of the majority of Inshindo's staff causes the topic to arise naturally in interactions with participants that are based on friendship. In such cases, the tutors and staff described how teaching interested individuals about the Bahá'í Faith was something that happened outside of PSA. Of the eight PSA tutors in Kabwe, five have become Bahá'ís after their interactions with other Bahá'í staff of Inshindo, and three of the Bahá'í tutors from Mwinilunga described how their students were becoming interested in the Bahá'í Faith. One stated:

"...Actually they [my students] even understand what the Bahá'í Faith is and they don't seem to blame it or something. To some extent I feel that some may even declare to be Bahá'ís" (Mwinilunga 1).

Another tutor explained:

"And one more thing that I have also experienced, and that I've seen that there's a change in, is they [my students] accept ... because at first they were saying that it's a Bahá'í programme, 
that's why most of the students they were dropping out from the programme. But now most of the students they are becoming Bahá'ís" (Mwinilunga 5).

It is interesting to note that of the students and tutors who became Bahá'ís after joining PSA, none of them explicitly linked their declaration of belief in Bahá'u'lláh as the Manifestation of God for today with the PSA programme itself. Personal spiritual transformation was connected with PSA (as later chapters will discuss), but becoming a Bahá'í was connected to interactions with the staff of Inshindo Foundation. For example, one tutor described how he and two of the other tutors in Kabwe became Bahá'í when, after being involved with PSA for some time, one of the director's of Inshindo Foundation invited them to participate in the first Ruhi Institute course (refer back to Table 4), 'Reflections on the Life of the Spirit', at his home.

\section{Faith practices}

Inshindo Foundation carries out spiritual practices in their day-to-day activities. These practices are an important part of the Bahá'í Faith and many of the world's major religions, and I observed that they are equally open to participation from individuals from all religious denominations. In the case of Zambia this is predominantly Christian. The main example of this that I witnessed during the research was the practice of saying prayers and devotions to begin meetings, training sessions, and other collective organizational activities. This would often consist of individuals reading excerpts from the Bahá'í writings or saying Bahá'í or Christian prayers, and every one present would frequently and joyously participate in singing songs from both religions.

vi. Choice of beneficiaries and partners

'Beneficiaries'/participants

To begin, the language of 'beneficiary' and connotations of dependency and lack of agency often associated with this term in development are inconsistent 
with how Inshindo Foundation, like many development organisations, describes those who participate in the PSA programme. As stated, a Bahá'í approach to development considers it not only the right but the latent capacity "of every people to trace its own path of development and direct its own affairs" (Bahá'í International Community, 2008, p. 6). Students and tutors are referred to as 'participants' in this section to reflect the language of Inshindo Foundation. Because Inshindo is concerned with the social transformation of entire communities and holds that it is the right and responsibility of every individual to access knowledge and contribute to these processes, the organisation adopts a clear approach of non-discrimination towards selection of participants. One staff member explained the inclusive approach of Inshindo in the following words:

“You find that so far most of the students are not Bahá'ís, but we have a lot of people who have remained faithful to the programme.... That fact that we have a lot of students that are not Bahá'ís does not really become an issue, because it's for the whole of mankind really this project, it's a service to mankind. It's not only Bahá'ís who are living in these areas that have problems but every single person is suffering. So it's a service to everybody. Whoever would like to participate in developing his community, that's very good, I think it's a duty for every human being, Bahá'í or non-Bahá'í" (Inshindo Staff 1).

Another staff member, the only Christian staff member of Inshindo, also spoke about how the purpose of Inshindo and PSA necessitates that the organisation's reach encompass everyone, regardless of religious affilliation:

"One thing that I see is that what the organisation wants to achieve is not only for the Bahá'í Faith, you know. Out there, when we transform our societies, we make them a better place to live in; no body's going to say 'this is a Bahá'í transformation'. I think they're going to say 'this community is transformed', you know? We're not going to put a tag on every development that takes place out there to say 'this was inspired 
by this'. Because a lot of people who take part in these activities, they're Christians, and people who believe differently out there, that are part and parcel of the activities that we are carrying out in these communities" (Inshindo Staff 2).

\section{Institutional partners}

Inshindo's approach to its choice of institutional partners is guided by the same inclusive principles. As outlined by the Bahá'í International Community's statement on the Bahá'í approach to development, projects are often "undertaken in collaboration with government agencies and organizations of civil society that share similar aims" (Bahá'í International Community, 2008, p. 6). In Kabwe, Inshindo Foundation entered into partnership with the Municipal Council and the Department of Community Development (DCD) in October 2009. The Memorandum of Understanding signed between the three parties commits them to "working together in accompanying the PSA students in their study of the texts and implementation of community service projects", as well as mobilizing resources, offering completion certificates to students and meeting together twice a year to review the programme (Inshindo Foundation, 2009). One of Inshindo's directors explained how the Bahá'í Faith was discussed openly in the initial meetings between the three institutions. Aside from this dialogue, the Department of Community Development (DCD) in Kabwe does not emphasize the religious character of Inshindo and instead focuses on the spiritual element. Staff from the Department described that this was in order to guard against the potential for division based on sectarian differences. The Director of the DCD explained:
“...On the spiritual part with us as the Department of Community Development that one was open, we don't look at which denomination this individual belongs to with us. That one I think is just silent to Inshindo only..."

The issue raised by the Department of Community Development in Kabwe relates to wider concerns that religion can have a potentially negative impact 
in development if it becomes a source of discrimination and disunity amongst people of different denominations (J. Paul Martin, 2007). In our interview, both the Director of the Department of Community Development and her assistant described how religion is a very sensitive issue for government institutions because of its potential to exclude or divide community members based on their religious denomination:

"The way we are here: she shares her religious belief, she shares her religious belief, but we discuss these just in passing, to say maybe 'when she went to Church she heard this or that'. We cannot look at [someone] and say 'no me I don't belong to that Church don't say that'. We are just trying to bring harmony. There shouldn't be a boundary, because you belong to this religious group [or] you belong to this religion. When we are here we have to work as a team no matter which religion we live in. Yes, we respect each other's religious belief. We don't even look at it to be important to us in our work when it comes to that, when we have a lot of people coming, we don't even ask them 'what religion are you?' It's not of any importance to the activities, because already it will bring a barrier. ... As a government institution we are nonpartial" (DCD Director).

That the faith identity of Inshindo Foundation is not readily identifiable by its choice of participants or institutional partners is indicative of the inclusive, non-discriminatory approach to development that it identifies with. When viewed alongside the Bahá'í Writings and international publications based on these, it reflects a characteristic of Bahá'í approaches to development that ultimately regard all of humanity as participants who must together towards a common goal: the spiritual and material prosperity of humankind.

vii. Staff and leadership

Faith-based organisations differ in their requirements pertaining to the religiosity of staff (James, 2009). While Inshindo does not have a formal policy 
on the religious beliefs of staff, that the vision and strategy of the organisation are inspired and guided by the Bahá'í teachings mean there is a natural attraction of Bahá'ís motivated to work in the area of socio-economic development, and vice versa.

The period of mid-2010 when the research was carried out was a time of significant transition in the staff and leadership structure of Inshindo Foundation. Two of the original directors, both Bahá'ís originally from the United States who had met in Zambia and been living there almost a decade, had recently moved to the United States for health reasons. The third founding director, a local Zambian, had been appointed to a role of international responsibility within the Bahá'í community that required him and his family to move to Haifa, Israel, the spiritual and administrative centre of the Bahá'í Faith. At the same time, three new fulltime staff members were hired to support a significant expansion in the reach of the PSA programme as the number of PSA groups in both Kabwe and Mwinilunga more than doubled. Thus of the paid staff members at Inshindo working at the time of this study, one was Catholic and the remainder Bahá'í. That several of the Bahá'í staff became involved with Inshindo through personal connections with members of the Zambian Bahá'í community illustrates the role of networks and social capital based on shared beliefs in processes of social and economic development.

The Catholic staff member spoke of how coming from a different religious background was not an issue when it came to working for a Bahá'í-inspired organisation: “...For me really it doesn't matter, so long as it doesn't conflict with my beliefs, and so long as I share in the vision of the organisation is what I believe should be transformed, should be delivered out there, so then it's cool" (Inshindo Staff 2).

viii. Organizational culture

James (2009) discusses how faith can influence the organizational culture of a faith-based organisation in distinct ways. It may be visible in certain rituals, decision-making processes, relationships, or the 'team spirit' of the 
organisation. The practice of saying Bahá'i and Christian prayers and devotions before meetings has already been mentioned as a distinct feature of Inshindo Foundation that contributes a spiritual element to its culture. The decision-making processes of the organisation are also distinct in two ways. Firstly, one staff member told me how decision-making processes are guided by a Bahá'í method known as 'consultation'. Bahá'í consultation is guided by principles laid down in Bahá'u'lláh's Writings for the purpose of building consensus and investigating truth. They include: conscious efforts to gather a diversity of points of view; frank and candid discussion while maintaining respect for others; a view of the ideas put forward as property of the group and not of any individual or constituency; and a spirit of unity where, once a decision is made, it must be acted upon by the entire group. In the broader context of viewing socio-economic development initiatives as a process of learning, consultation is an essential and distinct element of Inshindo's organizational culture. It is part of a "systematic and ongoing process of consultation, reflection, and action designed to bring about consistent patterns of change" (Bahá'í International Community, 2010a). I witnessed this process of consultation, action, and reflection on many occasions during the research in Kabwe and Mwinilunga.

\section{xi. Constituency and sources of funding}

As is the case with many faith-based organisations (James, 2009), Inshindo's funding comes from a variety of sources, both secular and within the Bahá'í international community. A certain (unknown) proportion its funding comes from the Office of Social and Economic Development (OSED), itself funded by the voluntary donations of Bahá'ís from around the world. This has parallels with many Islamic-based organisations that receive funding from zakat, obligatory donations from Muslims. In some cases of zakat funding, Kroessin and Mohamed suggest that there may be a "lack of accountability and transparency" (in Clarke, 2008: 193). However, Inshindo is fully accountable to OSED for its expenditure. 


\section{x. External relationships}

James (2009, p. 19) states: “Faith can affect an FBO's external relationships in a variety of ways." The external relationships of Inshindo Foundation are one of its most important and distinct organizational features, as much of this chapter has alluded to demonstrating how they shape many other organizational features. Belief in Bahá'í teachings and motivation to apply these to social and economic development is a fundamental bond connecting Inshindo with an international network of institutions and individuals involved in a systematic process of learning. It is this network that connects Inshindo Foundation to FUNDAEC.

\section{SUMMARY}

Through a discussion of the historical background and organizational features of Inshindo Foundation, this chapter has (1) provided one case study of how religious knowledge from the Bahá'í Faith is applied in development at an organizational level, and (2) explored this case within broader literature highlighting how religious knowledge shapes development organisations in many different ways that may distinguish them from their secular counterparts (Bradley, 2009a; J. Paul Martin, 2007; Jennings, 2008a). Whether these distinct organizational features mean that Inshindo's efforts accord with the potential of faith-based or faith-inspired organisations to act as "agents of transformation" will be explored in the following chapters in light of the conceptions and experiences of participants at the community level (Clarke, 2007).

As an organizational case study, the discussion of Inshindo Foundation contributes to a growing body of knowledge that explores the diverse ways in which religious knowledge shapes development organisations. It reaffirms a number of themes that have already been addressed in the religion and development interface. One central theme is the common ground that exists between secular and faith-inspired organisations in development. The case of Inshindo Foundation illustrates how a Bahá'í-inspired conception of development that is based upon Bahá'í principles shares and actively works 
towards many of the same principles as 'secular' development: the equality of men and women, developing capacities through education, nondiscrimination on the basis of religious denomination, sustainability and participatory grassroots development.

Up to this point the thesis has identified and described the conceptual framework, methodological approach and programme activities of Inshindo Foundation and of FUNDAEC. The conceptual background and methodological choices of my own research into the relationship between religious knowledge and development, explored through these case studies, has been explained. I have also presented a picture of the contexts where the research was carried out and the PSA programme is being operated. All of these chapters have provided an important background for the reader to contextualize and understand the experiences and conceptions of PSA students and tutors in relation to their participation in the programme. These are the focus of the remainder of this thesis. 


\section{CHAPTER SEVEN: EXPERIENCES OF PSA PARTICIPANTS - PERSONAL TRANSFORMATION}

\section{INTRODUCTION}

The discussion of the experiences and conceptions of PSA students and tutors in relation to their participation in the programme begins by focusing on the first of these. The purpose of this chapter is to explore the central experience that PSA students and tutors associated with their participation in the programme, that of personal transformation. As one student simply stated: “The way I was is not the way I am." Personal transformation is presented here as an overarching experience that encompassed many dimensions. Based on my analysis of interview conversations, five dominant dimensions emerged: self-perception, spiritual transformation, social responsibility, selfconfidence and language capabilities, and practical knowledge and skills. The chapter will explore how knowledge, identified as the primary cause of transformation for the participants, was characterized by a harmony between the spiritual and the material, and between theory and practice. In keeping with the objectives of this research and given its limited scope, the themes that are explored in most depth are those around that relationship between participants' experiences of transformation and religious knowledge. The dominant theme in this regard is the contribution that the spiritual principles found in the PSA programme make to participation in development practice through personal transformation. Participatory development, in this research, is defined as people's efforts to improve their individual and community life according to their own values and needs. The chapter will begin by clarifying three recurring concepts, as they are conceived of in the PSA programme, which will help the reader understand the themes in the remainder of the thesis.

\section{SPIRITUAL PRINCIPLES}

Bahá'í-inspired social and economic development is essentially a process of learning to apply spiritual principles to achieve spiritual and material 
progress (Bahá'í International Community, 2008; Lample, 2009). An understanding of what is meant by 'spiritual principles' will assist the reader in interpreting the themes discussed in the remainder of the thesis. A statement on spirituality in development issued by the Bahá'í International Community describes them as:

“...Universal principles which are essential to the development of the human spirit and, therefore, to individual and collective progress. ... Those essential truths given to mankind by that ultimate reality, the unknowable essence of essences called God. The religions brought to mankind by a succession of spiritual luminaries have been the primary link between humanity and that ultimate reality, and have galvanized and refined mankind's capacity to love, to comprehend reality and to achieve social progress" (Bahá'í International Community, 1998, pp. 4, 16).

FUNDAEC's approach to development is guided by spiritual principles drawn from Bahá'u'lláh's written Revelation, and these are an integral element of the textbooks that PSA students study. Spiritual principles connote an essential relationship between the material and spiritual in development. Material development, which is informed by scientific knowledge, must be guided by an understanding and application of spiritual principles if it is to lead to prosperity and collective wellbeing, as opposed to injustice and inequality. Some examples that are central in PSA include the oneness of humanity, justice, the equality of men and women, stewardship of nature, the harmony of science and religion, and that work done in the spirit of service is worship (Arbab, 2000).

\section{SPIRITUAL QUALITIES}

A core element of FUNDAEC's pedagogy seeks to cultivate 'spiritual qualities' in the participants of its educational processes. This approach is based on the notion that a human being has two natures: a lower physical or 
animal nature and a higher, spiritual nature. According to Arbab (2000), the challenge is to rise above the limitations and demands of the lower nature and "develop the qualities of the higher nature that struggles for expression." These spiritual qualities are viewed as a reflection of divine attributes of God. While Bahá'u'lláh's written Revelation acts as a primary source of knowledge from which the spiritual qualities included throughout the PSA curriculum are drawn, it will be clear to any reader that all of the world's religions emphasize such qualities as love, justice, truthfulness, compassion, generosity, and humility. In many societies, particularly in the West, these qualities are conceived of in secular or humanistic terms as their association with religion has become increasingly removed. In the context of PSA however, a statement by 'Abdu'l-Bahá gives insight into link between religious knowledge and the development of spiritual qualities:

\begin{abstract}
"The holy Manifestations of God come into the world to dispel the darkness of the animal or physical nature of man, to purify him from his imperfections in order that his heavenly and spiritual nature may become quickened, his divine qualities awakened, his perfections visible, his potential powers revealed and all the virtues of the world of humanity latent within him may come to life" ('Abdu'l-Bahá, 1979, p. 110)
\end{abstract}

\title{
SERVICE
}

Service is an important element of PSA and also deserves a few words of attention at the outset. The centrality of service to the PSA methodology is based on the notion that this is "the arena through which individuals achieve the highest form of development" (Inshindo Foundation, 2008). Service is seen as fulfilling a two-fold purpose of contributing to an individual's intellectual and spiritual development and building their capacity to contribute to the social and economic development of the community. Throughout the duration of the programme, each PSA group carries out a number of service activities where they apply the knowledge and skills they learn in the texts to the development of their communities. The groups choose 
the activities they carry out based on their understanding of the needs of the local community. A number of projects I observed while in Zambia were in the areas of environmental health, community health, small-scale agriculture, and education of children. ${ }^{11}$

\section{DIMENSIONS OF TRANSFORMATION}

This section will identify and describe the range of experiences that respondents associated with their personal transformation, focusing on those that emerged from analysis of the most salient. The relationship between the participants' experiences of personal transformation, religious knowledge, and development practice will be explored throughout.

\section{i. Self-perception}

One of the most fundamental transformations that a number of respondents associated with their involvement in PSA was in how they perceived themselves. Many of the respondents described how before becoming involved in PSA they were doing little in their day-to-day lives. A number had finished their schooling but were unable to find employment or could not afford to further their studies, while others were engaged in 'piece work' in order to support themselves. In many of the respondents' descriptions of their lives before PSA, a lack of belief in their own ability to change their situations was discernible. One female student from Natuseko explained:

\footnotetext{
“Before I joined I was just sitting, waiting for lunch, supper - I was boring. Even my vocabulary was low. I was just stagnant like that. I didn't know anything, because I had no money to go to university even though I had a school certificate."
}

Previous chapters have already explored the emphasis PSA places on the religiously inspired principle that sees the inherent nobility of all human beings based on their spiritual nature. In relation to personal transformation,

\footnotetext{
11 The following chapter will explore the concept of service at a conceptual level in greater depth.
} 
analysis of the interview responses suggested that knowledge of this principle led to a transformation in how many participants perceived themselves. A number of respondents described how they had gained an understanding that as human beings they too are noble and possess particular talents and capabilities that can be developed, and therefore have the capacity to do something purposeful in life. Two students described how a transformation in their self-perception has occurred since participating in PSA:

\begin{abstract}
"If I compare the way I was, even in thinking, even in looking, there is now a big, big cup. Because at the time [before PSA] I was even thinking I would do nothing here on the earth. Why I said so [was because] even at school I was very poor in mathematics. In other subjects I could do well, but in mathematics I was completely down, so I started thinking that maybe I can do nothing here on earth..." (Mwinilunga 9). ${ }^{12}$
\end{abstract}

“[PSA] promotes someone's self-esteem, because they know they can do something" (Natuseko D)

The transformation in self-perception to a stage where individuals see the potential in themselves is particularly important in relation to PSA's purpose of promoting community wellbeing. Respondents indicated that it enables them to see that they have the ability not only to advance as an individual but also to contribute to their community's advancement. One student from Chimanimani explained:
"[PSA] has built a foundation for me to make a self-realization that ... even as an individual I can still do something for my community to benefit" (Chimanimani 1 ).

\footnotetext{
12 To ensure confidentiality, students and tutors names have not been included. They are distinguished by location and each respondent was assigned a number. Mwinilunga and Kabwe are used to identify tutors, while Chimanimani, Site and Service, Makululu, and Natuseko refer to the student groups in Kabwe.
} 
Another tutor described:

"I never used to understand that I and those around the community can come together and do something that will help the advancement of this community. All I used to know or think about is that for this community to develop there has to be big, big, big programmes or organizations to come in. Now I am able to see that there is a lot that is in our community, that if we ourselves have the knowledge ... we can really help our community develop" (Mwinilunga 6)

The comments of these two tutors are illustrative of how, for many PSA participants, a transformation in self-perception inspired by an understanding of their spiritual nature was a motivating factor in efforts to work for the wellbeing of their communities. This transformative experience appears to indicate the potential of human nobility, a spiritual principle, to contribute to participatory development efforts at the grassroots. One of the core tenets of participatory development has been that development professionals and researchers must value the knowledge, beliefs and skills of local people (Chambers, 1983). While I agree that this is an indispensible element, the literature hardly touches upon the notion that people must be conscious of and value their own knowledge, beliefs and skills. Over two decades ago Nandy (1989, cited in Escobar, 1995b, p. 227) opined that "the recovery of the other selves of cultures and communities, selves not defined by the dominant global consciousness", may be the first task for those involved in processes of development. Muzaffar (2003) is another author who underlines the importance of a focus on human dignity in development. While the comment by Nandy seems to come closer, the literature places primary responsibility for this task on development specialists and seem to take for granted that all people possess a natural sense of dignity.

\section{ii. Spiritual transformation}

There is a close association between participants' transformations in selfperception and the experiences of spiritual transformation they described. 
Both experiences relate to the principle that human beings have an inherent spiritual nature. All of the PSA tutors and the majority of the students identified spiritual transformation as a significant experience associated with their participation in the programme. For some this appeared to have equal importance to the other dimensions of personal transformation they experienced, such as intellectual and material. For others, personal spiritual transformation appeared to be more fundamental and was attributed as the overwhelming driver of all the changes they were experiencing. The comments of one student from Chimanimani illustrate how spirituality was one element of his holistic experience of transformation:

\begin{abstract}
"We have changed a lot, in many ways ... spiritually, physically, in terms of the intellectual aspect of life, we have changed a lot. It [PSA] is something that has really built us, spiritually, on how we can extend our love, our kindness to our friends, how we can approach these concepts ..." (Chimanimani 3).
\end{abstract}

The way respondents described their spiritual transformation gives some insight into how religious knowledge is integrated into the PSA programme and how participants experience of it. Their reflections are consistent with the other experiences described in this chapter in highlighting how the basis for the personal transformation PSA students experienced was knowledge. Respondents identified the spiritual principles and qualities they studied in the PSA textbooks as central to their spiritual transformation:

"Before I studied the books I didn't have much concern about
my spiritual qualities, but as time went on, as I studied the
books, for now I think I've even changed because most of the
qualities I had not looked into, I'm able to look into them now.
For the past, I can say I was troublesome, but because of the
books I'm really now living a noble life" (Site and Service 1). 
"When I saw those spiritual qualities and I just bit by bit started applying them in my daily life, started meditating upon them, bit by bit I started developed" (Makululu 1).

"The texts, the way that they have been designed, you'll find that at the end from the reflections on the writing they talk about that [spiritual qualities], so my spiritual and moral life also has changed, to some extent it has grown" (Kabwe 4).

\section{Spiritual transformation and service}

The contribution that spiritual principles make to development practice is seen the in the relationship between participants' transformative experiences and service in the PSA programme. Analysis of the interviews suggested that the service activities the PSA groups carried out facilitate a mutually enhancing experience of service and spiritual transformation: carrying out acts of service helped PSA participants to develop spiritual qualities, and the development of these qualities helped them to better serve their communities. The respondents drew my attention to many spiritual qualities that they believed are important for an individual to possess when working to transform one's community: love, humility, patience, compassion, respect, trustworthiness, tolerance, kindness, honesty, righteousness, justice, generosity, and cooperation. A tutor from Mwinilunga explained the connection between service and spiritual transformation in the following words:

\footnotetext{
"The reason that I've changed so much is about the spiritual qualities that I've gained through the PSA materials ... because when we have been doing the service activities we have different people in our communities, and if you don't have these spiritual qualities we cannot work with them. Through these things it has changed me" (Mwinilunga 5).
}

The experiences of spiritual transformation described by many participants provide insight into the potential contribution of spiritual principles to 
development practice. They appear to further indicate that an individual's belief in the principle of their own nobility can build a foundation for participation in processes of development in their community. A potential contribution can also be discerned in the nature of how people participate in development. The conscious attention given to manifesting spiritual qualities in interactions with others adds a qualitative dimension to serving or working in a community that is often overlooked in secular development practice. In recognition of the motivations and qualities of many religious believers working in development, a number of contributions to the religion and development literature do acknowledge how "qualities much in demand in development work - humility, courage, and conviction - are often described as spiritual, of the soul" (Keough, 2004, p. 8). However, scant attention has been directed towards how these qualities are to be developed beyond the confines of institutional religion, and within those who must be the true protagonists of development at the grassroots level. The themes in this section have suggested that religious knowledge could contribute to development practice in this area through the spiritual principles enshrined therein. Development actors, including but not limited to faith-inspired organisations, can facilitate processes of education that foster a sense of human nobility and promote the development of spiritual qualities in participatory development.

\section{iii. Social responsibility}

Another fundamental transformative experience that emerged from analysis of the interviews with PSA participants was the development of an attitude of social responsibility. Sheldon Berman's conception of social responsibility is useful for this study. Berman writes how social responsibility is a personal quality or attitude that involves "social and political consciousness, a sense of connectedness, acting on ethical considerations, prosocial behaviour, integrity of action, and active participation" (1997, p. 14). This section will outline three interrelated elements of an attitude of social responsibility that emerged from my analysis of PSA participants' responses, and the insight these provide into the contribution of spiritual principles to development practice. 
The first element of this transformation in participants was a growing understanding of their social and physical reality and an ability to identify the problems that exist. This is not to say that the PSA participants were unaware of the problems facing their communities before entering the programme; the difference that many of the comments suggested was their consciousness of these problems not as 'just the way things are' but as problems they are able to address. As one tutor explained:

\begin{abstract}
"The way I look at the community now, I have become very much concerned about my community. At first maybe I thought it's just normal ... but this time I've come to see that there are serious problems in my community and I have become one person that would always be striving to see that there is a change. This time I look at it from a different angle, I look at it like my community is not fine, and I look at it like I have to strive ... to see a change in the future" (Mwinilunga 3).
\end{abstract}

The second element that I noticed from analysis of participants' comments was their recognition of the importance of serving one's community and the expression of a strong desire to do so. One of the tutors from Kabwe spoke about this theme in relation to the transformation he had observed in the students of his group:

\footnotetext{
"The programme has emphasized that you have to offer service to humanity, this is the aspect that has awakened them. Yes, God has created them, they have these faculties, but they have to offer back to humanity" (Kabwe 3).
}

Service to the community, as explored earlier, is one of the five core capabilities that PSA seeks to develop in participants. During the time I spent in Zambia, I observed how the service projects carried out by the PSA groups were a major arena where participants' attitudes of social responsibility were manifested in action. Beyond the group service projects, a number of respondents also explained how they were making efforts outside of PSA to put into practice the knowledge they were gaining for the wellbeing of their 
community. One student from the Chimanimani group described the transformation of his attitude towards the community in the following words:

\footnotetext{
"Before I joined PSA I actually had no passion of saying 'I can do something for the community'. But after going through this programme I've acquired the ability, that capacity, of relating to the community or interacting with the community, of how do I penetrate the community to solve different challenges that the community is facing?" (Chimanimani 2).
}

The tutor of the Chimanimani group explained his own transformation in relation to this theme since he became involved in PSA:

\begin{abstract}
"I'm not just thinking about myself, now I'm thinking about others. Even whatever I am doing in the community, I always invite people, I always consult [with] people, I always share with them what I'm thinking and try to get what they're thinking also, then we'll see how best we can do something in order for us to be at the same level" (Kabwe 2).
\end{abstract}

\title{
Social responsibility and the oneness of humanity
}

A third element of social responsibility, and one that highlights the relational nature of participants' experiences of personal transformation, was an understanding of the spiritual principle of oneness. Chapter Three highlighted how the oneness of humanity is a foundational principle in FUNDAEC's approach to development. The principle is introduced to participants in the PSA texts from an early stage, and is explored throughout the 18-month course at increasing levels of complexity. In one of the first texts studied, students and tutors explore this principle through the analogy of the human body. The different peoples of the world are likened to the various parts of the human body that, while different in form and function, make up an organic whole and must work together in unity for the fulfillment of a purpose greater than the sum of the parts. The text states how the same is true 
in the world of humanity, where every individual is intrinsically connected to every other and it is only through becoming unified that the affairs of humanity can develop and prosper. While the bonds that unite the different members of the body are physical, the nature of the bonds uniting humanity are spiritual.

Within the PSA curriculum, the principle of the oneness of humanity encourages students to recognise the interdependency and connectivity characteristic of the relationship between their individual actions and the community and wider society where they live. This particular conception of the relationship between individual and community appeared to be fundamental to participants' experiences of transformation. This was seen in how they described these not merely as passive outcomes of involvement in the programme, but part of a purposeful effort to promote their community's wellbeing. As one PSA tutor from Kabwe stated:

"I cannot transform the community when I personally have not transformed myself" (Kabwe 1).

Berman (1997, p. 13) writes about how, for socially responsible people, a sense of "connectedness and interdependence" often constructs "others and the world as a whole as part of the self." The comments of one tutor from Mwinilunga, who describes some of the problems he came to recognize in his community and how he was motivated to change his own behaviour to address these, illustrate an understanding of how the actions of one affect the wellbeing and progress of the whole:

"At first even myself, I was not knowing the impacts, negative and positive, that are coming from our daily activities. I was not aware of that. I was a farmer, just cutting down trees, killing animals. When I was young I was killing animals, I would go in the bush, I would come maybe with eight, sometimes even ten. But this time I've come to see if I kill ten one day, for two days it's twenty, next time it's forty - not even one animal is going to remain in the area after one year, which 
means if we are ten hunters we are going to finish everything. Another thing that we are hearing of global warming [is] it is coming because of our daily activities. We are cutting down trees carelessly, which is causing this to happen. But if people know the importance of why we are here, and know the importance of the creation of God, then we cannot destroy these things" (Mwinilunga 6).

The theme of social responsibility is central to Caroline Honeyman's (2010) study of SAT graduates, and the experiences of PSA participants have strong parallels with her findings. Honeyman (2010, p. 600) describes how a distinctive conception of 'unity' is explored throughout the SAT texts. The concept defines relationships between individuals in a community and appeared to contribute to SAT graduates' "understanding of the meaning and importance of 'personal investment in the well-being of others". Her study also explores this theme in relation to participatory development: "If educational processes can become more effective at helping young people gain a sense of social responsibility, then they will become a more reliable "bridge" to broad positive economic and social change as well" (2010, p. $600)$.

The central findings of Honeyman's study corroborate with the experiences of PSA participants in pointing to the contribution that education can make to developing a sense of social responsibility in students. A recent issue of Development looked at education "as one of the core pathways to human sustainable development" - through socializing future citizens and preparing future workers, transforming societies to be more just and equal, exploring different knowledge systems to build global consciousness, and "opening peoples' creative potential throughout their lives so they are more responsible citizens" (Harcourt, 2010, p. 449).

While the notion that societal transformation begins with changes in individual actions and attitudes is by no means mainstream in approaches to participatory development, social responsibility is not a new theme in development thinking. Amartya Sen (1999, p. 283) writes: “To deny the 
importance of social responsibility would be to miss something central about our social existence ... [and the need for] recognizing the relevance of our shared humanity in making the choices we face." It is interesting to note that Sen prefaces his remarks on social responsibility by acknowledging the centrality of the notion to religious thinking, before asserting that "one does not have to be either devout or nondevout to accept this basic connection" (1999, p. 283). The approach taken in Honeyman's (2010) study towards social responsibility in SAT participants reflects the truth in the latter assertion. Building upon these themes, I propose that the transformative experiences of PSA participants draw attention to the value of exploring the how spiritual dimensions of social responsibility can contribute to participatory development. Deneulin (2009) is one contributor to the religion and development literature who has voiced particular support for taking into consideration the transcendental roots of religious contributions to development.

In the context of FUNDAEC's education for development initiatives the oneness of humanity is conceived of as a spiritual principle, and it is explored throughout the PSA texts in this light. Honeyman (2010) describes how she noticed that the strength of the concept of unity in contributing to attitudes of social responsibility in SAT students depended on two factors: the emphasis on unity in diversity rather than uniformity, and a "level of fundamental similarity among human beings" (2010, p. 610). A later study carried out by Michael Leggett (2006) with SAT graduates suggests that this level of fundamental similarity is based on a spiritual conception of the individual, inspired by that same principle of human nobility that was explored in the first section of this chapter. Similarly, I noticed that the way PSA participants in Zambia spoke of oneness and unity reflected spiritually based conceptions of human nature and social existence. It appeared that the spiritual dimension of oneness played an important role in the development of an attitude of social responsibility in PSA participants, an attitude that makes an important contribution to participation in development. 
iv. Self-confidence and language capabilities

One of the greatest transformations that many of the respondents described was a growth in self-confidence that was intimately connected to the development of the ability to express oneself, especially in social situations. The development of language capabilities in students, both verbal and written, is one of the goals of PSA. The first text that students study together, Properties, is aimed at developing in students the ability to describe the world around them in accurate and precise language. The ability to express one's self and communicate with others is viewed as crucial for a promoter of community wellbeing to be effective. The following comments of students from the Makululu and Natuseko PSA groups address this dimension of their transformation, some in modest terms and some more dramatically:

"Personally, before I got into the PSA group I was unable to
express myself in the presence of people, in a group of people, I
was unable. Now ... I'm able to express myself and my ideas"
(Makululu 1).

"[Before I joined PSA] it was very difficult for me to talk to people, but at this time I can talk with many of them, even asking questions" (Natuseko 1).

"For me I have even learned how to interact with people, how to associate with them. Before this I just used to stay at home, watch TV, and if I visited ... a group of people I would just keep quiet, look at them, observe the things they are doing, without saying anything. But now I can at least add two or three words" (Natuseko 3).

Based on my personal reflections of interviews with students who had participated in PSA for almost two years and those who had only been in the programme for one month, there was a significant difference in how students expressed themselves. The students from the original groups were much more confident in talking with me. They asked many questions themselves, 
understood all of the questions I asked and were able to respond in depth, and had the ability to talk about complex material and spiritual concepts with clarity and conviction, employing a wide range of vocabulary. The new PSA students often asked for questions to be repeated or did not understand their meaning and tended to reply in short answers, suggesting a lack of confidence and/or the vocabulary necessary to communicate more complex thoughts.

The capability to communicate and express one's ideas and convictions is undoubtedly crucial for participation in development. Theorists and practitioners alike have been greatly concerned with how to achieve local participation in dialogue and community decision-making in order to improve wellbeing (Desai, 2008). This has been a particularly salient concern in societies where women's voices are often marginalized based on expectations of traditional gender roles. Attempts to promote the ability of individuals to participate in development are exemplified by programmes and policies that direct efforts towards capacity building and education to transform attitudes. Development theorists and practitioners have also been concerned with how 'outsiders' can facilitate local access to decision-making processes and resources. This research suggests there may be another important dimension to promoting participatory development: that for community decision-making to be truly participatory individuals must possess both the ability and the confidence to communicate their ideas and experiences.

The transformative experiences of PSA participants point towards the contribution that harmony between developing intellectual capabilities and understanding spiritual principles can make in this area. For the PSA participants, understanding the spiritual principle of nobility discussed earlier contributed to their growing confidence to express themselves amongst others and value their own contributions. In practice, this was combined with the development of intellectual and social capabilities. The experiences of a female tutor from Mwinilunga provide insight into the relationship between her personal transformation in this area and ability to participate in her community's development: 


\begin{abstract}
"Yes I've changed. I was such a person who never wanted to share ideas with people and I was very shy to mix with different people which I didn't know. If I [went] in a place where there were men, or there [were] a lot of people ... it was difficult for me expressing myself to people. ... But when I came, when I joined PSA it is a great thing ... and it has shaped me, because now I'm able to know if someone says things, I can relate it in another way, and express is in another way. When I was not in PSA it was very difficult for me to express myself to a person. It has really changed me and I've gained more" (Mwinilunga 4).
\end{abstract}

\title{
v. Practical knowledge and skills
}

Many respondents described how one of the most significant transformations they had experienced was in terms of the knowledge and skills they were gaining that could be applied to transform their social and physical reality. Harmony between theory and practice is central to the PSA methodology, in which "all texts are ... taken at the level of application" (Inshindo Foundation, 2008). 'Learning' through study of the materials and 'doing' through acting upon what was being learned emerged as two mutually enhancing components of knowledge leading to personal transformation in respondents. The following comments describe this experience:

"PSA is a programme that you learn and then you put what you're learning into action or reality. ... The knowledge that I've gained so far has helped me to learn a lot of things [and] this time I can do a lot of things" (Kabwe 4).

"I am really a different person now from how I used to be, I tell you for a fact. Because much of what I've learned in PSA, I'm even able to apply it in my everyday life, and really it is giving a picture even to those who visit my home to say 'I'm sure there is a difference in you'"' (Mwinilunga 3). 
The service projects that the groups carried out were one area where they applied the knowledge they were learning in the PSA texts and developed practical skills. Many respondents discussed these projects when asked what being a participant in PSA involved. The manner in which they spoke of their group's projects, often in great detail and with much enthusiasm, indicated that the practical application of knowledge through service is not an activity that occurs on the side but is wholly central to the PSA experience. Figure 9, Figure 10, and Figure 11 displayed at the end of this section show some of the service projects that I observed during my time in Zambia. Appendix G describes in more detail the range of service projects that the PSA groups were involved in, as well as examples of individual initiative to apply knowledge and skills outside of the programme. One student explained an aspect of his group's service project aimed at the promotion of backyard gardening by community members:

"We have a small garden where we want to apply the knowledge that we have learnt from these books, and not only that, we also want to show the community that hard working leads to success and ... that big things start from small things. Like that garden that we are doing is small [but] as time goes by we are looking forward to extending it. After all, even the highest tower begins from the ground" (Chimanimani 6). 
Figure 10. Students from Kabwe preparing a demonstration plot as a component of promoting household food production in the wider community

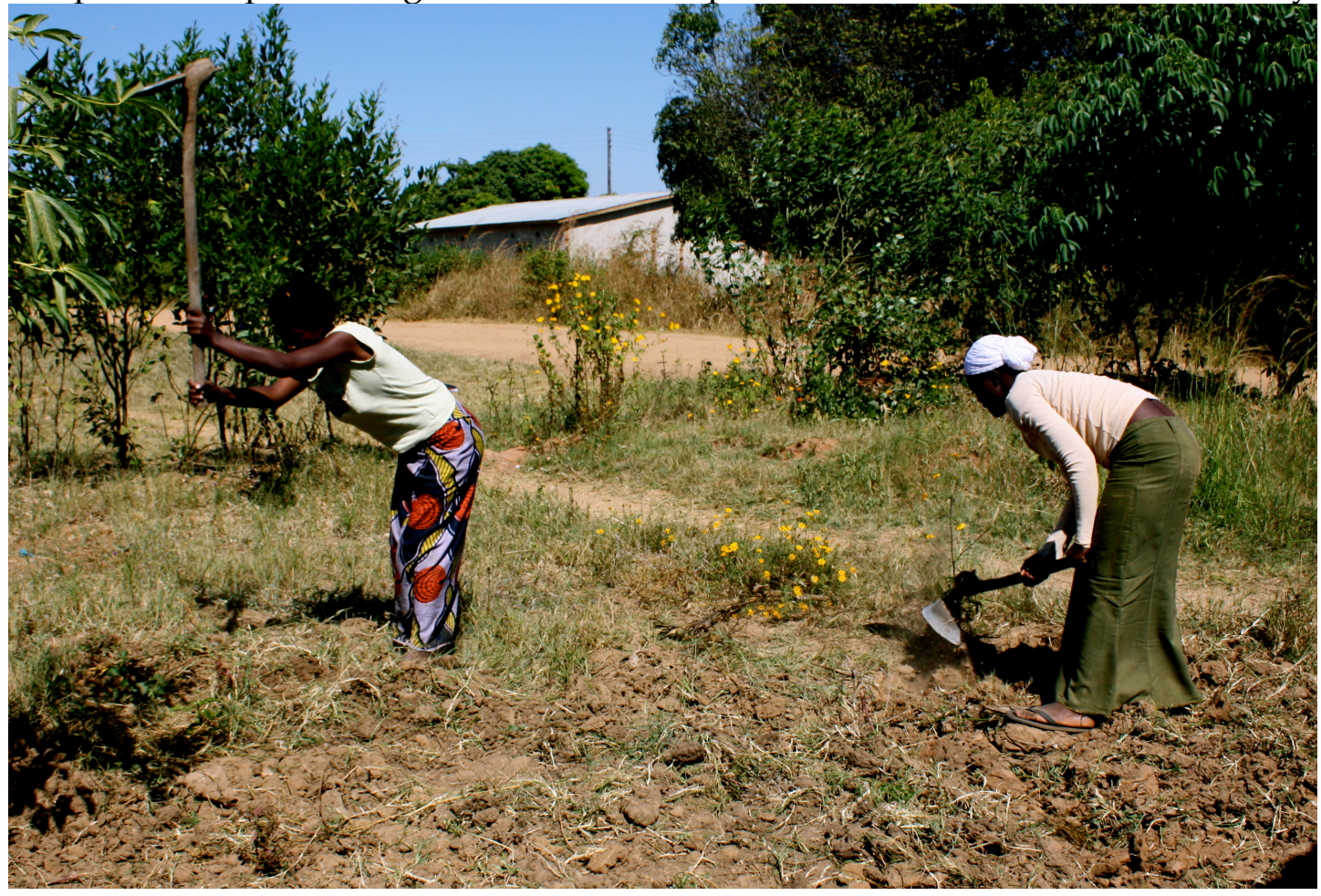

Figure 11. A PSA group's completed demonstration plot in Mwinilunga, behind the Inshindo Office

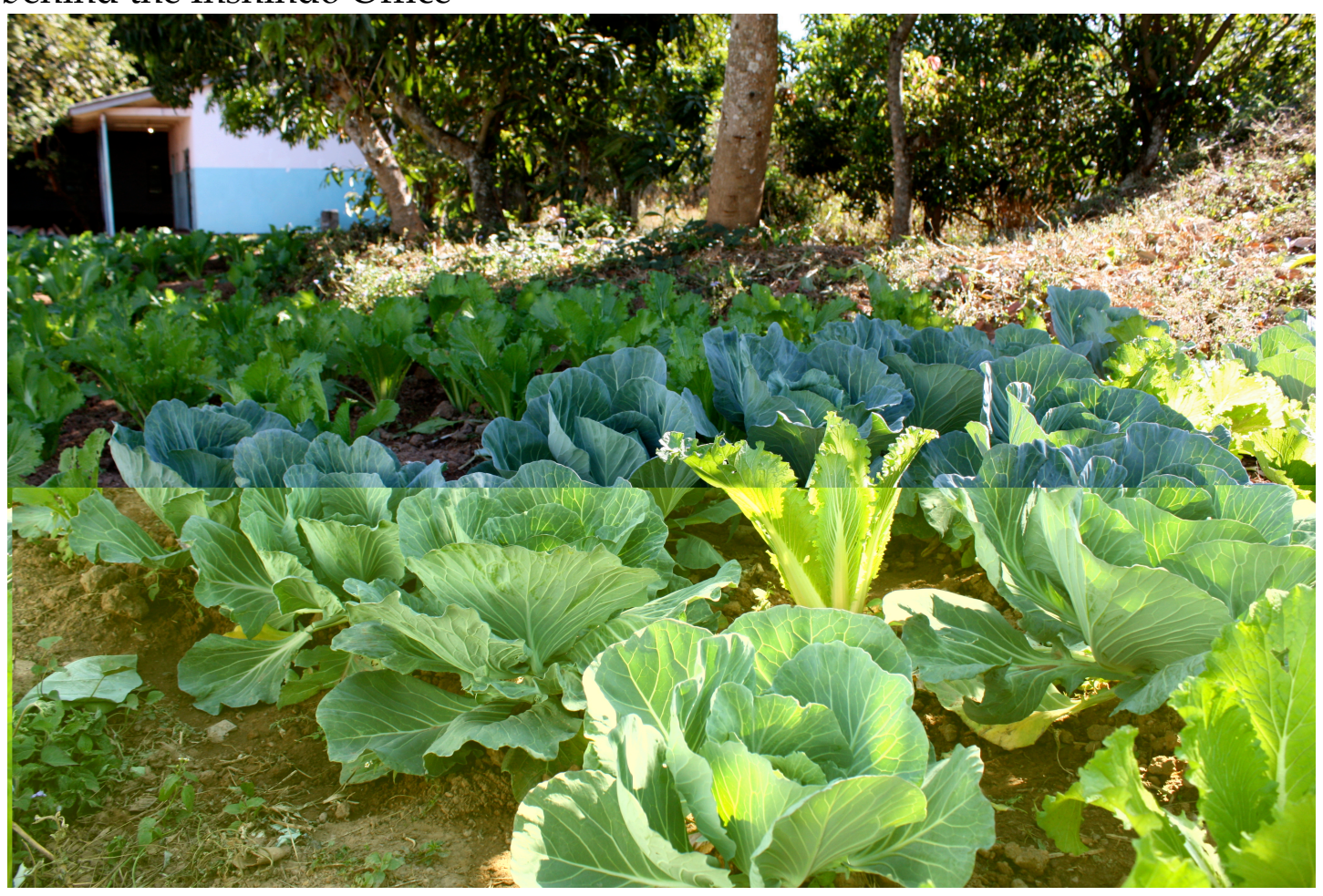


Figure 12. Members of the two environmental clubs that were established at local highschools by one PSA group perform a skit at a student encounter

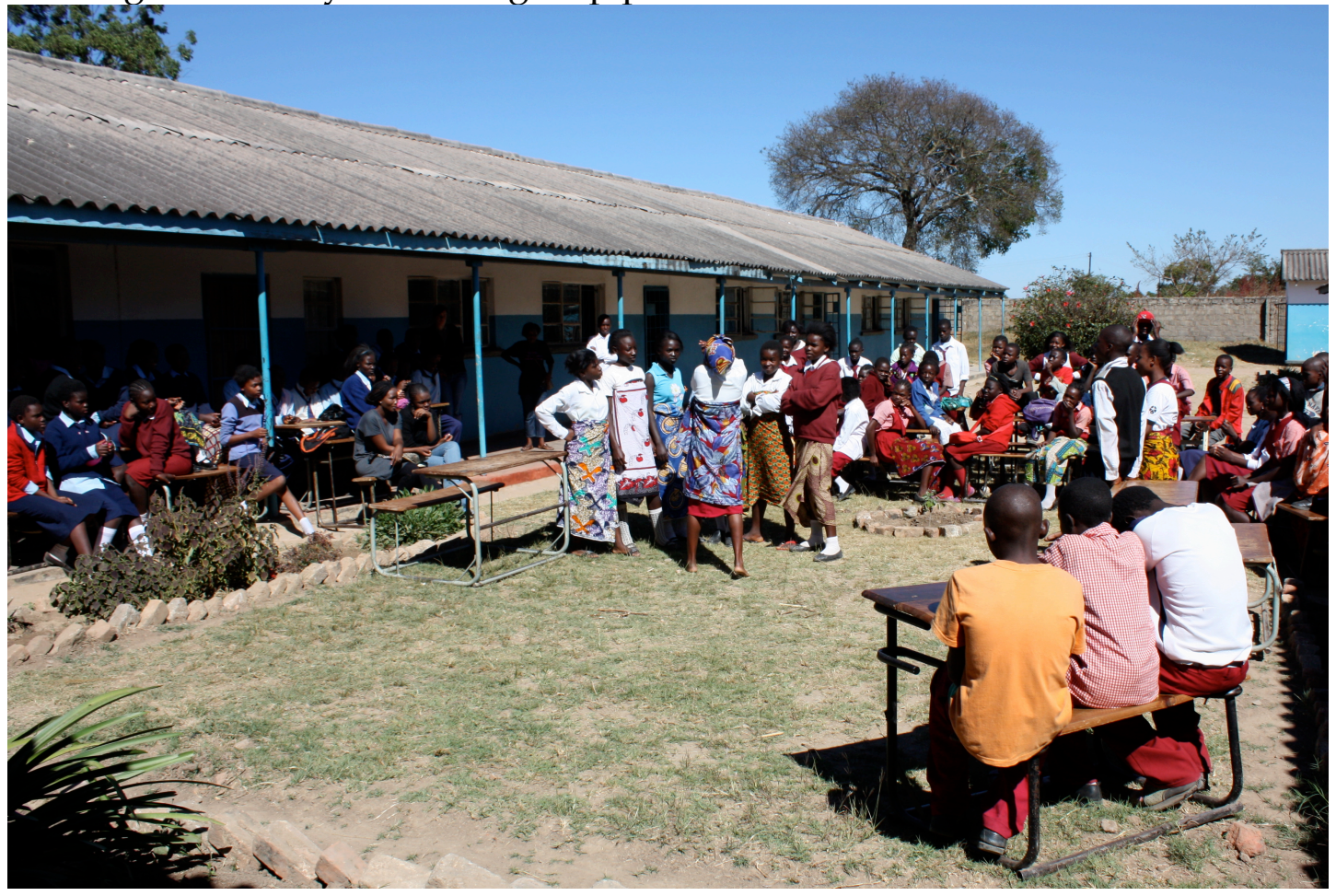

Respondents' transformative experiences in the area of practical skills illustrate how religious knowledge is integrated into the PSA programme in harmony with knowledge from other systems, such as scientific and traditional knowledge systems. This draws attention to the potential contribution of one final spiritual principle, harmony between science and religion, to participatory development efforts. The knowledge system of science, including traditional scientific knowledges, informs material development. How individuals contribute to material development has been the focus of capacity building initiatives in development practice and policy for several decades now. The role of religious knowledge in relation to the personal transformation of PSA participants, discussed in the rest of this chapter, suggests attention to spiritual principles and values can compliment practical skills and knowledge. Spiritual principles can inform and guide how an individual applies their knowledge and skills in a community through actions directed towards promoting its wellbeing and progress. 
This chapter will finish by describing one example that I observed of how spiritual principles and scientific methods come together in the service activities of PSA groups, and the skills, attitudes, qualities and knowledge developed by those involved. The PSA group in Chimanimani, Kabwe, carried out an action-research project around household food production over several months. Before going into the community, the group discussed the spiritual qualities they would need to practice when interacting with others, such as patience, kindness, humility, and respect. They then divided into pairs and went door-to-door to interview 20 families each, asking questions such as whether the family grew their own food, what enabled or discouraged them from having a backyard garden, and what knowledge they had about household food production already. They kept written records of all the responses to these questions. After analyzing the results, the group consulted about how to encourage families that were not producing their own food to do so. One project they initiated to address this was a demonstration plot sustained by the PSA group that provided an example to the community and could also assist with the provision of seedlings to families. Through this experience, a number of developments appeared to be occurring in the students: they were reinforcing their own knowledge of household food production by communicating it to others, gaining confidence and powers of expression, developing attitudes of humility and patience necessary when interacting with a diverse range of people, learning about community knowledge that already exists, and developing skills to produce their own food. Each dimension of personal transformation that may be associated with this project can be conceived of within the overarching framework of oneness. Under this framework, the action-research project of the Chimanimani group is both an arena for personal development and an act of service whose purpose is the promotion of community wellbeing.

\section{SUMMARY}

This chapter has explored the experiences of personal transformation that PSA students and tutors described in relation to their participation in the programme. Personal transformation for the participants encompassed the material, intellectual, social, and spiritual dimensions of their lives. In 
relation to the overall objective of this research, their experiences pointed to the several areas where religious knowledge was seen to contribute to development practice. Knowledge of two spiritual principles in particular the nobility of human nature and the oneness of humanity - appeared to play a strong role in the development of attitudes and qualities that can motivate and guide individual participation in processes of development.

A salient theme in the religion and development literature is that spirituallybased approaches to development may more effectively engage people at the grassroots than approaches based on material conceptions of life (refer back to Chapter Two). The argument here is that people are more likely to endorse initiatives and approaches whose values they share. The experiences of PSA participants advance this notion by implying that spiritually-based approaches to development may more effectively engage people because they address not only what a person values, but the fundamental reality of that person's nature. A statement by the Bahá'í International Community illuminates this theme (1998, p. 4): "Spiritual principles, which resonate with the human soul, provide an enormous motivational power for sacrifice and change." The notion here is that attitudes and actions contributing to participatory development begin inside the human heart and soul. After describing some of the changes she had experienced in herself since participating in PSA, particularly in her attitude of social responsibility towards her community and the actions she is now taking to promote its wellbeing, one PSA student explained:

"We are trying by all means that it should be coming from deep down in our hearts. It has changed us" (Site and Service 2). 


\section{CHAPTER EIGHT: CONCEPTIONS OF PSA PARTICIPANTS - KNOWLEDGE AND VALUES}

\section{INTRODUCTION}

The purpose of this chapter is to explore the central conceptions of PSA students and tutors in relation to their participation in the programme. Based on participants' experiences of personal transformation, the previous chapter explored the contribution that spiritual principles make to development at a practical level. This chapter seeks to build upon these themes by describing the participants' conceptions of the importance of knowledge in development and exploring how these relate to understandings of the relationship between religious knowledge and development at a more conceptual level. Concurrent with their practical involvement at all levels, enabling the knowledge and values of people at the grassroots to inform the vision of development at a more fundamental conceptual level is an equally critical element in the realization of true participation. The path of a peoples' development can only be considered their own when they are enabled to walk and trace its course. In considering how PSA participants' knowledge and values pertain to conceptions of development, this chapter builds particularly on the work of Goulet (1980) and Sen (1999) around 'instrumental' and 'non-instrumental' or 'intrinsic' treatment of values in development. In taking this approach, the research departs from much of the religion and development literature that is primarily concerned with how to instrumentally engage faith-based organisations within pre-existing secular visions of development. Instead, it supports a non-instrumental treatment of spiritual knowledge and values as both means and ends in development and explores what such visions may look like.

\section{THE ROLE OF KNOWLEDGE IN DEVELOPMENT}

The most salient theme that emerged from analysis of the interviews with PSA participants was the centrality of knowledge to both their experiences in the programme and to their conceptions of development. 'Knowledge' has been the focus of a range of development theories, particularly over the past 
three decades. In the 1980s, the principle of incorporating rural people's knowledge in participatory development was brought to mainstream attention largely through the work of Robert Chambers (1983). Around the same time and continuing on through the following decades, many theorists began to call for a 're-imagining' of development based on indigenous knowledge systems. In the 1990s, challenges to what Escobar described as "hegemonic discourses of development", based on ideas around the social construction of knowledge and its relationship with power, were a core focus of post-development theorists (1995a, p. 212). Around the turn of the century major publications such as the World Bank's 'Knowledge for Development' report of 1998/1999 represented an effort to mainstream knowledge as a development tool (McFarlane, 2006). Members of the World Bank have gone so far as to express that such considerations of knowledge mark a wholesale "shift in development paradigm" beyond chiefly economic considerations (Laporte, 2004 quoted in McFarlane, 2006, p. 290). The practical reality of this assertion is highly contestable, as this section will go on to explore in consideration of PSA participants' conceptions of knowledge.

The responses of the PSA students and tutors involved in this study highlighted how they conceived knowledge as the most valuable resource in development processes. Knowledge, according to their conceptions, is valued because of its potential to inspire, guide, and sustain actions that contribute to the development of a community. There were a number of reasons for this. Firstly, knowledge was described as a crucial component of sustainability in a process whereby a community becomes the protagonist of its own development (the ultimate purpose of PSA). Respondents described how knowledge had a different and greater value than money or material resources for a community because it is essentially infinite. In relation to this theme many respondents explained how the primary value of knowledge lay in its ability to stay with one for life, to be shared, and even to be passed down through generations. Speaking about the difference between the approach to development pursued by PSA and that of other community organisations, one tutor explained: 
"I've come to understand that if someone's given money, and one's given knowledge, the one who's given knowledge is very important. Because knowledge can stay with you for a long time, and you can even transfer knowledge to your children. But if you are given money, or a bicycle or a vehicle, [in a] short time it can be damaged and it will never exist anymore. ... If you are given little but you have that knowledge, at least you can expand it" (Mwinilunga 6).

The second theme that emerged around the centrality of knowledge to development addressed how knowledge enabled a community to develop in two practical ways. Analysis of participants' responses suggested that knowledge enables communities to first perceive and understand the reality of the world around them in its social, material and spiritual dimensions. Based upon this, a community will then be able to transform itself by applying relevant knowledge to its situation. This conception reflects the structure of students' learning in the PSA programme, where they first learn to describe the physical world around them, and then to increasing levels of complexity their social and even spiritual environment. They then strive to develop the skills, knowledge, attitudes and qualities required to change this reality as they see necessary.

The transformative potential of knowledge in development was seen in how a number of respondents described the social reality of their own localities and what was required to transform this. These respondents highlighted how a lack of knowledge, especially around environmental and health issues, was one of the greatest challenges facing the community and the root cause of harmful behaviours to the environment and community. One tutor from Mwinilunga explained:

"Certain things people do them, again, because they do not have knowledge. If they can know about it, then maybe to some extent they can change it. Because if you can look at the issue of the problem of promoting a healthy environment, some people don't even know what it means. Or certain human activities 
that contribute to harming the environment, sometimes people feel what they do is just the right thing, it's just the normal thing. But if we can have knowledge, or if we can have a number of people who have knowledge and then they share with other people, then people may begin to know things and become concerned [about] their environment" (Mwinilunga 1).

\section{CONCEPTIONS OF KNOWLEDGE}

Having established the value of knowledge to the PSA participants, I will now explore their conceptions of knowledge itself as it relates to broader conceptions of development. These differ significantly from what McFarlane (2006, p. 287) has described as "a pervasive rationalist conception of knowledge and knowledge transfer" that is dominant in development discourse. The kind of knowledge necessary for a community to develop, as identified by participants, would be drawn from traditional, scientific and religious systems of knowledge. This section will primarily address the conceptions of knowledge in relation to the spiritual dimension of human existence and how spiritual values inform visions of development. Before doing so, a brief example will be given of how respondents spoke of traditional and scientific knowledge. This is important in illustrating one of my main observations from the research that religious knowledge is integrated into the PSA programme, and consequently participants' conceptions of development, in harmony with knowledge from other systems.

\section{i. Modern scientific and traditional knowledge}

The importance respondents placed on drawing upon knowledge from different systems to guide community development was exemplified by how they spoke of the action-research projects that their groups carry out with their local community. The dual purpose of these projects, as stated in PSA and reaffirmed by participants, is that groups share with their community the scientific and technical knowledge and skills they learn from studying the PSA texts, and at the same time learn from the local, traditional knowledge 
held by other community members. A number of students used the terms 'conversation' and 'learning' when speaking of these projects, alluding to the reciprocal nature of the exchanges. The comments of one tutor from Mwinilunga and one student from Kabwe, respectively, describe the actionresearch projects their groups had carried out with local farmers and give insight into this theme:

\begin{abstract}
"Then we had another research with farmers in Ecosystems ${ }^{13}$ in which we first had to visit farmers that had fishponds. We visited one farmer who is Mr. Shinga and he has five fishponds. We tried to share ideas with him and he was very much willing to learn from us, and we learnt more from him. ... we shared with him, we learnt with him, he told us, he informed the group ... " (Mwinilunga 2).
\end{abstract}

"We had to build some kind of towers with the farmers, [and] find out the traditional knowledge about farming, and then we come and combine [this] with the science, technology we are applying from the books"' (Chimanimani 3).

These responses suggest that the methodology of PSA, particularly the arena of service, encourages students to draw on multiple knowledge systems to inform both their actions and the ultimate vision they are working towards. This seems to depart from the predominant reliance in many development programmes on the system of modern, Western science to provide the means and determine the end goal of development (Escobar, 1995a).

\title{
ii. Spiritual and material knowledge
}

The conception of knowledge relating to both the material and spiritual dimensions of life relates to the broader conviction of respondents that development is both a material and spiritual process. The notion that development involves a "dynamic coherence between the spiritual and the

\footnotetext{
13 Ecosystems is the title of one of the PSA texts.
} 
material" runs strongly throughout the development and religion literature (Tyndale, 2003, p. 23). Proponents of this view advocate an approach to development that prioritizes the values and beliefs of people in materially poor countries where development is being explicitly pursued. Studies such as Voices of the Poor highlight how a significant proportion of 'poor people' believe there is an indispensible spiritual dimension to human wellbeing (Narayan, 2000). Indicating the relevance of this conception to the experiences of those involved in PSA, one of the tutors from Mwinilunga explained:

\begin{abstract}
"What I can say is ... when we talk of community development and other aspects of society's advancement, it's like it lies on these two pillars, the material and the spiritual" (Mwinilunga 2).
\end{abstract}

In line with this conception of development, participants expressed how spiritual development must occur alongside material development if the latter is to occur in a way that is conducive to collective wellbeing. Just as knowledge from traditional and scientific systems informs material development, the responses of participants pointed to the need for spiritual principles to guide development. The previous chapter defined spiritual principles as those principles at the core of religious knowledge systems that guide material and spiritual development. They can be regarded as a kind of 'spiritual knowledge' that informs development at a conceptual as well as practical level. Five spiritual principles found within the PSA texts that were mentioned the most frequently by respondents were the oneness of humanity, the nobility of human beings, the equality of men and women, justice, and attraction to beauty. The comments of one PSA coordinator around how attraction to beauty guides material development are insightful:

"The connection with the spiritual and material development, for example, [can help us know] how we are supposed to use the material things that we have. If we associate everything with our spirituality, then we can be able to use the things that we have around us properly. For example, if we have a desire for beauty then we can take care of our environment because 
we want our environment to look very beautiful. And even the way we use our natural resources is going to be different, [because] we want to make sure that we will appreciate what we have and what the environment is offering us, and that the environment is there to assist in our existence. If we are not connecting our spirituality to our material being, then we would just exploit these things without caring about what is going to happen" (Inshindo Staff 3).

The importance that the participants attributed to the principles found in PSA suggested they had been translated from core spiritual teachings found in the major world religions to spiritual values in their own lives regarding human nature, the purpose of life, and how to create a better world. A number of tutors explained how tutors and students alike had internalized the values found in PSA, with one stating:

"Here nowadays we've seen that people are really focused on PSA, they've made it their way of life, they have internalized the values and the ethics of PSA so that you know this [has] maybe just become their way of life. Because they've seen the value in it: how it has transformed them, how it is transforming the students and the people around them" (Kabwe 5). 
understandings of development that are better informed by the values of its chief participants.

i. Spiritual values and the nature of human existence

The PSA curriculum is based on an understanding of human nature as physical and intellectual but also fundamentally spiritual. A passage by 'Abdu'l-Bahá addressing this conception explains:

In man there are two natures; his higher or spiritual nature and his material or lower nature. In one he approaches God, in the other he lives for the world alone. Signs of both these natures are to be found in men. In his material aspect he expresses untruth, cruelty and injustice; all these are the outcome of his lower nature. The attributes of his Divine nature are shown forth in love, mercy, kindness, truth and justice, one and all being expressions of his higher nature. Every good habit, every noble quality belongs to man's spiritual nature, whereas all his imperfections and sinful actions are born of his material nature. If a man's Divine nature dominates his human nature, we have a saint ('Abdu'l-Bahá, 1972, p. 60). ${ }^{14}$

One tutor from Kabwe spoke about how the dual nature of a human being is explored in the PSA curriculum in a way that has shaped his own views on human nature:

"Even though scientifically they are saying all human beings they are coming from the animal family, but we are different because we are created in the image of God, and God has given us the rational soul so we can think, so we can reason. ... So because of these spiritual aspects we have to thinking different from these other animals. A human being has two aspects: there's what we call spiritual nature and physical nature. When the spiritual nature is being dominated by the physical nature

\footnotetext{
14 'Abdu'l-Bahá was the son of Bahá'u'lláh and the authorized interpreter of His father's teachings.
} 
that simply means a human being, his thinking, will be worse than a wild animal" (Kabwe 2).

Tyndale (2001, p. 3) asserts that considerations of meta-physical questions concerning human nature are a key area of contribution for religion in development, and should provide the framework for any serious debate about its aims, methods, and indicators. These questions have traditionally been the focus of disciplines such as philosophy and anthropology, or at the other end of the scale the natural biological sciences; they have not been a traditional concern in development literature. However, the spiritual values of PSA participants suggest that they are paramount for the discipline in regards to conceptions of both individual identity and constructive collective endeavour.

The previous chapter illustrated how respondents often spoke about the spiritual nature of a human being based on understandings of human nobility as a spiritual principle. The focus was on the contribution of this principle to how individuals participate in development practice. If taken at the level of practice alone, the principle of human nobility can be engaged with instrumentally as a means for the achievement of development goals that may be derived from outside of a spiritual value system. At a more conceptual level, a vision of development that is based on a spiritual conception of human existence is fundamentally different from approaches that pay no attention to questions of human existence or are based on materialistic notions. If the spiritual principle of human nobility so highly valued by PSA participants was to be regarded as intrinsic to development, a "primary end" (Sen, 1999, p. 36), then a fundamental component of development becomes the realization of this principle. Such a vision might describe development as a process that enables people to develop the full range of their potentialities as noble beings, potentialities that are intellectual, material, and spiritual. The comments of one PSA tutor relate to this conception:

"I came to realize that PSA was not there to employ people, but was there to make people understand who they are and the 
potentialities that God has given them, and what they can do" (Kabwe 2).

The role of spiritual qualities in development was a recurrent theme throughout my interviews with PSA participants, as the previous chapter illustrated. To restate its basis, the theme reflected the dominant conception of human nature held by the respondents based on the principle of nobility. That the students and tutors of PSA discussed spiritual qualities as naturally as they discussed intellectual and physical capabilities illustrates how they were regarded as equally inherent to a human being's nature. Chapter Seven discussed how respondents highlighted that an individual must practice spiritual qualities when working with others in the community in order to contribute to its wellbeing. On the one hand, the value of spiritual qualities could be regarded instrumentally - participants were developing those qualities that are "much in demand in development work" based on aims and indicators developed without consideration of spiritual values (Keough, 2004, p. 8). On the other hand, the experiences of spiritual transformation described by participants could be regarded as the ongoing realization of an alternative goal in development based on spiritual values: the cultivation of spiritual potentialities in human beings. One student from the Natuseko PSA group spoke about the importance of spiritual qualities to him:

"It's important for the human being to have these qualities, because these qualities ... make the original form of the human being. Without these qualities a human being I think can't advance, you can't go anywhere" (Natuseko 2).

The conception of human nature described by participants raises some interesting points in relation to the third objective of this research. A commonly expressed fear of engaging with religion in development is around the potential for religious values or beliefs to be imposed upon people, robbing them of their individual freedom of belief. Clarke (2007) raises the point, however, that spiritual values should not be viewed as an imposition if they are shared by participants in development processes. This could be true of the many cultures still connected to their religious roots. Earlier chapters 
have described how FUNDAEC has attempted to integrate religious knowledge into PSA in a way that does not lean towards religious education or identify with specific sectarian beliefs. Instead, it strives to focus on the unity of spiritual teachings amongst religions. It was interesting to experience how PSA participants spoke of spiritual qualities as inherently human, regardless of the religion they are drawn from or the religious belief of a person. A student from Natuseko described his attitude towards spiritual qualities in the following way:

"We should love one another, we should love our communities,
we should have deep respect for each other, to our fellow
students and to everyone in our community, and out of our
community. In spite of [the] age, the race, and the status of that
person" (Natuseko 2).

ii. Spiritual values and the purpose of human existence

The conception of human nature as inherently noble and spiritual formed the basis for how a number of respondents described the purpose of life, giving insight into how spiritual values further contribute to alternative conceptions of development. The development of an attitude of social responsibility, inspired significantly by the principle of oneness, suggested that many participants conceived of service as central to the purpose of their life. A number of respondents also spoke of service to humanity as a core capability that PSA was trying to develop in participants. One tutor stated:

"...A human being who is created by God, he or she should be dominated by the spiritual so that he can be able to love, share, give, and do all of those sorts of good things to other people" (Kabwe 6).

Another tutor described how he felt his students' understanding of service to humanity was growing as they took part in PSA: 
"Of course they had the potential, they had all finished A-levels and maybe they were just waiting for opportunities to come up. ... I think it [PSA] has helped them to widen up their horizon ... especially in the aspect of service to humanity. Because most of them they thought maybe you have to have an individualistic attitude, you just work for [your] self, but this programme has emphasized that you have to offer service to humanity. This is the aspect that has awakened them. Yes, God created them, they have these faculties, but they have to offer back to humanity" (Kabwe 3).

A passage from the writings of 'Abdu'l-Bahá that is included in the PSA curriculum calls students to service:

Be thou a summoner to love, and be thou kind to all the human race. Love thou the children of men and share in their sorrows. Be thou of those who foster peace. Offer thy friendship, be worthy of trust. Be thou a balm to every sore, be thou a medicine for every ill ('Abdu'lBahá).

As one of the central features of FUNDAEC's approach to development for education, service to humanity is regarded as a religiously inspired principle. The last chapter discussed service as a practical contribution to development. It is this contribution that much of the religion and development literature attributes with the potential to galvanize moral commitment to global development challenges, particularly the achievement of the Millennium Development Goals (Clarke, 2008a; Keough, 2004; Lunn, 2009; Saanen, 2007). Without undermining the value of this contribution in any way, I suggest that it represents an instrumental treatment of service as a spiritual principle.

When engaged non-instrumentally as a spiritual value, the concept of service that was so important to PSA participants' appears to embody much more than a means to achieve externally dictated development goals. It informs a conception of development where participation in processes of development in one's community, if carried out in a spirit of service to humanity, is 
simultaneously the performance of an individual's purpose in life and a celebration of their own nobility. The interpretation of the spiritual value of service, based on the comments of PSA participants in this study, provides an insight at the grassroots level into what is so clearly articulated by Muzaffar in the literature. Muzaffar (2003, p. 32) proposes that spiritual values, when comprehensively understood, contribute to a conception of development that "embraces the very purpose of human life and the ultimate destiny of the human being."

\section{iii. Spiritual values and a vision of development}

The final section of this chapter looks at one spiritual principle in particular that appeared to contribute to an ultimate 'vision of development' that a number of respondents expressed they were working towards. The contribution of the oneness of humanity to participatory development through personal transformation was articulated in the last chapter. The respondents' attitudes of social responsibility and the comments they made in our interviews also pointed towards this spiritual principle as the vision of development. One student explained:

“What I've been observing in our community is that there isn't much unity. And I've learnt; I also never knew about unity. Since I joined PSA, we have been collaborating, we have been working together as members of the PSA. We have been trying by all means to create unity in our group, to work together. I think back to the time our tutor taught us about unity. He said: 'if you send a child to go and bring one stick, and if you tell the child to break it, it can easily be broken. But if you send a child to go and bring five sticks or ten sticks and then tell the child to break them, they won't be broken. Why? Because that's a sign of unity.' Without unity people, the community, it cannot go anywhere. What we are trying to do is to bring unity and collaborate, so that our community can advance in terms of development" (Chimanimani 7). 
During a tutor training session held near Kabwe, I listened to the group of tutors from Mwinilunga and Kabwe discussing how a community is not merely a social and physical construct, but also has a spiritual character. Based on a discussion question presented in one of the PSA texts, Teckson from Mwinilunga compared the individuals within a community to different physical elements and compounds that are united by strong bonds for a common purpose. For example, the elements of hydrogen and oxygen are united and become water. Unlike a mixture of individuals who merely exist within a shared social space and physical place, Teckson explained that spiritual bonds should exist between individuals in a community that it hold it together for a common higher purpose - the wellbeing of the whole and service to God. Some of the spiritual bonds mentioned by other tutors in response to Teckon's comments were unity, fairness, justice, love, and cooperation.

The discussion amongst the PSA tutors builds upon Hayne's (2007, p. 62) discussion of how religion and spirituality contribute to human development by facilitating the development of positive values that encourage community cohesion. Goulet (1980, p. 485) writes: "A non-instrumental treatment of values draws its development goals from within the value system to which communities still adhere." When regarded as an intrinsic value, the spiritual principle of oneness contributes to a more fundamental conception of development. Community cohesion, or 'unity' in the language of PSA participants, is not only the means for the realization of other development goals but the very vision of development itself. Participants spoke of a whole range of issues in their communities that needed to be addressed relating to health, education, the environment, politics and leadership, gender equality, and many more. Ultimately though, it appeared that a particular conception of the relationship between the individual and the community based on the spiritual principle of oneness encompassed all these goals.

\section{SUMMARY}

This chapter has explored how knowledge was central to the conceptions of PSA tutors and students involved in this study. Knowledge was described as 
the most important means for enabling individuals and communities to understand and transform their reality. As participants conceived of collective transformation as a simultaneously spiritual and material process, it was implied that the knowledge informed it had to be both spiritual and material in nature. The objective of this study, understanding the relationship between religious knowledge and development, focused the lens of exploration throughout this chapter on knowledge relating to the spiritual dimension of participants' conceptions. In this regard, the conception of development articulated by PSA participants was shaped by their spiritual values and, as such, differs significantly from both mainstream and many alternative conceptions found in development literature. Given the diversity of spiritual values that are held across the world - and just as importantly the unity amongst many of these - more research in the area could give insight into how these values may "harbour within them a latent dynamism which, when properly respected, can serve as a springboard for modes of development which are more humane than those drawn from outside paradigms" (Goulet, 1980, pp. 484-485). 


\section{CHAPTER NINE: SUMMARY AND CONCLUDING REMARKS}

\section{INTRODUCTION}

The purpose of this final chapter is to summarize the thesis and its central findings and to present concluding remarks in relation to the research objectives introduced in Chapter One. The centrality of knowledge to social existence, and thus to processes of development, has been the salient area of inquiry throughout the thesis. This chapter highlights how the initial grounding of the thesis in a discourse between religion and development shaped a particular theoretical approach to the study and the questions that were asked around 'knowledge'. Two characteristics of knowledge - type and application - focused the study on the contribution of religious knowledge to development at a conceptual and practical level and the role of faith-inspired organisations in this process. In light of the conceptions and experiences of participants, however, a number of unexpected themes have been advanced, as the progression of this thesis has demonstrated. The importance of a third characteristic of knowledge, access, became increasingly apparent. Furthermore, the essential harmony between religious and scientific knowledge in regards to both type and application became more prominent. As it was not within the scope of this research to explore in greater depth all of the questions that arose, this chapter will also make a number of recommendations for future research in the area and acknowledge the major limitations of this study.

I began this thesis by drawing attention to the growing consensus by theorists and practitioners alike that there is an urgent need to "take religion seriously" in development (Linden, 2008). The custom of marginalizing or discrediting religion and ignoring the spiritual values of the majority of the world's population is a progressively untenable position. However, the historical, contemporary, and potential relationship between religion and development has only begun to be explored. Chapter Two outlined some of the central convictions, and gaps, of an emerging body of literature at this interface. It also highlighted that the mainstream discourses of development are deeply 
rooted in what has been described as a modern, Western system of scientific knowledge. Based on the works of a few of key authors, I introduced the conviction that knowledge is one of the cornerstones for individual and collective change. The implication of this was that we cannot content ourselves with a traditional 'reductionist' approach to knowledge in development that only encompasses the material dimension of existence (Goulet, 1980). If development's purpose is to advance the lofty aim of transforming the world into a more just, peaceful and prosperous place than surely only the fullest conception of rigorously tested knowledge can be sufficient. As a knowledge system that has propelled the development of civilizations throughout the ages, and that contributes teachings relevant to the global challenges, it was asserted that further research was needed into the relationship between religion, as a system of knowledge and practice, and development.

In Chapter Three I introduced my view that taking religion seriously in development requires researchers to be open about their own worldviews and how religious beliefs may inform these. I described how the Baháí teachings were a source of insight and guidance for many aspects of the research process, particularly my interactions with the research participants in Zambia. A case study approach and qualitative interviews were the primary features of this study's methodology. Indeed, the ultimate source of any contribution this research may make comes from the conceptions and experiences of PSA participants that they described to me in our interviews. I believe that my own positionality, grounded in a spiritually based ontology, enabled me to then gain a number of insights that may not have otherwise arisen. I feel it is also important to acknowledge, however, some of the limitations I perceived in relation to my positionality. One challenge relates to carrying out research from a spiritually based ontology within what are largely secular and materially based discourses of development. The paucity of research precedents and language to communicate spiritual and religious concepts in a way that is accessible to any reader presented an ongoing challenge in my study. 
A further limitation of my personal worldview that I have struggled to address is the ability to clearly distinguish between my own beliefs as a Bahá'í and the theory and practice of Inshindo Foundation and FUNDAEC as Bahá'í-inspired organisations. Literature at the religion and development interface about the role of religious networks in development and faith-based organisations led me to a particular conception of my relationship with this case study. As I began interpreting the findings however, I became increasingly aware of the need to distinguish my own understanding of Bahá'í teachings from their function as a source of insight for Inshindo Foundation and FUNDAEC. In an attempt to address this challenge, I sought to understand the meanings PSA students and tutors were trying to convey first in the context of the kind of activity they were describing, and the structure and aims of the PSA programme. Engaging in a closer conversation with FUNDAEC throughout the research may have contributed in this area, and is a strong recommendation for future research into its programmes.

Further limitations of this study relate directly to the requirements and opportunities afforded by research at master's level. The time available to carry out the research meant that I was only able to involve PSA participants in the study, and not the wider localities of Kabwe and Mwinilunga where the programme is being implemented. Furthermore, this meant that insights into how participants have changed over time were based largely on personal testimony. Future longitudinal studies that broaden the scope of investigation to the wider community and assess the impacts of PSA over time would make significant contributions to understanding the themes and questions that arose in this study. The infancy of the programme has also meant that the insights drawn are based on the experiences of students and tutors who had not completed the entire course of study at the time of the research.

\section{SUMMARY OF MAIN FINDINGS}

With the conceptual and practical framework of the study in mind, this chapter will now go on to restate the specific research objectives before presenting concluding remarks in relation to each one. Once again, these findings are presented in a spirit of learning as a contribution to conversations 
within development and are open to interpretation from any conceptual framework. The overall objective of this study has been to explore the relationship between religious knowledge and development. This exploration has been made through investigating the experiences and conceptions of participants in a programme that, as part of its development theory and practice, draws upon religious knowledge as a source of insight. Three areas of investigation have structured the investigation of this overall objective:

1. To identify and describe how religious knowledge informs the theory and practice of FUNDAEC and Inshindo Foundation as development organisations.

2. To identify and describe the experiences and conceptions of PSA students and tutors in relation to their participation in the programme.

3. To examine how the experiences and conceptions of PSA participants contribute to understanding the relationship between religious knowledge and development at a conceptual and practical level.

\section{OBJECTIVE ONE}

Based on my own experiences with the programme in Kabwe and Mwinilunga, interviews and conversations with the staff of Inshindo Foundation, and analysis of materials produced by FUNDAEC and its founding members, this thesis has explored how religious knowledge informs the development theory and practice of FUNDAEC and Inshindo Foundation.

The relationship between religious knowledge and FUNDAEC is seen in three areas: the conceptual framework of the organisation, its methodological choices, and its programme activities.

1. Conceptual framework: Bahá'í teachings are identified as one source of knowledge that shapes the conceptual framework of FUNDAEC, together with scientific knowledge. Three fundamental beliefs were identified that influence this framework: the dual material and spiritual nature of human existence, the centrality of knowledge to 
social existence, and the oneness of humanity. Development, then, is conceived of as a process of material and spiritual transformation in which every human being must be a protagonist of individual and collective progress. The two repositories of knowledge and practice that together guide this process are science and religion.

2. Methodological approach: FUNDAEC's focus on education and capacity building in its development programmes is shaped by a belief in the nobility of every human being. This belief holds access to knowledge as a God given right of every individual. Access to knowledge, it is believed, enables individuals to realise their latent potential and understand their noble nature. Thus, access to knowledge is seen as the means for enabling participation in processes of collective transformation for the betterment of the world.

3. Programme activities: The conceptual framework of FUNDAEC is reflected in its programme activities through the PSA programme. Religious knowledge is integrated into PSA in a way that seeks to achieve harmony with other systems of knowledge - scientific and traditional. Spiritual qualities and principles are included throughout the texts and participants study, reflect, discuss, and apply these in their groups. The incorporation of both religious and scientific knowledge aims to develop in PSA participants a range of capabilities their personal development. The curriculum revolves around the axis of service; participants apply the capabilities they develop through service to their communities that seeks to promote wellbeing.

The central purpose of Inshindo Foundation is to offer and coordinate the PSA programme in Zambia. As such, there are many parallels with FUNDAEC around how religious knowledge informs its theory and practice. However, Inshindo is also distinct from FUNDAEC. As a Bahá'í-inspired organisation, the Bahá'í teachings are one of a number of influences shaping distinct organizational characteristics. These features do not represent a generalisable picture of a Bahá'í-inspired or faith-inspired organisation. Instead, they illustrate the complexity of ways that spiritual principles and values can influence development organisations. That such values are an inherent dimension of Inshindo Foundation, and shared with participants 
from the population they are serving, suggests that their marginalisation in development processes would be inappropriate.

A final theme that was discussed around the relationship between religious knowledge and the work of Inshindo Foundation was the role of global networks in facilitating the sharing of experiences, resources, and knowledge. A particular conception in the literature of 'religious networks', frequently linking them with institutional religious structures, was not applicable to Inshindo Foundation. A different conception emerged of a network of individuals who were motivated to contribute to social and economic development and sought to draw upon the Bahá'í teachings as one source of insight.

\section{OBJECTIVE TWO}

The second objective of this research was to explore the experiences and conceptions of PSA students and tutors in relation to their participation in the programme. As I sought first and foremost to gain a broad understanding of those experiences and conceptions that were most important to them, this objective was advanced in ways that I had not anticipated. The centrality of a holistic conception of knowledge to both their own experiences of transformation and conceptions of development more broadly was clear. This theme was intimately connected with service, the arena where knowledge was applied and an organic connection between the individual and community realised. The lens of this research has focused on understanding these themes and others that arose within the context of a discourse around religious knowledge and development. While many more questions were raised and areas of insight brought to light, it was not within the scope of this study to address all of these. The main themes will be summarized here as they relate firstly to experiences and then to conceptions of the PSA participants. 


\section{i. Experiences}

Personal transformation was identified as the most significant experience that PSA students and tutors associated with their participation in the PSA programme. Five dominant areas of transformation were identified: selfperception, spiritual transformation, social responsibility, self-confidence and language capabilities, and practical knowledge and skills. The primary cause of personal transformation, as identified by my own analysis and highlighted explicitly by several participants, was knowledge. The holistic nature of the transformative experiences participants described, encompassing material, intellectual, spiritual, and social dimensions, suggested two primary characteristics of knowledge in the PSA programme. One was the harmony between knowledge relating to the material and spiritual dimensions of life, and the other the close relationship between theory and practice. This latter characteristic highlighted the role of 'service' in experiences of personal transformation. Service was the arena where participants sought to manifest in action the knowledge, skills, qualities and attitudes they were learning from the PSA textbooks within their community, in an effort to contribute to its wellbeing.

Spiritual principles were identified as the link between participants' experiences of personal transformation and religious knowledge in the programme. Acting as a nexus between the material and the spiritual, it appeared an understanding of spiritual principles guided how participants understood and then applied the capabilities they were developing in practice. Two main principles were identified in this regard: the oneness of humanity and the nobility of every human being. It appeared that as many participants deepened their understanding that every human has a noble, spiritual nature, they gained a greater sense of self-confidence and a belief in their own ability to do something purposeful in life. An understanding of the deeper spiritual level that connects all human beings in an organic yet diverse whole seemed to contribute to the development of an attitude of social responsibility. In practice, it appeared that this attitude motivated participants to apply the intellectual and material capabilities they were developing in a way that would promote the wellbeing of their communities. 


\section{ii. Conceptions}

The thesis identified how the conceptions of PSA students and tutors in relation to their participation in the programme centred around the role of knowledge in processes of individual and collective transformation. The responses of a large number of participants suggested that access to knowledge can enable people to understand reality in its material, social, and spiritual dimensions, and then transform this reality according to their own values and needs. As the primary means for development, participants' responses suggested that knowledge had to be relevant to both the material and spiritual dimensions of life. Certain spiritual principles were identified that should be central to how a community progresses so that material development will occur in a way that promotes collective wellbeing: the oneness of humanity, the nobility of human beings, justice, equality of men and women, and attraction to beauty which was directly related to beauty in nature.

The way that many of the participants seemed to conceive of the nature and purpose of human existence suggested that spiritual values were fundamental to their conceptions of development. A belief in the dual material and spiritual nature of every human being pointed to a conception of development that should enable people to develop the full range of their potentialities and realise their inherent nobility. An understanding of the interconnections between all human beings that participants spoke of pointed to 'service to humanity' as an individual's purpose in life. The way that participants spoke of these spiritual values suggested that they were not only means to promote externally-derived development goals, but contributed to a spiritually based vision of development that is, in part, the realization of human nobility and spiritual principles. 


\section{OBJECTIVE THREE}

The third objective of this research has been to further understanding around the relationship between religious knowledge and development by analyzing the experiences and conceptions of PSA participants in the context of broader development discourses. This objective is regarded as a particularly important aspect of this study given the recent and growing interest in the role of religion and spirituality in development. There is a need for a diverse range of actors to contribute to this discourse at all levels. I believe, however, that those whose voices are of the utmost value, yet tend to be heard the least, are those involved in processes of development at the grassroots level. Their contributions are indispensible in the promotion of truly participatory development at the level of theory and practice.

Chapters Seven and Eight highlighted some key themes around participants' experiences and conceptions of PSA in relation to religious knowledge and wider development literatures. A number converge with themes found in the religion and development literature around the need to engage with spiritual values as intrinsic to development theory and practice. Others depart from mainstream development discourses, particularly around participatory development, that are still rooted in material and secular worldviews. Eight primary themes are presented below.

1. Knowledge is fundamental to processes of individual and collective transformation. Knowledge can enable individuals and communities to better understand their material and spiritual reality and empower them to transform this reality according to their own values and needs. This grassroots perspective points to the need for a much more holistic conception of knowledge than is currently emphasized in mainstream development discourses. Knowledge must be relevant to both the material and spiritual dimensions of progress. While scientific knowledge informs material progress, religious knowledge contains teachings, principles and values and can worked together with science to guide both spiritual and material progress. The centrality of knowledge to human existence also shifts conceptions of what is 
important in bringing about participatory development. It is not material means, but access to knowledge and the ability to generate and apply it that may be regarded as fundamental to a people's ability to trace and walk the path of their own development.

2. At both a conceptual and practical level, development is a material and spiritual process. This conception held by the PSA participants does not accord with mainstream conceptions that focus predominantly on the material aspects of reality and progress. It finds relevance within much of the religion and development literature, where the "dynamic coherence between the spiritual and the material" is of central concern (Tyndale, 2003, p. 23). This theme implies that spiritual values are intrinsic to how the majority of people in the world view development and should be regarded and engaged with non-instrumentally (Goulet, 1980).

3. Spirituality, in the context of development, is best understood as relational and practically applicable. This conception departs from both secular development discourses and some of the literature at the religion and development interface. PSA participants' experiences of spirituality were not contained to the personal and private realm of an individual. Personal spiritual transformation implied that certain spiritual principles resonated with the spiritual nature of an individual, but this was not an end in itself. Spiritual qualities were manifested in and developed throughout interactions with others, particularly in the arena of service. Spiritual principles were applied at the level of the community to guide its collective material and spiritual progress.

4. Religious knowledge has the potential to be a force for unity in processes of development when it focuses on the core spiritual principles of the major world's religions and the spiritual qualities inherent to the higher nature of all human beings. The experiences of PSA participants suggested that the integration of religion in development programmes as a system of knowledge, drawing upon 
spiritual principles in way that avoids sectarian division, is one way that faith-inspired organisations can positively contribute to processes of development.

5. The spiritual principle of oneness can make a distinct contribution to development theory and practice. At a conceptual level, experiences and conceptions of PSA participants suggested that this principle was integral to an ultimate vision of development. An understanding of the interconnectedness of all things - human beings and nature - and in particular the links between human beings on a deeper spiritual level characterized a conception of reality. When organized around this principle, development can be seen as a process of working towards unity. At the level of practice, oneness implies an interconnection between the individual and society that has the potential to motivate individuals to transform themselves in order to transform their communities.

6. An understanding of the dual material and spiritual nature of human beings also contributes to development at the level of theory and practice. This belief held by the participants suggests that development must give greater attention to the spiritual dimension of human existence. Development theory may be more aligned with this belief if it was concerned with the realization of human nobility as its vision, and sought to promote the development of human potentialities that are material, intellectual, and spiritual in development practice.

7. Based on the spiritual principles of oneness and human nobility, the concept of service to others emerges as the purpose of human life and the arena where individuals achieve the highest form of development. From the experiences of PSA participants, service appeared to create a space where an attitude of social responsibility, spiritual qualities, and practical knowledge and skills could be manifested in actions directed towards community wellbeing. This concept of service moves beyond the notion found in the literature of a 'spirit of service' that motivates action to a spiritually grounded conviction of service as a dynamic 
space between the individual and society that can contribute to the transformation of both.

8. Religious knowledge contains principles and values that are relevant to the spiritually based conceptions of existence held by many people across the world. As such, it stands as a source of insight for development organisations that are concerned with how to promote participatory development and contribute to the social, economic, and spiritual development of communities. In order for such organisations to be 'agents of transformation', affirmation of spiritual principles and values should go hand in hand with scientific methods and knowledge that also address the material dimension of existence. Given the concern in development literature that religion can be a force that perpetuates disunity, inequality, injustice and intolerance, it would seem that its fullest potential is realised when the core spiritual principles and qualities central to all the world's major religions are emphasized. These are those that promote unity, equality, justice, tolerance, and human nobility.

\section{PERSONAL REFLECTIONS}

The thesis began by setting the study in the context of the monumental challenges, and opportunities, that humanity is currently facing. The opening assertions - that knowledge is central to processes of individual and collective advancement and that for the majority of people around the world development involves a harmony between the spiritual and the material have been continually reinforced by the experiences and conceptions of PSA participants that formed the basis of this study. In relation to the challenges that those in development seek to address, I propose that this study has pointed to a distinct area where religious knowledge can potentially contribute: an understanding of the fluid and interconnected relationship between the individual and society founded in the principles of oneness and human nobility. Such an understanding entails that collective transformation which seeks to overcome injustice, inequality and poverty requires a 
simultaneous transformation within those who co-create the social reality that allows for the continued existence of these issues. This requires access to knowledge by the great masses of humanity, knowledge that promotes the realization of their inherent nobility. The traditional conviction that spirituality is a personal matter still stands; the experiences of PSA participants suggest that spiritual principles are a knowledge that has the potential to transform precisely because they resonate with the human soul. The conviction is found wanting when it views spirituality as a solely personal matter and overlooks the connection between an individual and their community and society - a connection ultimately based on oneness. 


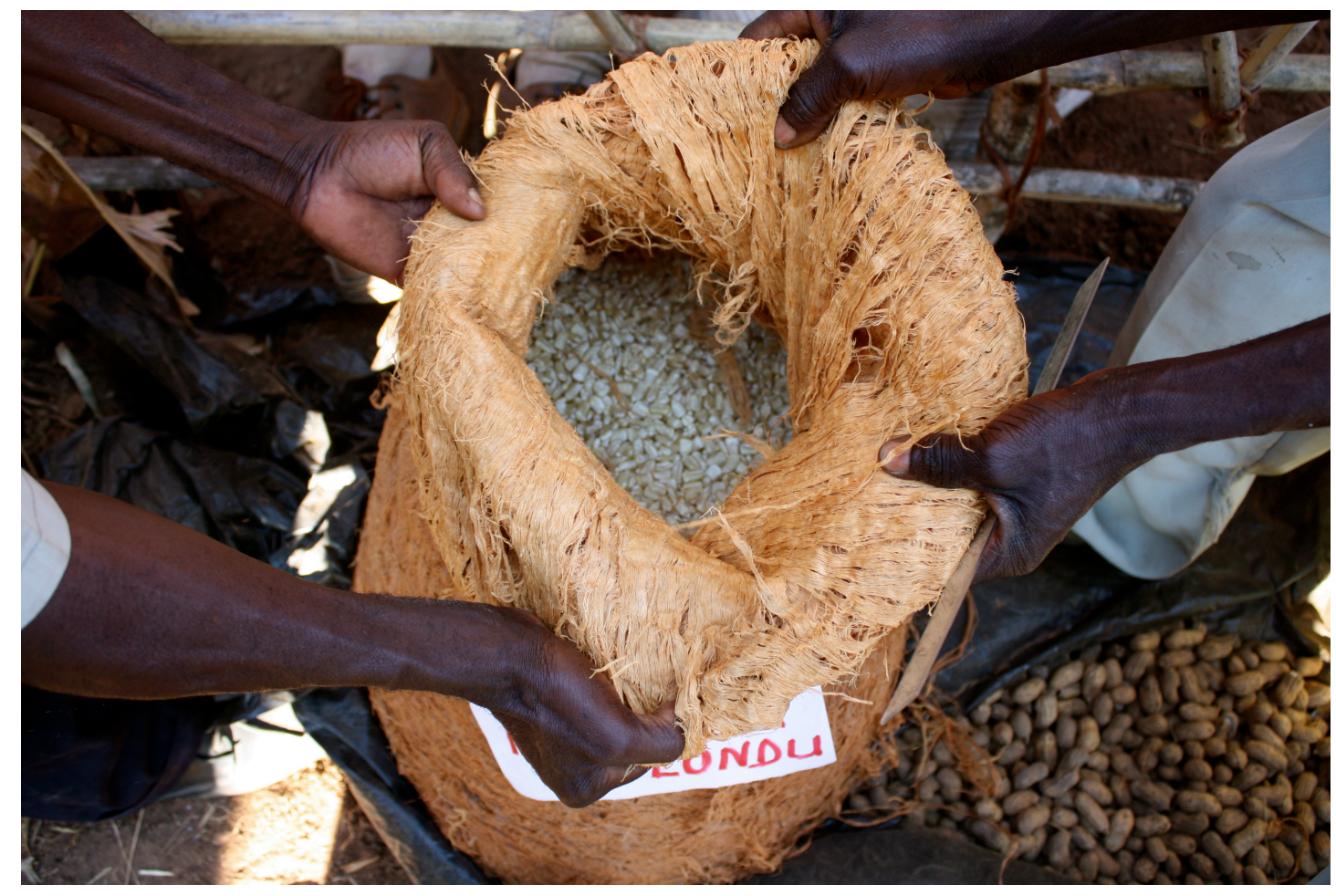

"When we talk of community development and other aspects of society's advancement, it's like it lies on these two pillars, the spiritual and the material" - PSA tutor, Mwinilunga 


\begin{tabular}{|c|}
\hline 1. Name: \\
\hline 2. Age: \\
\hline 3. Gender: \\
\hline 4. Community: \\
\hline 5. Religion: \\
\hline 6. Year education completed and highest grade: \\
\hline 7. When did you first become involved with PSA? \\
\hline 8. What were you doing before you became involved? \\
\hline $\begin{array}{l}\text { 9. What was it about the PSA programme that made you want to be involved } \\
\text { as a tutor? }\end{array}$ \\
\hline 10. What motivates you to continue working as a tutor? \\
\hline 11. What do you think the PSA programme is all about, what is its purpose? \\
\hline 12. How does it work to try and achieve this purpose? \\
\hline $\begin{array}{l}\text { 13. Can you please describe what takes place in your group? (when you meet, } \\
\text { where you meet, how many are in your group, what a typical session involves, how } \\
\text { the students relate to each other, how the students relate to you as the tutor) }\end{array}$ \\
\hline $\begin{array}{l}\text { 14. What activities has your PSA group carried out in the community? (what } \\
\text { do you think were the impact of these, what was the response of the community to } \\
\text { these activities) }\end{array}$ \\
\hline $\begin{array}{l}\text { 15. As your students have participated in the programme, how do you think } \\
\text { their views of their communities have changed? }\end{array}$ \\
\hline 16. How do you think their views of themselves have changed? \\
\hline $\begin{array}{l}\text { 17. What aspects of the programme do you feel contributed to these changes } \\
\text { in the students? }\end{array}$ \\
\hline $\begin{array}{l}\text { 18. If you think back to how you were before joining PSA and how you are } \\
\text { now, would you say that you have changed as a result of being involved? } \\
\text {-Before joining PSA, how do you think you viewed and related to your community? } \\
\text { How do you view and related to your community now? } \\
\text {-How did you feel about yourself? How do you feel about yourself now? }\end{array}$ \\
\hline $\begin{array}{l}\text { 19. Are there any specific aspects of the programme that you feel contributed } \\
\text { to this change? }\end{array}$ \\
\hline $\begin{array}{l}\text { 20. What does 'community wellbeing' mean to you. What does an ideal } \\
\text { community that has 'wellbeing' look like? }\end{array}$ \\
\hline $\begin{array}{l}\text { 21. In your view, what makes PSA different from other development } \\
\text { programmes? }\end{array}$ \\
\hline $\begin{array}{l}\text { 22. Can you please describe the relationship between the spiritual and the } \\
\text { material in PSA? }\end{array}$ \\
\hline $\begin{array}{l}\text { 23. Is spirituality something that is important to you about the PSA } \\
\text { programme? If so how? What does it mean? }\end{array}$ \\
\hline 24. Is spirituality important to how you approach your role as a tutor? \\
\hline $\begin{array}{l}\text { 25. Is there anything that we haven't talked about that is important to you } \\
\text { about your experiences so far with PSA and Inshindo Foundation? }\end{array}$ \\
\hline
\end{tabular}




\section{APPENDIX B: SEMI-STRUCTURED INTERVIEW GUDIE AND FOCUS GROUP GUIDE: PSA STUDENTS}

\begin{tabular}{|c|}
\hline 1. Name: \\
\hline 2. Age: \\
\hline 3. Gender: \\
\hline 4. Community: \\
\hline 5. Religion: \\
\hline 6. Marital status: \\
\hline 7. Children: \\
\hline 8. Religion: \\
\hline 9. Highest grade of education completed/year completed: \\
\hline 10. When did you first join PSA? \\
\hline 11. What were you doing before you joined PSA? \\
\hline 12. What made you decide to join PSA? \\
\hline $\begin{array}{l}\text { 13. What does a typical session involved for your PSA group? (How do the } \\
\text { students relate to each other? How do the students relate to the tutor?) }\end{array}$ \\
\hline $\begin{array}{l}\text { 14. What activities has your PSA group carried out in the community? (What } \\
\text { do you think were the impact of these, what was the response of the community to } \\
\text { these activities?) }\end{array}$ \\
\hline $\begin{array}{l}\text { 15. Can you please describe what PSA is all about, what is the purpose of } \\
\text { PSA? }\end{array}$ \\
\hline 16. How does it work to achieve this purpose? \\
\hline $\begin{array}{l}\text { 17. How is PSA different from other education programmes that you have } \\
\text { experienced? }\end{array}$ \\
\hline $\begin{array}{l}\text { 18. If you think back to how you were before joining PSA and how you are } \\
\text { now, would you say that you have changed as a result of being involved? } \\
\text {-Before joining PSA, how do you think you viewed and related to your community? } \\
\text { How do you view and related to your community now? } \\
\text {-How did you feel about yourself? How do you feel about yourself now? }\end{array}$ \\
\hline $\begin{array}{l}\text { 19. Are there any specific aspects of PSA that you feel contributed to this } \\
\text { change? }\end{array}$ \\
\hline $\begin{array}{l}\text { 20. Is spirituality something that is important to you in the PSA programme? } \\
\text { If so, how? What does it mean? }\end{array}$ \\
\hline $\begin{array}{l}\text { 21. Can you please describe the relationship between the spiritual and the } \\
\text { material in PSA? }\end{array}$ \\
\hline $\begin{array}{l}\text { 22. Is there anything that we haven't talked about that is important to you } \\
\text { about your experiences so far with PSA and Inshindo Foundation? }\end{array}$ \\
\hline
\end{tabular}




\section{APPENDIX C: SEMI-STRUCTURED INTERVIEW GUIDE: INSHINDO STAFF/PSA COORDINATORS}

1. What is the purpose of Inshindo Foundation?

2. What is the purpose of the PSA programme?

3. How does Inshindo work to try and achieve these goals?

4. When did you first start working for Inshindo?

5. What was it about Inshindo or the PSA programme that made you become involved?

6. In what capacity do you work with Inshindo and what does your role involve?

7. If you think back to how you were before working with PSA, and how you are now, would you say that you have changed as a result of being involved with the programme? If so, how?

8. Have you observed that others around you have changed? If so, how?

9. What would you say that you've gained from your experiences working with Inshindo and PSA?

10. What would you say that you've contributed to the work of Inshindo and PSA?

11. In your view, what makes PSA different from other development programmes?

12. Can you please describe how spirituality or spiritual principles are important to the PSA programme?

13. Can you please describe the relationship between the spiritual and the material in PSA?

14. What are your own beliefs about the role of spirituality/spiritual principles in community development?

15. What does it mean to you that Inshindo is a Bahá'í-inspired organisation? 


\section{APPENDIX D. SEMI-STRUCTURED INTERVIEW GUIDE: KABWE DEPARTMENT OF COMMUNITY DEVELOPMENT}

1. Could you please start us off by telling me a bit more about the Department of Community Development. What is the purpose of the DCD? What are some of the main areas that you are working in or initiatives that you are supporting?

2. What are your roles within the Department of Community Development? What does this involve?

3. What motivates you to carry out this role in the community?

4. What do you see as being some of the greatest challenges facing communities and individuals in Kabwe?

5. Can you please share with me your views on what you think is needed to address these challenges?

6. When did your involvement with Inshindo Foundation begin?

7. What was it about Inshindo Foundation or the PSA programme that made the Department of Community Development partner with this organization?

8. Can you please describe for me the relationship between the DCD and Inshindo Foundation?

9. Based on your experiences with them so far, what do you see as being the purpose of the PSA programme? How does it seek to achieve this purpose?

10. In what ways, if any, do you see that PSA is different or the same from other development programmes being offered in the community?

11. Have you seen that the PSA programme has had an impact around Kabwe at this early stage?

12. Inshindo is a Bahá'í-inspired organization. What does this mean to you? Do you feel that this influences the relationship between the Department of Community Development and Inshindo Foundation?

13. One central aspect of the PSA programme is the harmony between the spiritual and the material. Were you aware of this aspect of PSA? What are your views about spirituality in PSA?

14. If you are comfortable, could you please share with me your views about the role of spirituality in community development? Is this something that is discussed in the Department of Community Development? 
APPENDIX E. TABLE OF RESEARCH ACTIVITIES

\begin{tabular}{|c|c|c|c|c|}
\hline Date & Location & Category & Context & Activities \\
\hline $\begin{array}{l}22 / 04- \\
24 / 04\end{array}$ & $\begin{array}{l}\text { Banani } \\
\text { School }\end{array}$ & $\begin{array}{l}\text {-PSA } \\
\text { experiences - } \\
\text { Inshindo } \\
\text { activities }\end{array}$ & Tutor training & $\begin{array}{l}\text {-Morning devotions; } \\
\text { Group reflection on } \\
\text { training; Conversations } \\
\text { with tutors; Focus group } \\
\text { with Mwinilunga tutors } \\
\text {-Inshindo staff } \\
\text { consultation and reflection } \\
\text { on training }\end{array}$ \\
\hline $\begin{array}{l}22 / 04- \\
28 / 06\end{array}$ & $\begin{array}{l}\text { Kabwe and } \\
\text { Mwinilunga }\end{array}$ & $\begin{array}{l}\text {-Inshindo } \\
\text { activities } \\
\text {-PSA } \\
\text { experiences }\end{array}$ & $\begin{array}{l}\text { Office } \\
\text { interaction }\end{array}$ & $\begin{array}{l}\text {-Worked at the office and } \\
\text { observed day-to-day } \\
\text { functioning of Inshindo } \\
\text { Foundation, conversations } \\
\text { with staff, assisting with } \\
\text { the organization of } \\
\text { research-related tasks and } \\
\text { Inshindo activities } \\
\text {-Observation and } \\
\text { conversation with tutors } \\
\text { preparing for their PSA } \\
\text { groups; Tutor material } \\
\text { refreshers }\end{array}$ \\
\hline $\begin{array}{l}22 / 04- \\
28 / 06\end{array}$ & $\begin{array}{l}\text { Kabwe and } \\
\text { Mwinilunga }\end{array}$ & $\begin{array}{l}\text { Interaction } \\
\text { with } \\
\text { communities }\end{array}$ & $\begin{array}{l}\text { Daily } \\
\text { conversations }\end{array}$ & $\begin{array}{l}\text { Conversations with } \\
\text { Representatives of } \\
\text { Community Development } \\
\text { office; conversations with } \\
\text { residents of Kabwe and } \\
\text { Mwinilunga about Zambia, } \\
\text { the culture, social, } \\
\text { economic and political } \\
\text { situation; conversations } \\
\text { with public servants, } \\
\text { academics in Zambia, and } \\
\text { Bahá'ís about PSA and } \\
\text { Zambia; conversations } \\
\text { with FUNDAEC trainers } \\
\text { from USA/Colombia and } \\
\text { Turkey/Haifa }\end{array}$ \\
\hline $27 / 04$ & Kabwe & $\begin{array}{l}\text { PSA } \\
\text { experiences }\end{array}$ & $\begin{array}{l}\text { PSA tutor } \\
\text { meeting }\end{array}$ & $\begin{array}{l}\text {-Meeting of } 2010 \text { tutors to } \\
\text { plan for the establishment } \\
\text { of ten new PSA groups in } \\
\text { Kabwe }\end{array}$ \\
\hline $27 / 04$ & Kabwe & $\begin{array}{l}\text { PSA } \\
\text { experiences }\end{array}$ & $\begin{array}{l}\text { PSA group } \\
\text { visit }\end{array}$ & $\begin{array}{l}\text {-Observation of } \\
\text { Chimanimani group's } \\
\text { analysis of research into } \\
\text { food production; } \\
\text { conversations with } \\
\text { students; visit to group } \\
\text { garden }\end{array}$ \\
\hline $1 / 05-$ & Banani & Bahá'í & Bahá'í & -National Convention, \\
\hline
\end{tabular}




\begin{tabular}{|c|c|c|c|c|}
\hline $2 / 05$ & School & activities & meeting & $\begin{array}{l}\text { consultation on guidance } \\
\text { to Bahá'í communities on } \\
\text { 'social action' }\end{array}$ \\
\hline $4 / 05$ & Kabwe & $\begin{array}{l}\text { PSA } \\
\text { experiences }\end{array}$ & $\begin{array}{l}\text { PSA group } \\
\text { visit }\end{array}$ & $\begin{array}{l}\text {-Observation of } \\
\text { Chimanimani group's } \\
\text { analysis of research into } \\
\text { food production }\end{array}$ \\
\hline $12 / 05$ & Kabwe & $\begin{array}{l}\text {-Inshindo } \\
\text { activities }\end{array}$ & $\begin{array}{l}\text { Internal } \\
\text { meeting }\end{array}$ & $\begin{array}{l}\text {-First meeting of old and } \\
\text { new Inshindo staff about } \\
\text { plans for the future of the } \\
\text { organisation }\end{array}$ \\
\hline $14 / 05$ & Kabwe & $\begin{array}{l}\text { PSA } \\
\text { experiences }\end{array}$ & $\begin{array}{l}\text { Organisational } \\
\text { meeting }\end{array}$ & $\begin{array}{l}\text {-Planning meeting about } \\
\text { formation of new groups } \\
\text { in Kabwe }\end{array}$ \\
\hline $14 / 05$ & Kabwe & $\begin{array}{l}\text { PSA } \\
\text { experiences }\end{array}$ & $\begin{array}{l}\text { PSA group } \\
\text { visit }\end{array}$ & $\begin{array}{l}\text {-Observation of Makululu } \\
\text { group studying the text } \\
\text { 'Addition and Subtraction' }\end{array}$ \\
\hline $17 / 05$ & Kabwe & $\begin{array}{l}\text { PSA } \\
\text { experiences }\end{array}$ & $\begin{array}{l}\text { PSA group } \\
\text { visit }\end{array}$ & $\begin{array}{l}\text {-Observation of Natuseko } \\
\text { group doing a test }\end{array}$ \\
\hline $18 / 05$ & Kabwe & $\begin{array}{l}\text { PSA } \\
\text { experiences }\end{array}$ & $\begin{array}{l}\text { PSA group } \\
\text { formation }\end{array}$ & $\begin{array}{l}\text {-Participation in group } \\
\text { formation activities in } \\
\text { Makululu; conversations } \\
\text { with the Makululu } \\
\text { community about the } \\
\text { programme; recruiting } \\
\text { new students; } \\
\text { conversations with current } \\
\text { PSA students }\end{array}$ \\
\hline $19 / 05$ & Kabwe & $\begin{array}{l}\text { PSA } \\
\text { experiences }\end{array}$ & $\begin{array}{l}\text { PSA group } \\
\text { formation }\end{array}$ & As above \\
\hline $20 / 05$ & Kabwe & $\begin{array}{l}\text { PSA } \\
\text { experiences }\end{array}$ & $\begin{array}{l}\text { PSA group } \\
\text { formation }\end{array}$ & As above \\
\hline $20 / 05$ & Kabwe & $\begin{array}{l}\text { PSA } \\
\text { experiences }\end{array}$ & $\begin{array}{l}\text { PSA group } \\
\text { formation }\end{array}$ & $\begin{array}{l}\text { Observation of first } \\
\text { community meeting in } \\
\text { Mukobeko }\end{array}$ \\
\hline $21 / 05$ & Kabwe & $\begin{array}{l}\text { PSA } \\
\text { experiences }\end{array}$ & $\begin{array}{l}\text { Organisational } \\
\text { meeting }\end{array}$ & $\begin{array}{l}\text { Reflection on group } \\
\text { formation process }\end{array}$ \\
\hline $22 / 05$ & Kabwe & $\begin{array}{l}\text { PSA } \\
\text { experiences }\end{array}$ & $\begin{array}{l}\text { PSA group } \\
\text { visit }\end{array}$ & $\begin{array}{l}\text { Visit to Natuseko group; } \\
\text { observation and } \\
\text { participation in plot } \\
\text { preparation of their } \\
\text { learning garden; } \\
\text { conversations with } \\
\text { students }\end{array}$ \\
\hline $24 / 05$ & Kabwe & $\begin{array}{l}\text { PSA } \\
\text { experiences }\end{array}$ & $\begin{array}{l}\text { PSA group } \\
\text { visit }\end{array}$ & $\begin{array}{l}\text { Observation of first } \\
\text { orientation of new group } \\
\text { in C-Gate }\end{array}$ \\
\hline $26 / 05$ & Kabwe & $\begin{array}{l}\text { PSA } \\
\text { experiences }\end{array}$ & $\begin{array}{l}\text { Organisational } \\
\text { meeting }\end{array}$ & $\begin{array}{l}\text { Reflection on group } \\
\text { formation process }\end{array}$ \\
\hline $27 / 05$ & Kabwe & $\begin{array}{l}\text { PSA } \\
\text { experiences }\end{array}$ & $\begin{array}{l}\text { PSA group } \\
\text { visit }\end{array}$ & $\begin{array}{l}\text { Visit to Natuseko to } \\
\text { observe garden project; }\end{array}$ \\
\hline
\end{tabular}




\begin{tabular}{|c|c|c|c|c|}
\hline & & & & $\begin{array}{l}\text { study of text 'Transition to } \\
\text { Agriculture' with students }\end{array}$ \\
\hline $28 / 05$ & Kabwe & $\begin{array}{l}\text { PSA } \\
\text { experiences }\end{array}$ & $\begin{array}{l}\text { PSA bi-annual } \\
\text { student } \\
\text { encounter }\end{array}$ & $\begin{array}{l}\text { Presentations by PSA } \\
\text { groups (speeches, skits, } \\
\text { music, drama); } \\
\text { presentations by Inshindo } \\
\text { staff; community meetings } \\
\text { to finalize new groups; } \\
\text { sports; conversations with } \\
\text { students }\end{array}$ \\
\hline $31 / 05$ & Kabwe & $\begin{array}{l}\text { PSA } \\
\text { experiences }\end{array}$ & $\begin{array}{l}\text { PSA group } \\
\text { visit }\end{array}$ & $\begin{array}{l}\text { Observation of new C-Gate } \\
\text { and Natuseko/Kapatula } \\
\text { groups' first session } \\
\text { studying the text } \\
\text { 'Properties' }\end{array}$ \\
\hline $1 / 06$ & Kabwe & $\begin{array}{l}\text { PSA } \\
\text { experiences }\end{array}$ & $\begin{array}{l}\text { PSA group } \\
\text { visit }\end{array}$ & $\begin{array}{l}\text { Study of the text with } \\
\text { Makululu PSA group, } \\
\text { 'Addition and Subtraction' }\end{array}$ \\
\hline $2 / 06$ & Kabwe & $\begin{array}{l}\text { PSA } \\
\text { experiences }\end{array}$ & $\begin{array}{l}\text { Organisational } \\
\text { meeting }\end{array}$ & $\begin{array}{l}\text { Reflection on group } \\
\text { formation process; } \\
\text { discussion of future plans } \\
\text { for the organisation and } \\
\text { changes to organizational } \\
\text { structure }\end{array}$ \\
\hline $3 / 06$ & Kabwe & $\begin{array}{l}\text { PSA } \\
\text { experiences }\end{array}$ & $\begin{array}{l}\text { Inshindo } \\
\text { research tasks }\end{array}$ & $\begin{array}{l}\text { Conducting student } \\
\text { profiles with new PSA } \\
\text { students in Bwacha }\end{array}$ \\
\hline $4 / 06$ & Kabwe & $\begin{array}{l}\text { PSA } \\
\text { experiences }\end{array}$ & $\begin{array}{l}\text { Inshindo } \\
\text { research tasks }\end{array}$ & $\begin{array}{l}\text { Conducting student } \\
\text { profiles with new PSA } \\
\text { students in Chimanimani }\end{array}$ \\
\hline $5 / 06$ & Kabwe & $\begin{array}{l}\text { PSA } \\
\text { experiences }\end{array}$ & $\begin{array}{l}\text { PSA service } \\
\text { project }\end{array}$ & $\begin{array}{l}\text { Site and Service student } \\
\text { encounter; observation of } \\
\text { activities and presentations } \\
\text { of student environmental } \\
\text { awareness groups (music, } \\
\text { drama, quiz, poetry) }\end{array}$ \\
\hline $8 / 06$ & Kabwe & $\begin{array}{l}\text { PSA } \\
\text { experiences }\end{array}$ & $\begin{array}{l}\text {-Tutors } \\
\text { refresher } \\
\text {-Inshindo } \\
\text { research tasks }\end{array}$ & $\begin{array}{l}\text {-Conversations with new } \\
\text { tutors } \\
\text { - Conducting student } \\
\text { profiles with new PSA } \\
\text { students in Makululu }\end{array}$ \\
\hline $\begin{array}{l}9 / 06- \\
14 / 05\end{array}$ & $\begin{array}{l}\text { Banani } \\
\text { School }\end{array}$ & $\begin{array}{l}\text {-PSA } \\
\text { experiences } \\
\text {-Inshindo } \\
\text { activities }\end{array}$ & Tutor training & $\begin{array}{l}\text { Morning devotions; study } \\
\text { of the Block } 5 \text { and Block } 6 \\
\text { texts with tutors from } \\
\text { Kabwe and Mwinilunga; } \\
\text { conversations with tutors; } \\
\text { conversations with } \\
\text { FUNDAEC trainers; } \\
\text { conversations with project } \\
\text { leaders from Kenya, } \\
\text { Cameroon and Haifa }\end{array}$ \\
\hline $16 / 06$ & Kabwe & PSA & Inshindo & Conducting student \\
\hline
\end{tabular}




\begin{tabular}{|l|l|l|l|l|}
\hline 25/06 & Mwinilunga & $\begin{array}{l}\text { PSA } \\
\text { experiences }\end{array}$ & $\begin{array}{l}\text { Mwinilunga } \\
\text { office }\end{array}$ & $\begin{array}{l}\text { profiles with new PSA } \\
\text { students in Mukobeko }\end{array}$ \\
\hline $26 / 06$ & Mwinilunga & $\begin{array}{l}\text { Observation of planning } \\
\text { for student encounter; } \\
\text { conversations with } \\
\text { students and tutors; } \\
\text { observation of garden } \\
\text { learning project }\end{array}$ \\
\hline experiences & $\begin{array}{l}\text { PSA bi-annual } \\
\text { student } \\
\text { encounter }\end{array}$ & $\begin{array}{l}\text { Presentations by PSA } \\
\text { groups (speeches, skits, } \\
\text { music, drama); } \\
\text { presentations by Inshindo } \\
\text { staff; community meetings } \\
\text { to finalize new groups; } \\
\text { sports; conversations with } \\
\text { students } \\
\text {-Reflections with Inshindo } \\
\text { staff }\end{array}$ \\
\hline $28 / 06$ & Mwinilunga & $\begin{array}{l}\text { PSA } \\
\text { experiences }\end{array}$ & $\begin{array}{l}\text { PSA group } \\
\text { visits }\end{array}$ & $\begin{array}{l}\text { Visits to three different } \\
\text { groups in Mwinilunga; } \\
\text { conversations with tutors } \\
\text { and coordinators; } \\
\text { conversations with } \\
\text { students }\end{array}$ \\
\hline
\end{tabular}




\section{APPENDIX F: ACTIVITIES OF PSA STUDENTS AND THEIR GROUPS IN KABWE AND MWINILUNGA}

In Kabwe, some of the main activities that groups have carried out have been in the areas of malaria sensitization, solid waste management, promotion of a healthy environment, household food production, and youth empowerment. While many of the PSA groups carry out service projects on the same issues, there are variations within these and some choose to focus on other areas. Groups choose projects that will best address the particular needs of their local community. For example, the Site and Service PSA group in Kabwe has been involved in running environmental clubs at two local schools in which they teach the younger students what they have learnt in PSA and are together involved in sharing this knowledge with the community to promote a healthy and clean environment. In Mwinilunga, a number of the groups have been involved in action-research projects involving small-scale farmers and sharing knowledge about sustainable farming practices that will promote a healthy environment. The groups have been promoting the use of organic fertilisers and pesticides, as well as engaging a growing number of farmers in growing nitrogen-fixing acacia trees. Another group in Mwinilunga has been active in running informal community classes for early childhood aged children, as there are few opportunities for education at this level in the region.

A number of respondents also described how they were applying the knowledge from the textbooks to their individual and family lives outside of PSA. Many students from Mwinilunga were small-scale farmers and described how they practicing what they learned in the agricultural textbooks in their own farms, with a few even mentioning that this had boosted their yields. In Kabwe, several students from the groups had begun their own backyard gardens growing vegetables for themselves or their families. They proudly explained how they do not use chemical fertilizers and enjoy vegetables that are "very free and very healthy." Another example was given by a young mother from the Makululu group who happily described how she had gone from sitting "doing nothing" before joining PSA to working as a 'marketeer' selling vegetables. She said that 
she was able to do this because of the mathematics capabilities she had developed studying the PSA texts. 


\section{APPENDIX G. INFORMATION AND CONSENT SHEET}

\section{INFORMATION SHEET FOR INTERVIEWS}

\section{Title of project: Preparation for Social Action: The Harmony of Spiritual and Material Means in Promoting Community Well-being.}

Researcher: Laura Skeaff: School of Geography, Environment and Earth Sciences, Victoria University of Wellington, New Zealand.

I am a Masters student in Development Studies at Victoria University of Wellington, New Zealand. As part of this degree I am undertaking a research project leading to a thesis. The project I am undertaking is focusing on the approach to development taken by the Preparation for Social Action (PSA) program that is offered by the Insindo Foundation. In particular, the research sets out to explore how spiritual principles are related to material means of development and shape the PSA program and the activities that it carries out to contribute to community wellbeing. Of particular importance are the views and experiences of those involved in PSA about the programme and community wellbeing. By focusing on one case study this research project aims to contribute to understanding of how harmony between the spiritual and material may enhance development work and bring light to new ways of promoting community wellbeing, not only in Zambia, but also in other countries around the world.

Responses collected from interviews will form the basis of my research project and will be put into a written report on an anonymous basis. It will not be possibly for you to be identified personally, although the Inshindo Foundation and PSA will be named. All material collected will be kept confidential. No other person beside me will listen to the tape recordings. The thesis will be submitted for marking to Victoria University and held in the University Library. It is intended that one or more articles will be submitted for publication in scholarly journals, and that results will be shared with the Inshindo Foundation and any other organisations interested.

The University requires that ethics approval be obtained for research involving human participants.

\section{What is involved?}

- $\quad$ The interviews are designed to take around one hour and can take place at a mutually agreed time and place. You will be interviewed by Laura Skeaff. You will need to sign the attached consent form prior to the interview.

- Your participation is entirely voluntary. If you agree to take part in the interviews you are free to withdraw at any time. You are also free to withdraw any information you have provided, so long as this is done before the $20^{\text {th }} \mathrm{July}$ 2010 .

- $\quad$ You will be asked several questions in each interview about the your experiences with PSA and views on community wellbeing. You will also be 
asked about your own spiritual beliefs. You do not have to answer all questions.

- $\quad$ The interviews will be tape-recorded and transcribed. The recording will be used to complement the notes taken during the interview.

- $\quad$ All data collected during these interviews will be accessed by the principal investigator and research supervisor only. These will be stored on a computer protected by a password and destroyed no more than 2 years after the research.

Please feel free to contact the researcher or research supervisor if you have any questions or would like to receive further information about this study.

\section{Principal Investigator:}

Laura Skeaff

Masters in Development Studies student - Victoria University of Wellington stuartskeaff@gmail.com

Phone number:

\section{Research Supervisor:}

Dr Andrew McGregor

Senior Lecturer of Development Studies - Victoria University of Wellington andrew.mcgregor@vuw.ac.nz 
CONSENT FORM FOR INTERVIEWS

Title of project: Preparation for Social Action: The Harmony of Spiritual and Material Means in Promoting Community Well-being.

- I have read and understood the attached 'Information sheet for interviews'. I have had an opportunity to ask questions and have them answered to my satisfaction.

- I agree to participate in these interviews and understand that I may withdraw myself or any information I have provided at any time before the $20^{\text {th }} \mathrm{July}$ 2010 .

- I understand that the interviews will be tape recorded and transcribed, and that only the researcher and her supervisor will have access to this material.

- I understand that all written material and taped interviews will be stored on a computer protected by a password and then destroyed 2 years after the research.

- I understand that I will not be named in any report, and that the information I provide will not be used for any other purpose or released to others without my written consent.

- I would like to receive a summary of the research findings Yes / No (Please circle one) (full name) hereby consent to take part in this study by participating in this interview.

Signature: Date:

Interview conducted by:

Signature: Date: 


\section{REFERENCES:}

'Abdu'l-Bahá (1972). Paris Talks. London: UK Bahá'í Publishing Trust.

'Abdu'l-Bahá (1979). Foundations of World Unity: US Bahá'í Publishing Trust.

Angrosino, M. V. (2005). Recontextualizing Observation: Ethnography, Pedagogy, and the Prospects for a Progressive Political Agenda. In N. K. D. a. Y. S. Lincoln (Ed.), The Sage Handbook of Qualitative Research (3rd ed., pp. 729-745). Thousand Oaks: Sage.

Arbab, F. (2000). Promoting a Discourse on Science, Religion, and Development. In S. Harper (Ed.), The Lab, the Temple and the Market (pp. 145-246). Ottawa: International Development Research Centre.

Arbab, F. (unknown). Rural University: Learning about Education and Development: International Development Research Centre.

Association, G. I. (2001). Gallup International Millennium Survey. In R. i. t. W. a. t. E. o. t. Millennium (Ed.): Gallup International Association.

Association, T. I. M. F. a. T. I. D. (2005). Enhanced Initiative for Heavily Indebted Poor Countries Completion Point Document: Zambia: The International Monetary Fund and The International Development Association.

Bahá'í International Community (1996). Two Bahá'í International Community Projects: Cameroon and Zambia. Retrieved from http://www.bic.org/statements-and-reports/bic-statements/960430.htm

Bahá'í International Community (1998). Valuing Spirituality in Development. Paper presented at the World Faiths and Development Dialogue.

Bahá'í International Community (2008). For the Betterment of the World.

Bahá'í International Community (2010a). Consultation. Retrieved from http://info.bahai.org/article-1-3-6-3.html

Bahá'í International Community (2010b). Processes of Development: The Bahá'í Approach Retrieved from http://info.bahai.org/article-1-8-1-2.html

Bahá'í International Community (2010c). The Masetlha Foundation: Health, Literacy, \& Education in Zambia. Retrieved from http://info.bahai.org/article-1-8-1-23.html 
Bahá'u'lláh Gleanings from the Writings of Bahá'u'lláh. Haifa: Bahá'í Publishing Trust.

Bahá'u'lláh (2003). The Hidden Words (S. Effendi, Trans.). Bundoora, Victoria: Bahá'í Publications Australia.

Bahá'u'lláh (2006). The Tabernacle of Unity. Haifa: Bahá'í World Centre.

Balchin, C. (2007). The F-word and the S-word - too much of one and not enough of the other. Development in Practice, 17(4-5), 532-538.

Beerk, K. A. V. (2000). Spirituality: a development taboo. Development in Practice, 10(1), 31-43.

Belshaw, D., Calderisi, R., Sugden, C. (Ed.). (2001). Faith in Development: Partnership between the World Bank and the Churches of Africa. Oxford and Irvine: Regnum Books International.

Bennett, A. L. G. a. A. (2004). Case Studies and Theory Development in the Social Sciences. London: MIT Press.

Berger, P. L. (1999a). The Desecularization of the World: A Global Overview. In P. L. Berger (Ed.), The Desecularization of the World: Resurgent Religion and World Politics. Washington: Ethics and Public Policy Centre.

Berger, P. L. (Ed.). (1999b). The Desecularization of the World: Resurgent Religion and World Politics. Washington: Ethics and Public Policy Centre.

Berman, S. (1997). Children's Social Consciousness and the Development of Social Responsibility. Albany, New York: State University of New York Press.

Bernard, H. R. (Ed.). (1994). Research Methods in Anthropology: Qualitative and Quantiative Approaches (2nd ed.). London: Sage

Bernstein, R. J. (1983). Beyond Objectivism and Relativism: Science, Hermeneutics, and Praxis: Basil Blackwell.

Bornstein, E. (2005). The Spirit of Development: Protestants NGOs, Morality, and Economics in Zimbabwe. Stanford, California: Stanford University Press.

Bradley, T. (2009a). A call for clarification and critical analysis of the work of faith-based development organizations (FBDO). Progress in Development Studies, 9(2), 101-114. 
Bradley, T. (2009b). Physical Religious Spaces in the Lives of Rajasthani Village Women: Ethnographic Study and Practice of Religion in Development. Journal of Human Development and Capabilities, 10(1), 18.

Carmody, B. (2006). Zambia: multi-faith religious education? Journal of Beliefs and Values, 27(3), 291-301.

Carmody, B. (2007). The Nature and Role of Christian Conversion in Zambia. International Journal for the Study of the Christian Church, 7(2), 109-133.

Carmody, P. (2009). An Asian-Driven Economic Recovery in Africa? The Zambian Case. World Development, 37(7), 1197-1207.

Central Statistical Office (CSO) (2006). Zambian Census 2000. Retrieved 20 September 2010. from http://www.zamstats.gov.zm/census.php.

Central Statistical Office (CSO), M. o. H. M., Tropical Diseases Research Centre (TDRC), University of Zambia, and Macro International Inc. (2009). Zambian Demographic and Health Survey 2007. Calverton, Maryland.

Chambers, R. (1983). Rural Development: Putting the Last First. New York: Wiley.

Charmaz, K. (2003). Grounded Theory: Objectivist and Constructivist Methods. In N. K. D. a. Y. S. Lincoln (Ed.), Strategies of Qualitative Inquiry (pp. 249291). Thousand Oaks: Sage Publications.

Clarke, G. (2007). Agents of Transformation? Donors, faith-based organisations and international development. Third World Quarterly, 28(1), 77-96.

Clarke, G. (2008a). Faith-Based Organizations and International Development: An Overview. In G. C. a. M. Jennings (Ed.), Development, Civil Society and Faith-Based Organizations (pp. 17-45). New York: Palgrave Macmillan.

Clarke, M. J. a. G. (2008b). Conclusion: Faith and Development - of Ethnoseparatism, Multi-culturalism, and Religious Partitioning. In G. C. a. M. Jennings (Ed.), Development, Civil Society and Faith-Based Organizations (pp. 260-274). New York: Palgrave Macmillan.

Cobin, S. a. (1998). Basics of Qualitative Research: Techniques and Procedures for Developing Grounded Theory (2nd ed.). Thousand Oaks, CA: Sage.

Cordier, B. d. (2009). The 'Humanitarian Frontline', Development and Relief and Religion: what context, which threats and which opportunities. Third World Quarterly, 30(4), 663-684. 
Costantino, T. E. (2008). Constructivism. In L. M. Given (Ed.), The SAGE Encyclopedia of Qualitative Research Methods (Vol. 1, pp. 116-119). Thousand Oaks: SAGE Publications, Inc.

Creswell, J. W. (2009). Researh Design: Qualitative, Quantitative and Mixed Methods Approaches. London: Sage.

Crush, J. (1995a). Introduction: Imagining Development. In J. Crush (Ed.), Power of Development. London: Routledge.

Crush, J. (1995b). Power of Development. London: Routledge.

Deneulin, S. (2009). Religion in Development: Rewriting the Secular Script. ?: Zed Books.

Desai, V. (2008). Community participation in development. In V. D. a. R. Potter (Ed.), The Companion to Development Studies (2nd ed., pp. 115-119). London: Hodder Education.

Descartes, R. (2008). Discourse on the Method: Project Gutenberg Literary Archive Foundation.

Dimitriadis, G. K. a. G. (2005). Focus Groups: Strategic Articulations of Pedagogy, Politics, and Inquiry. In N. K. D. a. Y. S. Lincoln (Ed.), The Sage Handbook of Qualitative Research (3rd ed., pp. 887-907). Thousand Oaks, London and New York: Sage Publications.

Diversi, M. (1998). Glimpses of Street Life: Representing Lived Experience Through Short Stories. Qualitative Inquiry, 3, 131-147.

DL Publications, D. L. P. (2007). Development Learning Association, "Partnership for Sustainable Development" Retrieved 22nd October, 2010, from http://www.devlp.com/dla.html

Dugbazah, J. (2009). The Relationships between Values, Religious Teaching and Development Concepts and Practices: A Preliminary Literature Review: University of Birmingham.

Ellis, G. T. H. a. S. (2006). The Role of Religion in Development: Towards a New Relationship between the European Union and Africa. The European Journal of Development Research, 18(3), 351-367.

Emmanuel Kamwi, R. K. a. K. (2003). Mwinilunga District Poverty Monitoring Report. Lusaka. 
Escobar, A. (1995a). Encountering Development: The Making and Unmaking of the Third World. Princeton and Chichester: Princeton University Press.

Escobar, A. (1995b). Imagining a Post-Development Era. In J. Crush (Ed.), Power of Development (pp. 211-227). London and New York: Routledge.

Escobar, A. (1997). The Making and Unmaking of the Third World Through Development. In M. R. w. V. Bawtree (Ed.), The Post-Development Reader (pp. 85-93). London and New Jersey: Zed Books.

Esteva, G. (1992). Development. In W. Sachs (Ed.), The Development Dictionary: A Guide to Knowledge as Power (pp. 26-37). London and New Jersey: Zed Books Ltd.

Farzam Arbab, G. C., and Francia de Valcarcel (1988). FUNDAEC: Its Principles and its Activities. Retrieved from http://www.fundaec.org/en/institution/celater doc.htm

Freeman, M. (2008). Hermeneutics. In L. M. Given (Ed.), The SAGE Encyclopedia of Qualitative Research Methods (Vol. 1, pp. 385-388). Thousand Oaks: SAGE Publications, Inc.

Freire, P. (1970). Pedagogy of the Oppressed. New York: Seabury.

Frey, A. F. a. J. H. (2005). The Interview: From Neutral Stance to Political Involvement. In N. K. D. a. Y. S. Lincoln (Ed.), The Sage Handbook of Qualitative Research (3rd ed., pp. 695-727). Thousand Oaks: Sage.

Goulet, D. (1980). Development Experts: The One-Eyed Giants. World Development, 8, 481-489.

Hand (2003). The mentor's tale: A reflexive account of semi-structured interviews. Nurse Research, 10, 15-27.

Harcourt, A. A. a. W. (2010). Editorial: Education for What Purpose? Development, 53(4), 449-450.

Harcourt, W. (2003). Editorial: Clearing the Path for Collective Compassion. Development, 46(4), 3.

Hawkins, J. J. (1991). Understanding the Failure of IMF Reform: The Zambian Case. World Development, 19(7), 839-849.

Haynes, J. (2007). Religion and Development: Conflict or Cooperation? Houndsmill, Basingstoke: Palgrave Macmillan. 
Hennink, M. M. (2007). International Focus Group Research: A Handbook for the Health and Social Sciences. Cambridge: Cambridge University Press.

Herath, D. (2009). The Discourse of Development: has it reached maturity? Third World Quarterly, 30(8), 1449-1464.

Holenstein, A. (2005). The role and significance of religion and spirituality in endogenous development: A learning process between SDC and NGOs. Retrieved from http://www.bioculturaldiversity.net/Downloads/Papers\%20participants /Holenstein.pdf

Honey, Z. G. (2011). Retrieved January 25, 2011, from http://www.zambiagold.org/

Honeyman, C. (2010). Social responsibility and community development: Lessons from the Sistema de Aprendizaje Tutorial in Honduras. Journal of Educational Development, 30, 599-613.

Honeyman, C. A. (2004). An Orientation Toward Human Progress: Developing Social Responsibility in Rural Honduran Youth through the Sistema de Aprendizaje Tutorial. Harvard College.

Inshindo Foundation (2008). Preparation for Social Action Program Description. Kabwe: Inshindo Foundation.

Inshindo Foundation (2009). Inshindo enters into partnership with Municipal Council and Department of Community Development Retrieved 24 October, 2010, from http://www.inshindo.org/index.php?option=com content\&view=article\& id=49:inshindo-enters-into-partnership-with-municipal-council-anddepartment-of-community-development\&catid=1:latest$\underline{\text { news\&Itemid }=50}$

J. Mills, A. B. a. K. F. (2006). Adopting a constructivist approach to grounded theory: Implications for research design. International Journal of Nursing Practice, 12, 8-13.

J. Paul Martin, J. C. a. S. P. (2007). Religions and International Poverty Alleviation: The Pluses and Minuses. Journal of International Affairs, 61(1), 69-92.

James, R. (2009). What is Distinctive about FBOs? How European FBOs define and operationalise their faith. Praxis Paper 22. Retrieved from http://www.intrac.org/resources database.php?id=367 
Jan-Bart Gewald, M. H. a. G. M. (2008). Introduction. In M. H. a. G. M. Jan-Bart Gewald (Ed.), One Zambia, Many Histories (pp. 1-13). Leiden and Boston: Brill.

Jane Mills, A. B. a. K. F. (2006). The Development of Constructivist Grounded Theory. International Journal of Qualitative Methods, 5(1), 1-10.

Janesick, V. J. (2003). The Choreography of Qualitative Research Desgin: Minuets, Improvisations, and Crystallization. In N. K. D. a. Y. S. Lincoln (Ed.), Strategies of Qualitative Inquiry (pp. 46-79). Thousand Oaks, CA: Sage Publications.

Jennings, G. C. a. M. (2008a). Development, Civil Society and Faith-Based Organizations. New York: Palgrave Macmillan.

Jennings, G. C. a. M. (2008b). Introduction. In G. C. a. M. Jennings (Ed.), Development, Civil Society and Faith-Based Organizations (pp. 1-16). New York: Palgrave Macmillan.

Jennings, O. B. a. M. (2001). The charitable impulse: NGOs and development in East and North-East Africa. Bloomfield, CT: Kumarian Press.

Kadt, E. D. (2009). Should God Play a Role in Development? Journal of International Development, 21, 781-786.

Keating, D. d. P. a. M. (2008). How many approaches in the social sciences? An epistemological introduction. In D. d. P. a. M. Keating (Ed.), Approaches and Methodologies in the Social Sciences: A Pluralist Perspective (pp. 1939). Cambridge: Cambridge University Press.

Keough, K. M. a. L. (2004). Mind, Heart and Soul in the Fight against Poverty. Washington, DC: The World Bank.

Kliksberg, B. (2003). Facing the Inequalities of Development: Some lessons from Judaism and Christianity. Development, 46(4), 57-63.

Kumar, S. (2003). Development and Religion: Cultivating a sense of the sacred. Development, 46(4), 15-21.

Lample, P. (2009). Revelation and Social Reality: Learning to Translate What Is Written into Reality. West Palm Beach, Florida: Palabra Publications.

Leggett, M. (2006). As Drops Become Waves: A Case Study of Education and Transformation Through the Sistema Aprendizaje Tutorial (SAT) in Rural Colombia. University of Guelph, Guelph. 
Lincoln, E. G. G. a. Y. S. (2005). Paradigmatic Controversies, Contradictions, and Emerging Confluences. In N. K. D. a. Y. S. Lincoln (Ed.), The Sage Handbook of Qualitative Research (3rd ed., pp. 191-215). Thousand Oaks: Sage.

Lincoln, N. K. D. a. Y. S. (2003). Introduction: The Discipline and Practice of Qualitative Research. In N. K. D. a. Y. S. Lincoln (Ed.), Strategies of Qualitative Inquiry (2nd ed., pp. 1-45). Thousand Oaks: Sage Publications.

Linden, I. (2008). The Language of Development: what are International Development Agencies talking about? In G. C. a. M. Jennings (Ed.), Development, Civil Society and Faith-Based Organizations (pp. 72-93). New York: Palgrave Macmillan.

Linge, D. E. (1977). Editor's Introduction (D. E. Linge, Trans.). In D. E. Linge (Ed.), Philosophical Hermeneutics (pp. xi-lviii). Berkeley: University of California Press.

Loy, D. R. (2003). The Poverty of Development: Buddhist reflections. Development, 46(4), 7-14.

Lunn, J. (2009). The Role of Religion, Spirituality and Faith in Development: a critical theory approach. Third World Quarterly, 30(5), 937-951.

Marsh, K. M. a. R. (Ed.). (2003). Millennium Challenges for Development and Faith Institutions. Washington, DC: The World Bank.

Martinez, S. (2003). Women's Leadership in Mexico: Education for social change at the grassroots level. Development, 46(4), 79-84.

McFarlane, C. (2006). Knowledge, learning and development: a post-rationalist approach. Progress in Development Studies, 6(4), 287-305.

McLennan, G. (2007). Towards postsecular sociology? Sociology, 41(5), 857-870.

Morgan, L. (2009). Development Aid and Its Criticisms: The View from Zambia. CGD Essay. Retrieved from http://www.cgdev.org/content/publications/detail/1422445

Muzaffar, C. (2003). The Global Rich and the Global Poor: Seeking the middle path. Development, 46(4), 29-34.

Narayan, D., Chambers, Robert, Shah, Meera K., and Petesch, Patti (2000). Voices of the Poor: Crying out for Change. Oxford: Oxford University Press for the World Bank. 
Nietzsche, F. (1924). The Joyful Wisom ("La Gaya Scienza") (T. Common, Trans.). New York: The Macmillan Company.

Noy, D. (2009). Material and Spiritual Conceptions of Development: A Framework of Ideal Types. Journal of Developing Societies, 25(3), 275-307.

O. Odumosum, R. 0. a. S. A. (2009). Mapping the Activities of Faith-Based Organizations in Development in Nigeria. Ibadan: Nigerian Institute of Social and Economic Research.

Pierre, L. R. a. E. A. S. (2005). Writing: A Method of Inquiry. In N. K. D. a. Y. S. Lincoln (Ed.), The Sage Handbook of Qualitative Research (pp. 959-978). Thousands Oaks, CA: Sage Publications.

Rahnema, M. (1997). Towards Post-Development: Searching for Signposts, A New Language and New Paradigms. In M. R. w. V. Bawtree (Ed.), The PostDevelopment Reader (pp. 377-403). London and New Jersey: Zed Books.

Richards, M. (not stated). The Honduras projects Retrieved 7 November 2010, 2010, from http://www.baseduk.org.uk/project honduras sat.htm

Richardson, L. (1994). Writing: A method of inquiry. In N. D. a. Y. Lincoln (Ed.), Handbook of Qualitative Research (1st ed., pp. 923-948). Thousand Oaks, CA: Sage.

Rist, G. (1997). The History of Development: From Western Origins to Global Faith. London and New York: Zed Books.

Saanen, K. M. a. M. V. (2007). Development and Faith: Where Mind, Heart and Soul Work Together. Washington: World Bank Publications.

Sachs, W. (1992). Introduction. In W. Sachs (Ed.), The Development Dictionary: A Guide to Knowledge as Power (pp. 1-5). London and New Jersey: Zed Books Ltd.

Schwandt, T. A. (2007). The Sage Dictionary of Qualitative Inquiry (3rd ed.). London: Sage.

Sen, A. (1999). Development as Freedom. New York: Alfred A. Knopf.

Shamdasani, D. W. S. a. P. N. (1990). Focus Groups: Theory and Practice. London: SAGE Publications.

Shenton, M. P. C. a. R. W. (1996). Doctrines of Development. London: Routledge. 
Slater, T. R. (2004). Encountering God: personal reflections on 'geographer as pilgrim'. Area, 36(3), 8.

Smith, L. T. (1999). Decolonizing Methodologies: Research and Indigenous Peoples. London and New York: Zed Books.

Stake, R. E. (2003). Case Studies. In N. K. D. a. Y. S. Lincoln (Ed.), Strategies of Qualitative Inquiry (pp. 134-164). Thousand Oaks: Sage Publiations.

Stake, R. E. (2005). Qualitative Case Studies. In N. K. D. a. Y. S. Lincoln (Ed.), The Sage Handbook of Qualitative Research (3rd ed., pp. 443-466). Thousand Oaks: Sage.

Sullivan, D. B. a. S. (2003). Qualitative Research. In R. S. a. D. Storey (Ed.), Development Fieldwork: A Practical Guide (pp. 57-74). London: Sage.

Thaut, L. C. (2009). The Role of Faith in Christian Faith-Based Humanitarian Agencies: Constructing the Taxonomy. Voluntas, 20(4), 319-350.

The Club of Budapest International Foundation (not stated). FUNDAEC, Colombia: Gustavo Correa Retrieved 7 November 2010, 2010, from http://www.clubofbudapest.org/p-aw-fundaec-correa.php

The Ruhi Foundation (2008). The Ruhi Institute Retrieved 25 October 2010, from http://www.ruhi.org/index.php

Thomas, S. M. (2004). Building Communities of Character: Foreign Aid Policy and Faith-Based Organizations. SAIS Review, 24(2), 133-148.

Thomas, S. M. (2007). Outwitting the Developed Countries? Existential Insecurity and the Global Resurgence of Religion. Journal of International Affairs, 61(1), 21-45.

Timmel, A. H. a. S. (2003). A Kenyan Experience for Faith-Based Transformative Action. Development, 46(4), 6.

Tomalin, E. (2008). Faith and Development. In V. D. a. R. Potter (Ed.), The Companion to Development Studies (2nd ed., pp. 485-489). London: Hodder Education.

Tsele, M. (2001). The Role of the Christian Faith in Development. In D. Belshaw, Calderisi, R., Sugden, C. (Ed.), Faith in Development: Partnerships between the World Bank and the Churches of Africa (pp. 203-218). Oxford and Irvine: Regnum Books International. 
Tyndale, W. (2001). Towards Sustainable Development: A Shift in Values. Commentary: International Movement for a Just World, 1(8), 1-4.

Tyndale, W. (2003). Idealism and Practicality: The role of religion in development. Development, 46(4), 22-28.

Tyndale, W. (Ed.). (2006). Visions of Development: Faith-Based Initiatives. Cornwall: Ashgate.

Unruh, R. J. S. a. H. R. (2004). Typology of Religious Characteristics of Social Service and Educational Organizations and Programs. Nonprofit and Voluntary Sector Quarterly, 33(1), 109-134.

Wallis, J. (2005). God's Politics: Why the American Right Gets it Wrong and the Left Doesn't Get It. San Fransciso, CA: Harper.

Yin, R. K. (2003). Case Study Research: Design and Methods. Thousand Oaks: Sage.

Zambia Daily Mail (2007). Kabwe: From discovery to recovery. Zambia Daily Mail. $\quad$ Retrieved 7 September 2010, from http://www.zamnet.zm/newsys/news/viewnews.cgi?category=4\&id=11 $\underline{00549219}$ 